\title{
Rh-Catalyzed Base-Free Decarbonylative Borylation of Twisted Amides
}

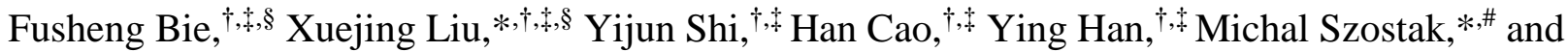
Chengwei Liu*,\#

${ }^{\dagger}$ Zaozhuang University, 1 Bei'an Road, Zaozhuang, Shandong 277160, China

${ }^{\text {}}$ Shandong Lunan Coal Chemical Research Institute of Engineering and Technology, 1 Bei'an Road, Zaozhuang, Shandong 277160, China

${ }^{\#}$ Department of Chemistry, Rutgers University, 73 Warren Street, Newark, New Jersey 07102, United States

lxj3786749@126.com; michal.szostak@rutgers.edu; chengwei.liu@rutgers.edu

\section{Supporting Information}

Table of Contents

SI-1

${ }^{1} \mathrm{H}$ NMR, ${ }^{13} \mathrm{C}$ NMR and ${ }^{19} \mathrm{~F}$ NMR Spectra

\section{Corresponding Author:}

Prof. Dr. X. Liu

Zaozhuang University 1xj3786749@126.com
Prof. Dr. M. Szostak

Rutgers University

michal.szostak@rutgers.edu
Prof. Dr. C. Liu

Rutgers University

chengwei.liu@rutgers.edu 

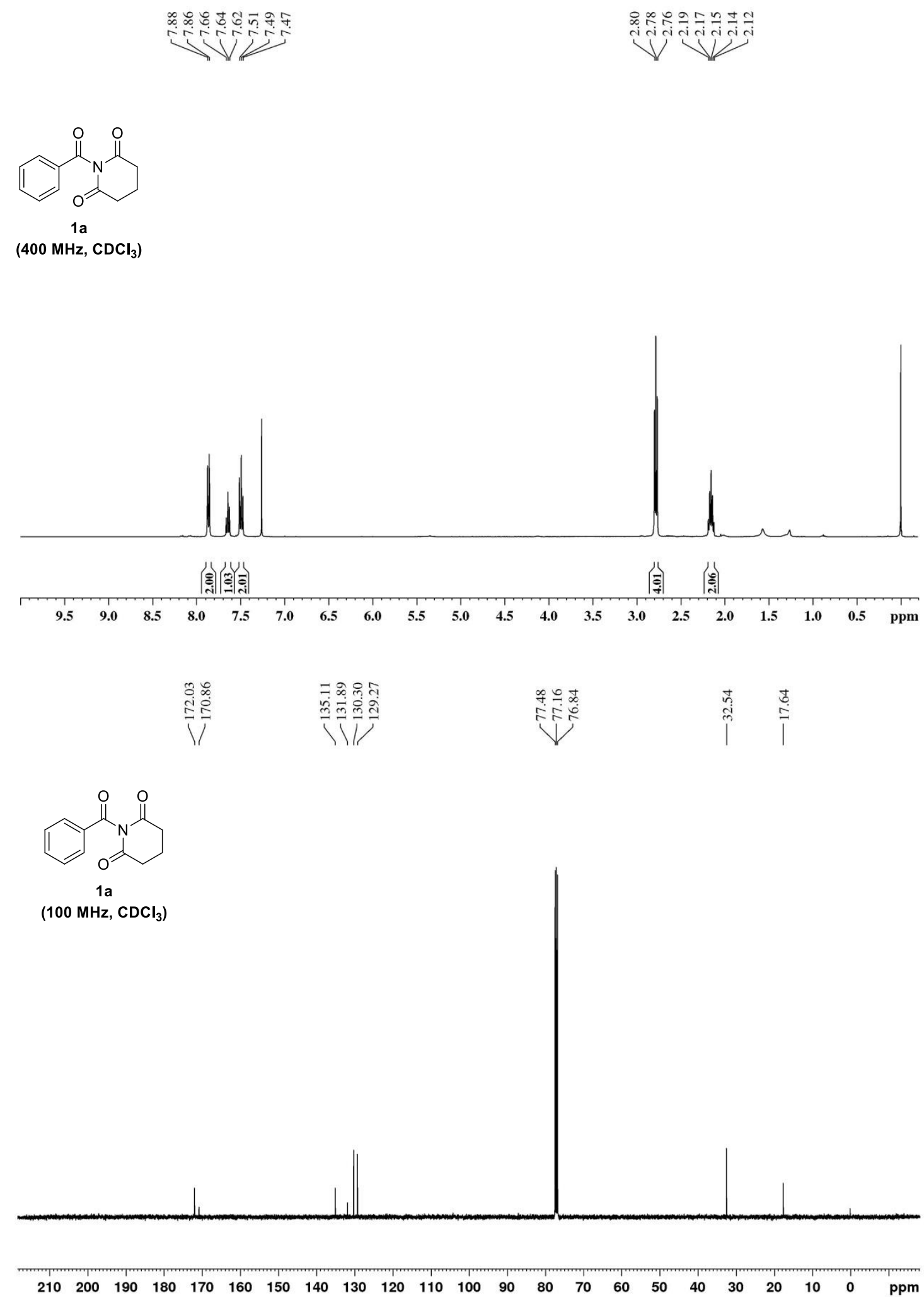

SI-2 


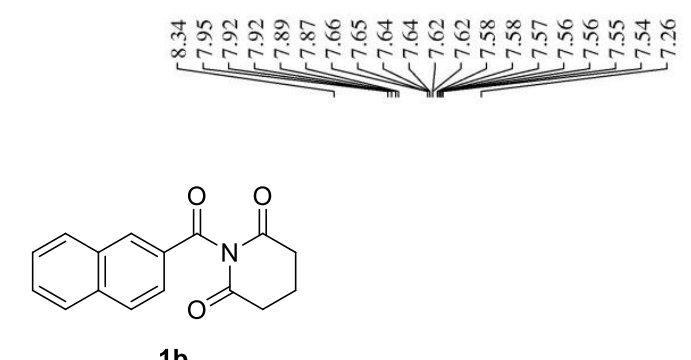

$\left(400 \mathrm{MHz}, \mathrm{CDCl}_{3}\right)$

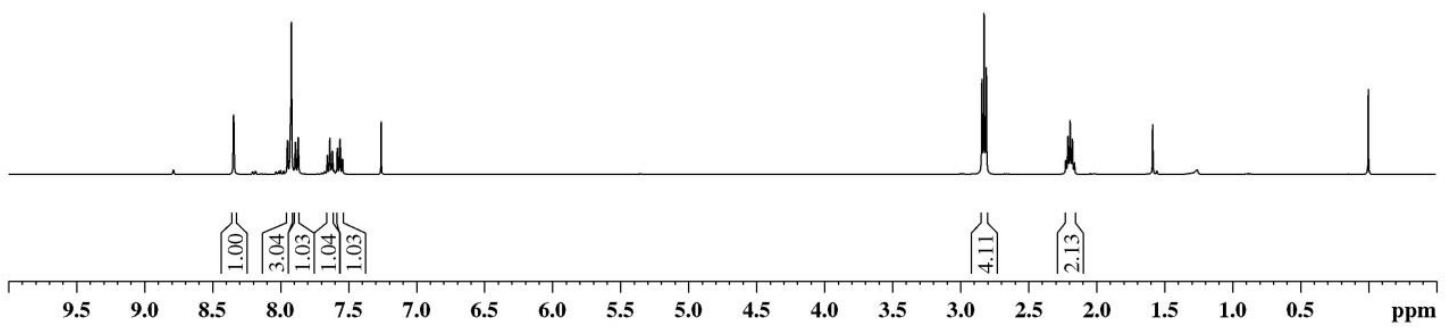

\begin{tabular}{|c|c|c|c|}
\hline 空 & 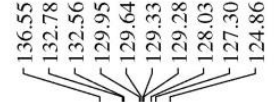 & $\underbrace{\infty}$ & i \\
\hline
\end{tabular}

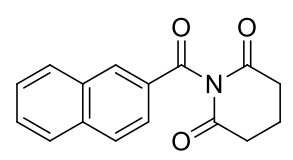

1b

$\left(100 \mathrm{MHz}, \mathrm{CDCl}_{3}\right)$

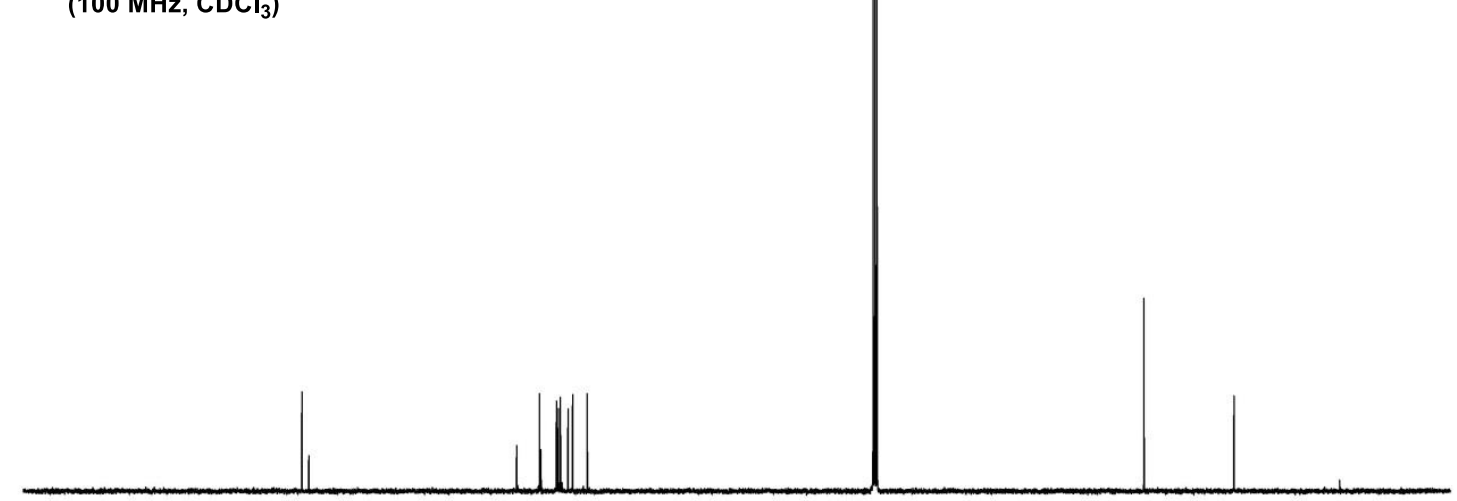

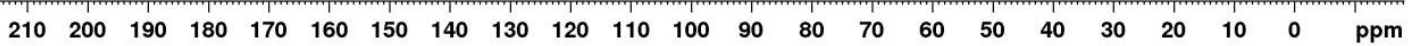

SI-3 

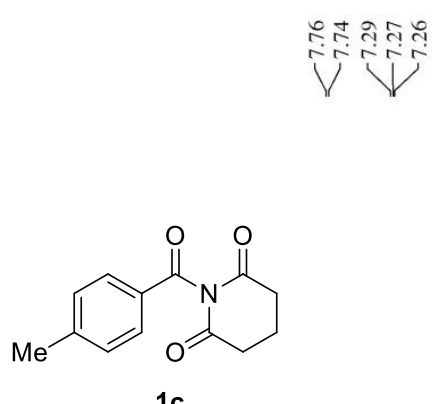

$\left(400 \mathrm{MHz} \mathrm{CDCl}_{3}\right)$

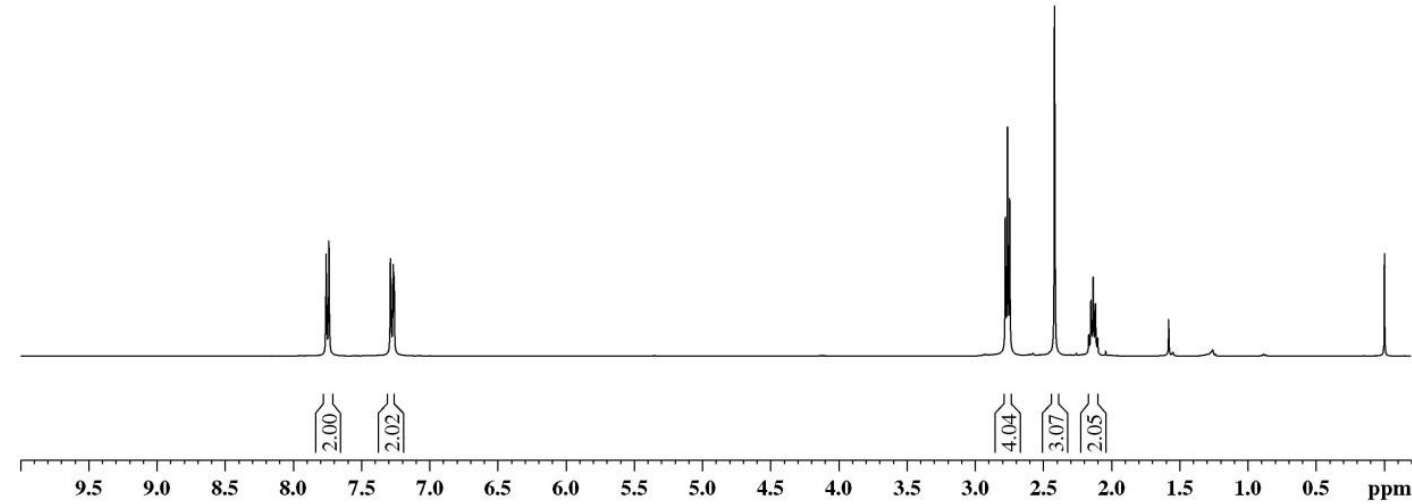

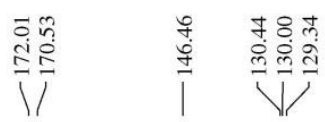
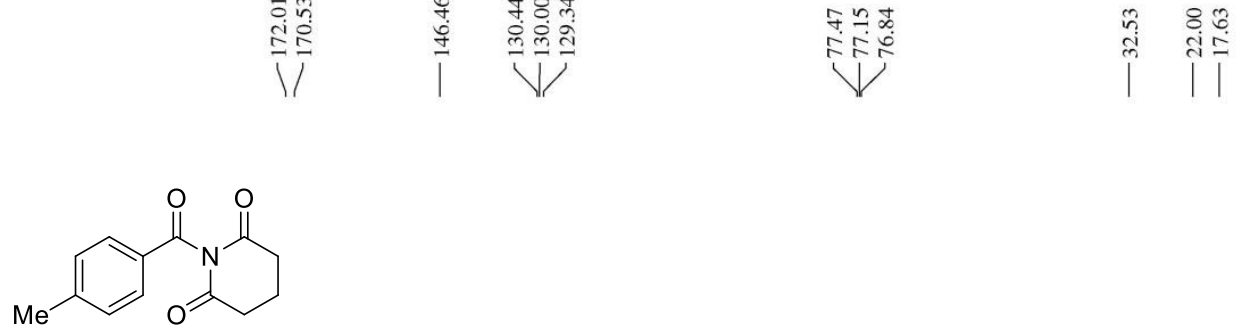

$1 c$

$\left(100 \mathrm{MHz}, \mathrm{CDCl}_{3}\right)$

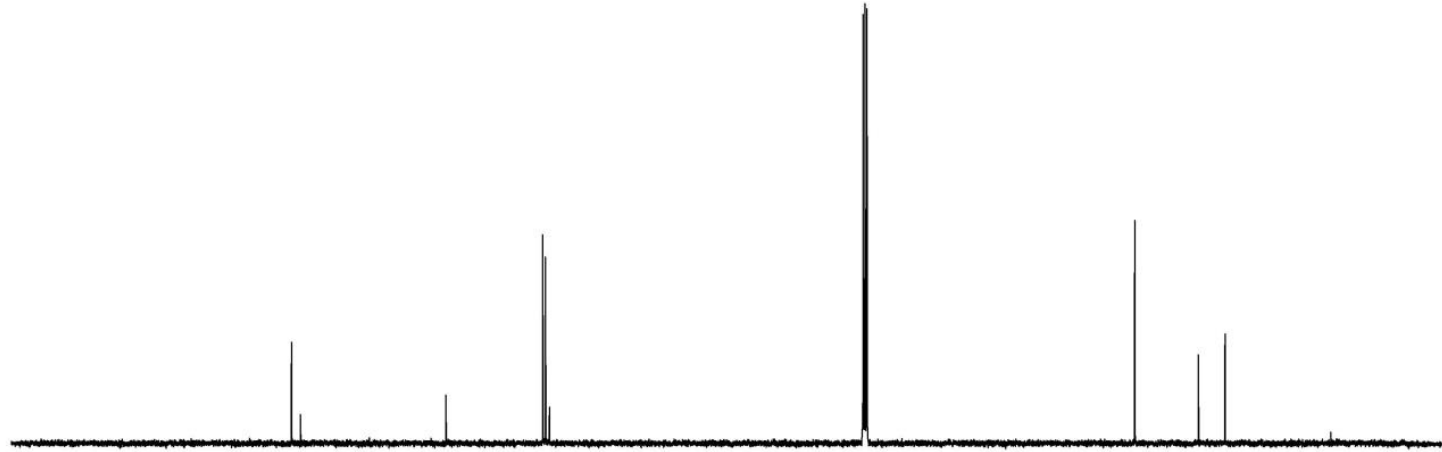

$\begin{array}{llllllllllllllllllllllll}210 & 200 & 190 & 180 & 170 & 160 & 150 & 140 & 130 & 120 & 110 & 100 & 90 & 80 & 70 & 60 & 50 & 40 & 30 & 20 & 10 & 0 & \mathrm{ppm}\end{array}$ 

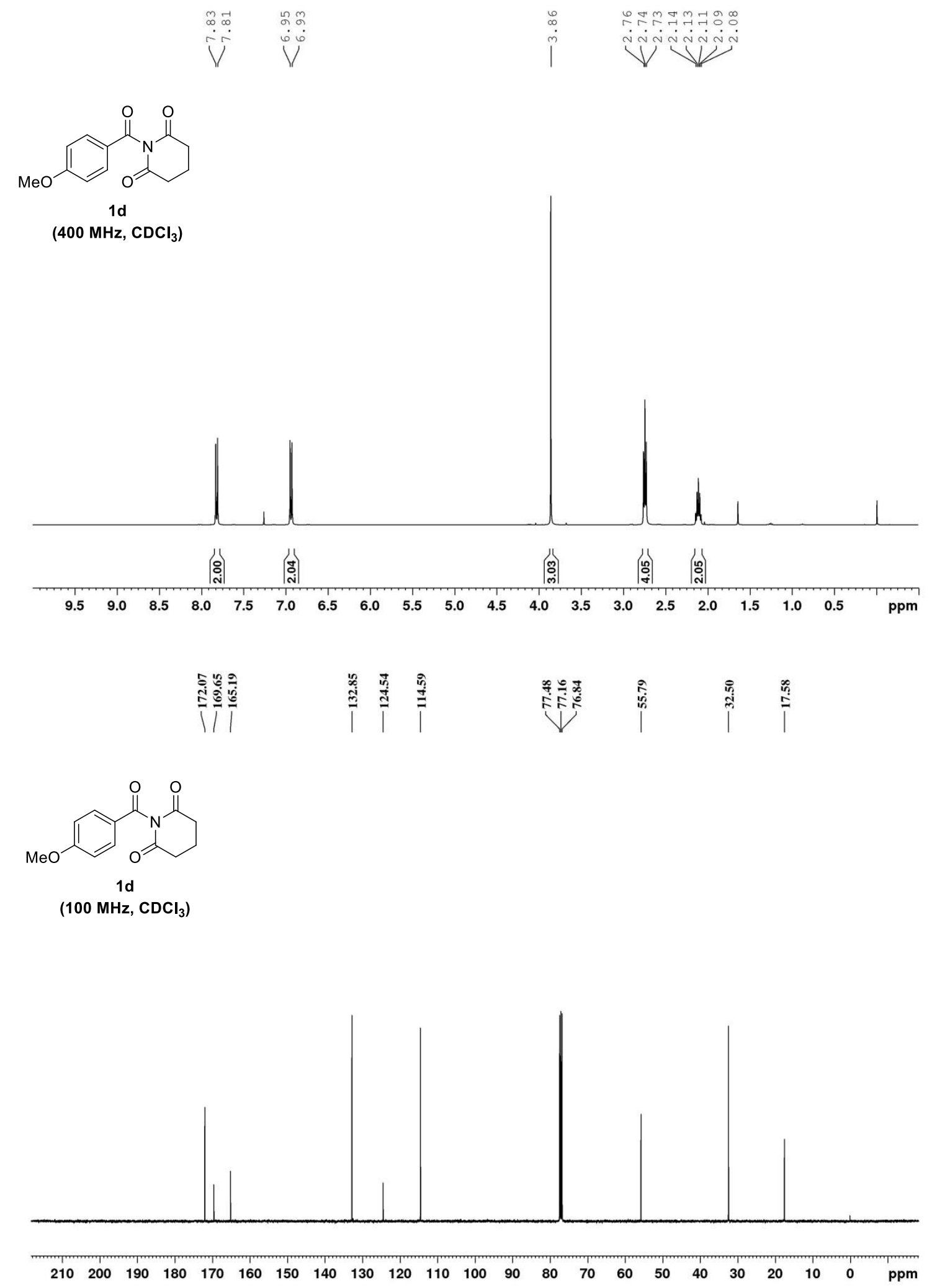


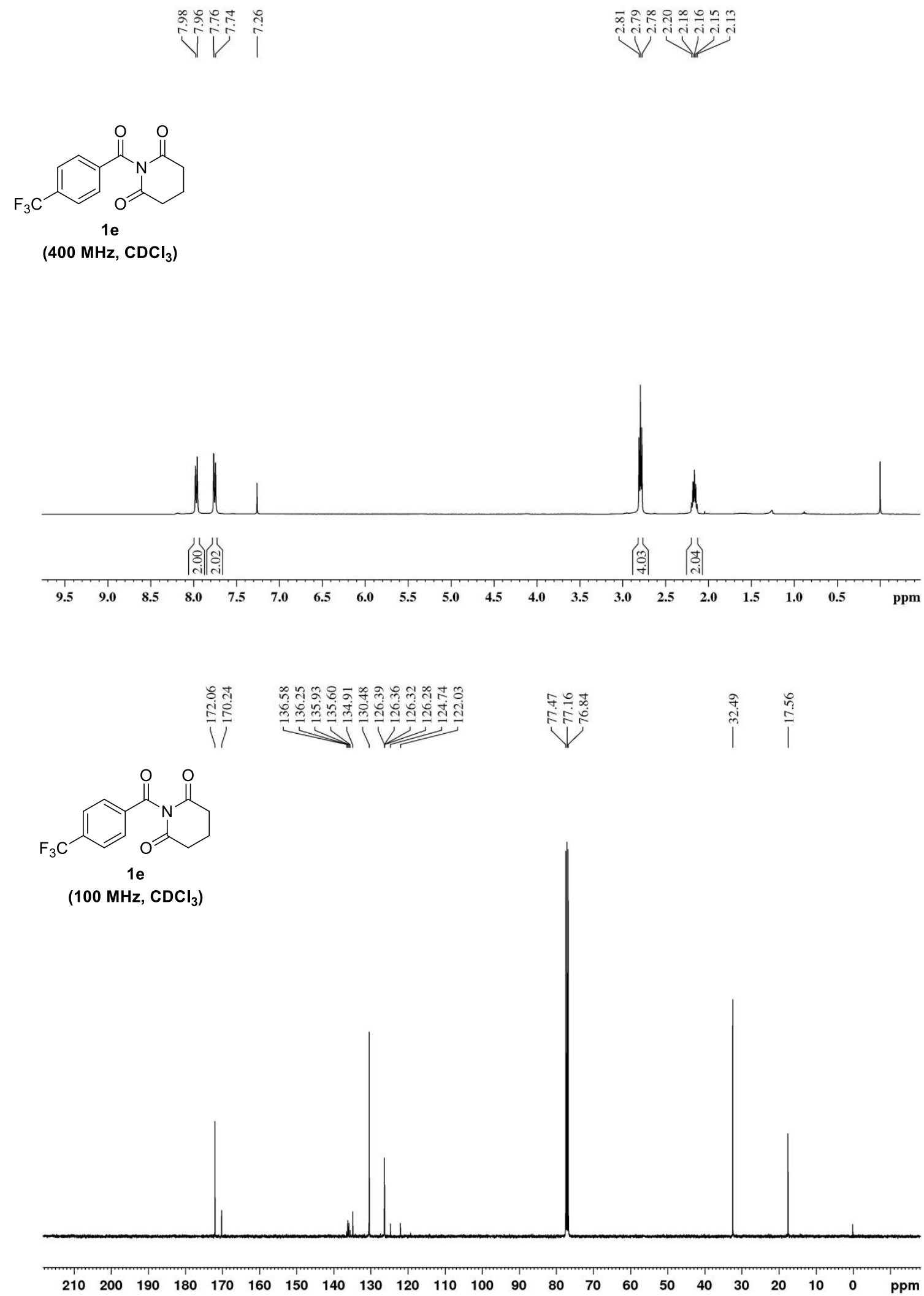



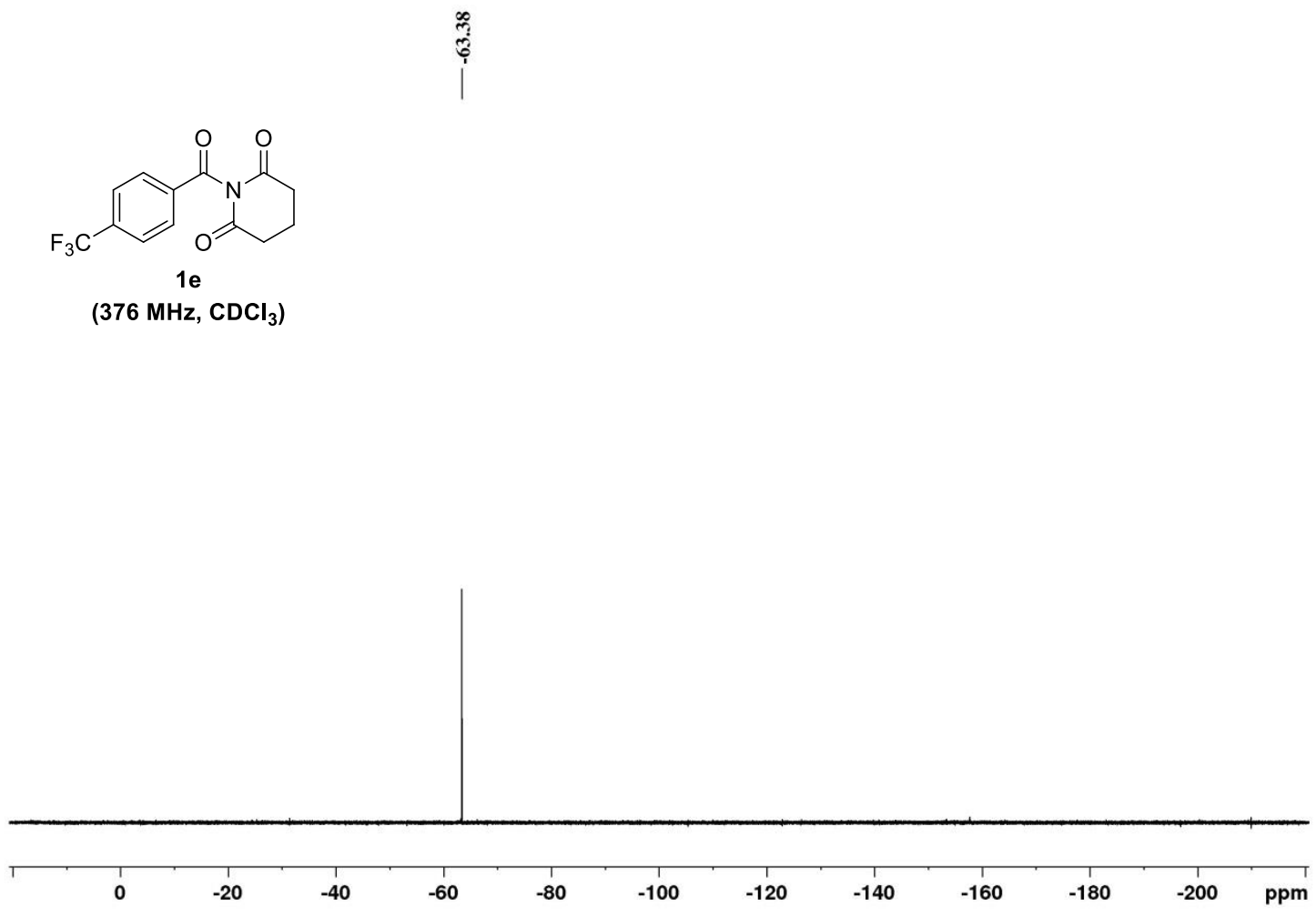


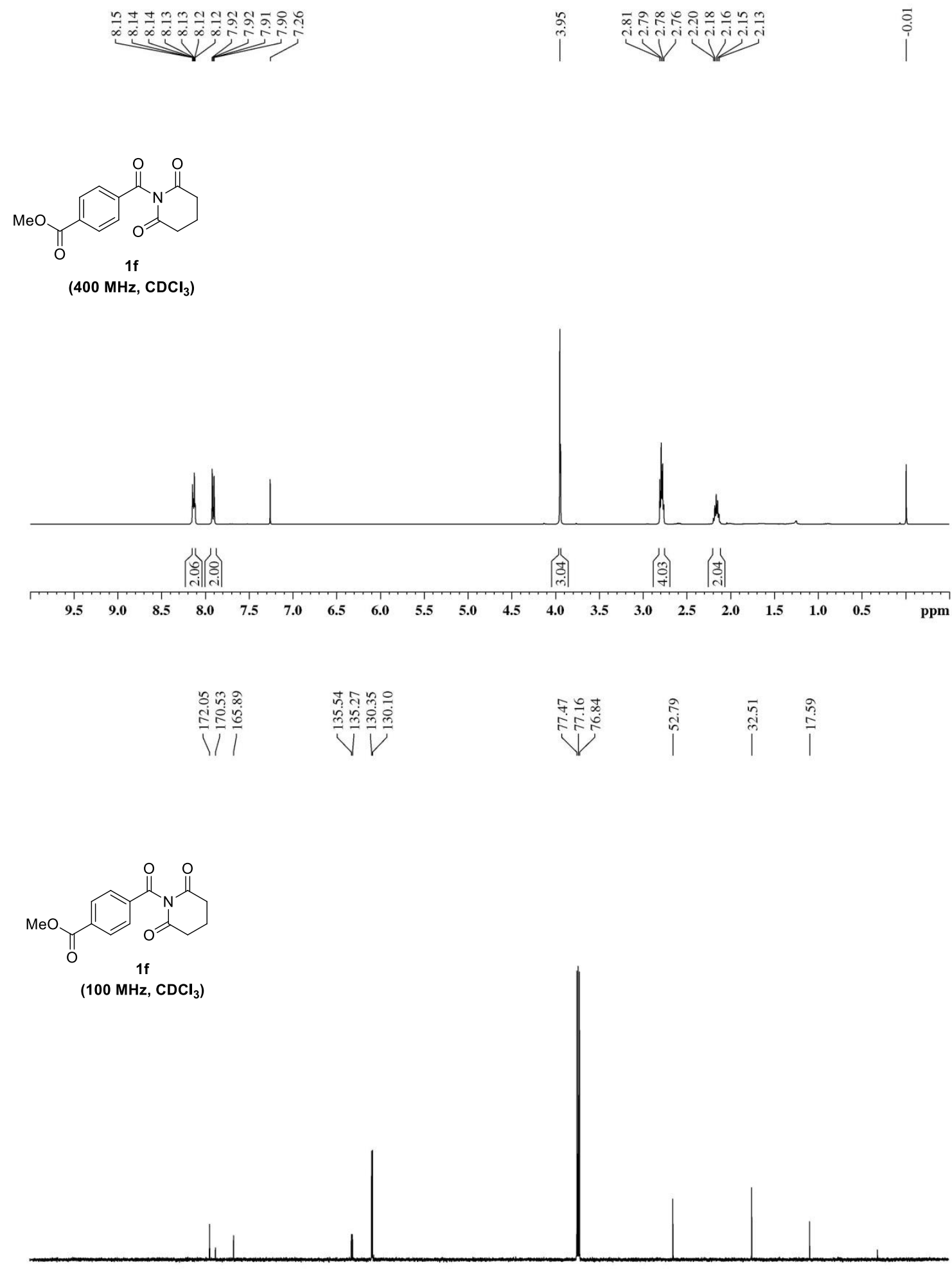

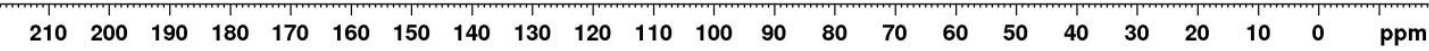



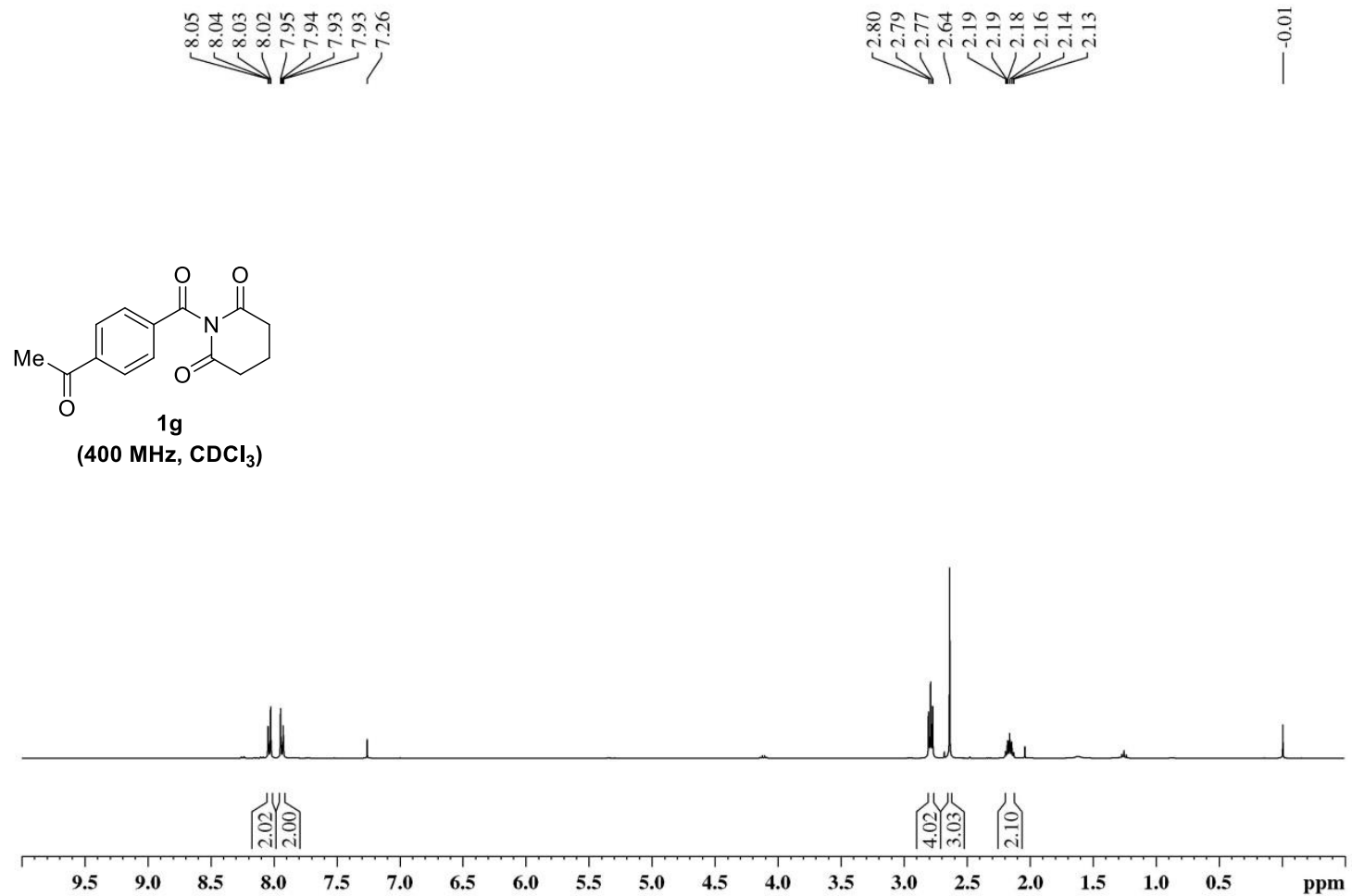

lll

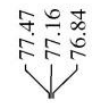

|
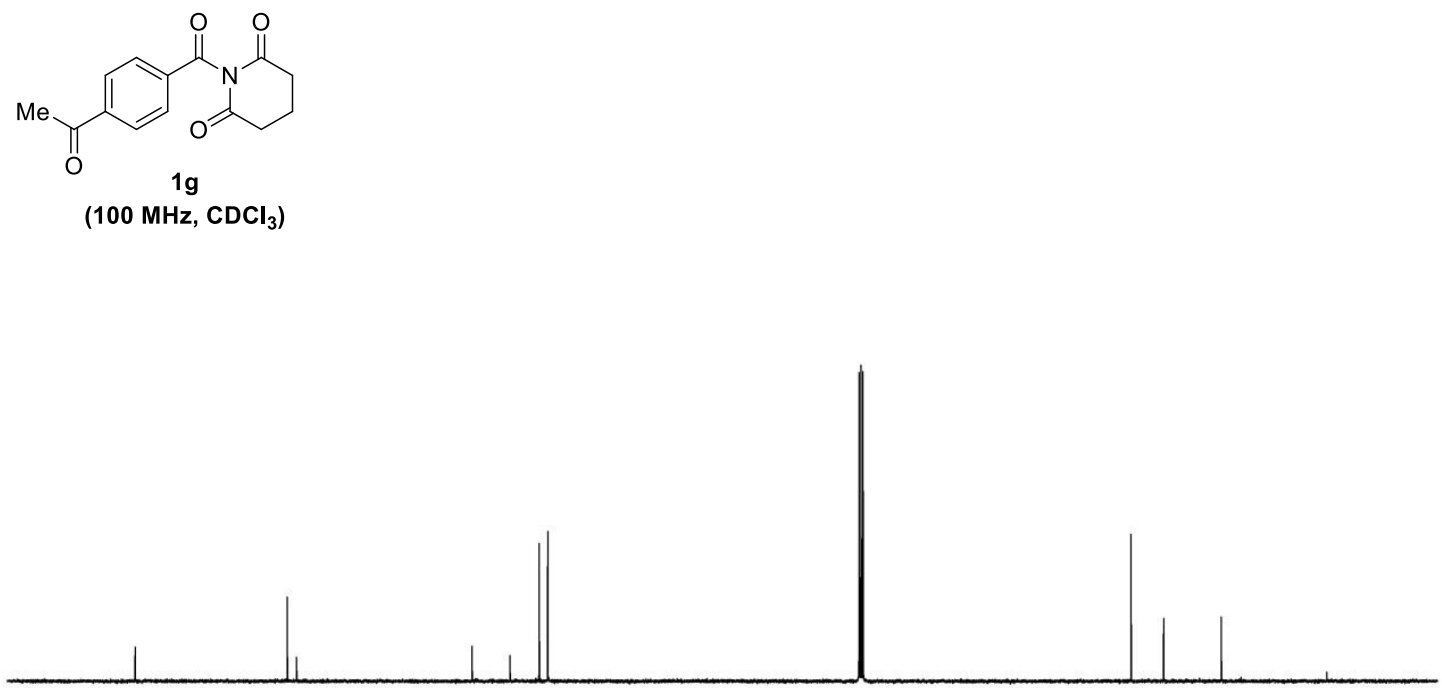

$\begin{array}{lllllllllllllllllllllll}210 & 200 & 190 & 180 & 170 & 160 & 150 & 140 & 130 & 120 & 110 & 100 & 90 & 80 & 70 & 60 & 50 & 40 & 30 & 20 & 10 & 0 & \mathrm{ppm}\end{array}$ 

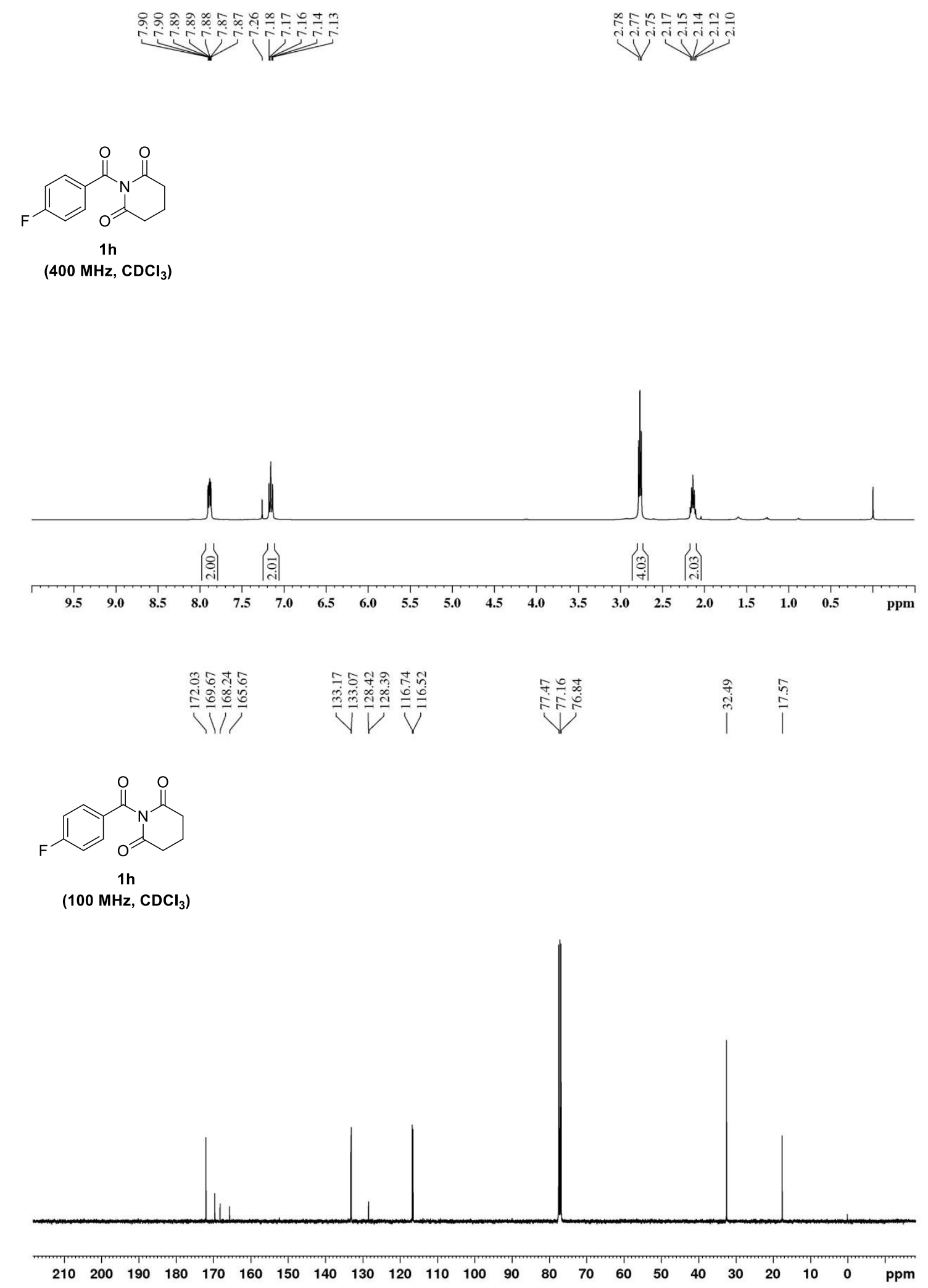


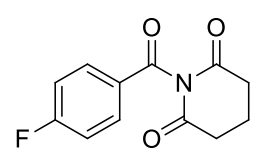

1h

(376 $\mathrm{MHz}, \mathrm{CDCl}_{3}$ )

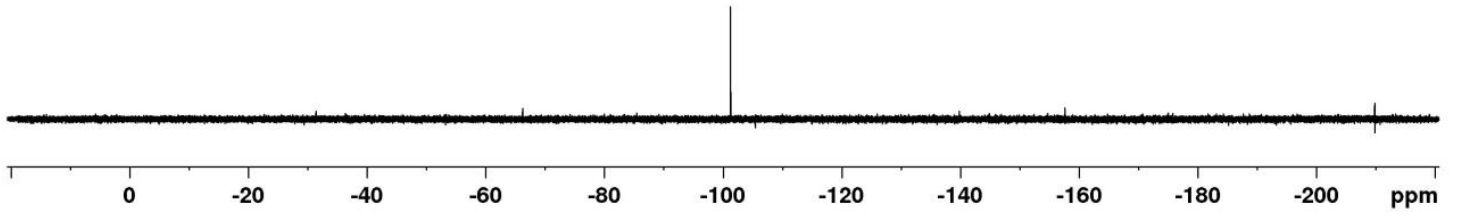




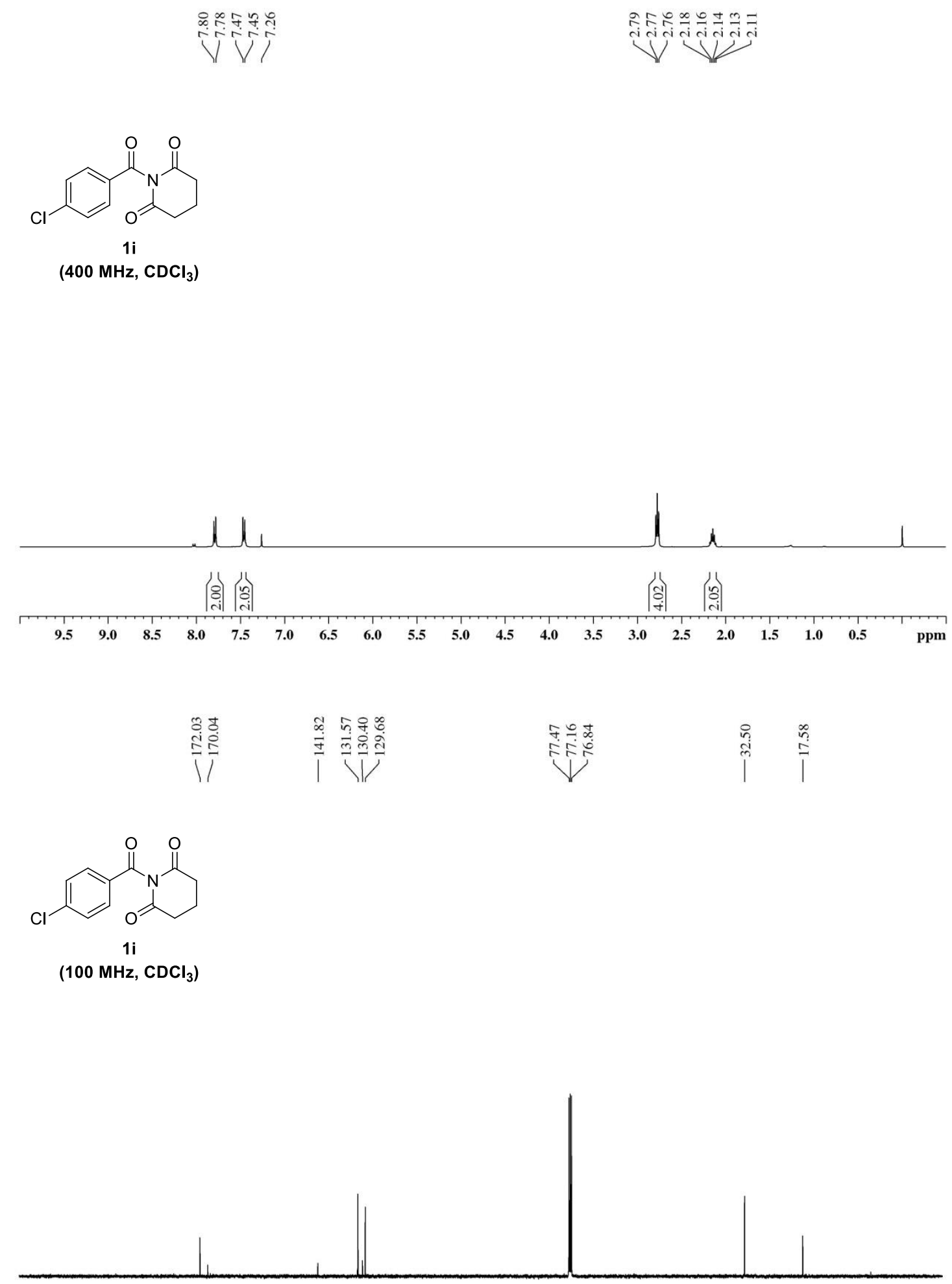

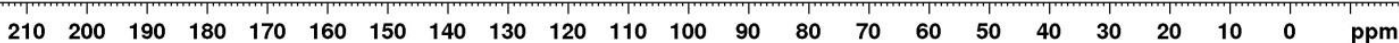



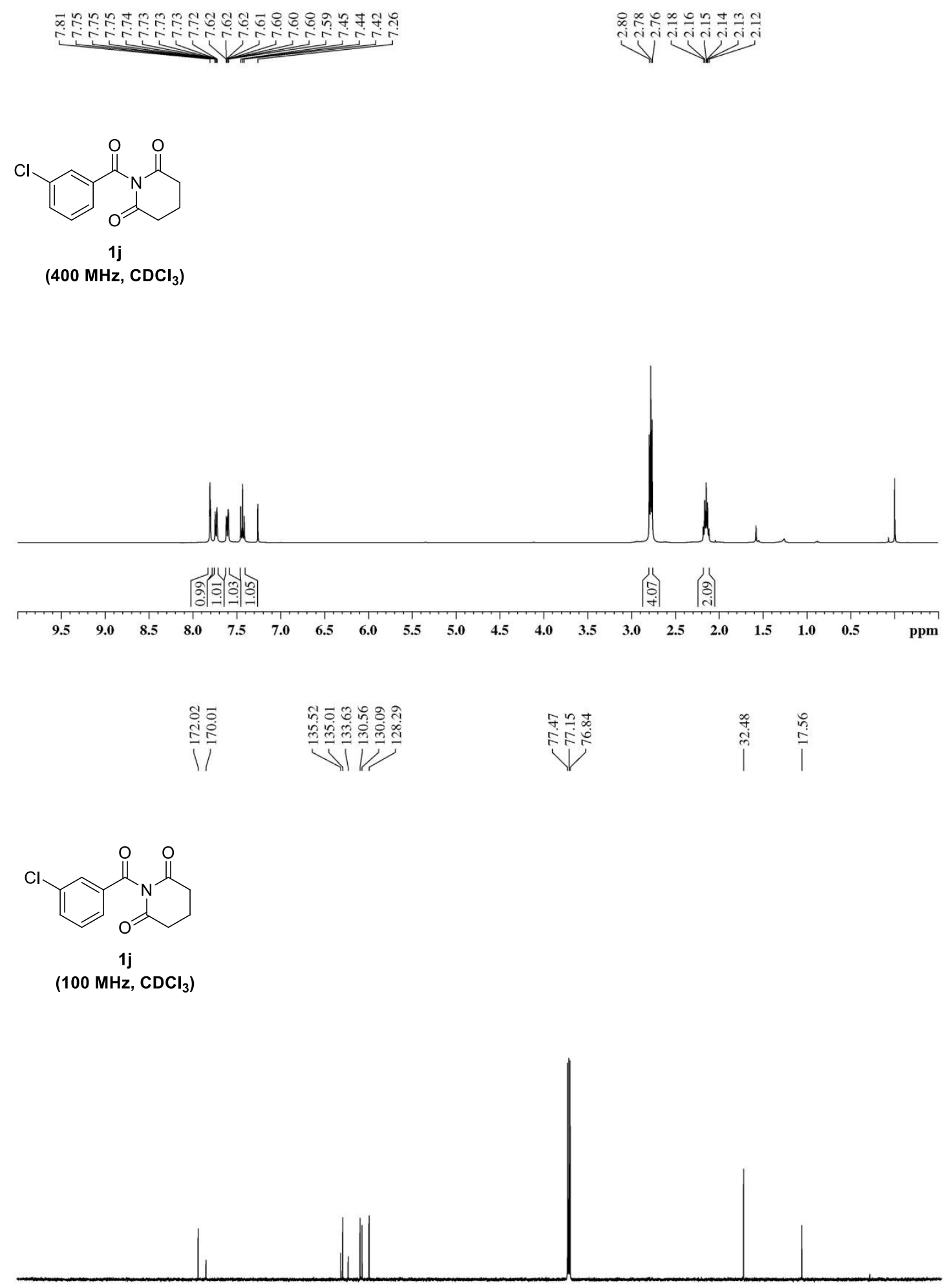

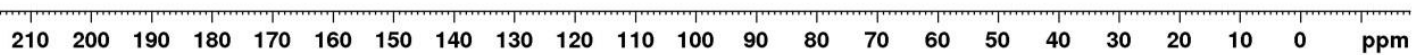




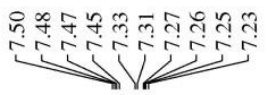

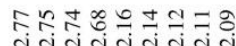

N/V V

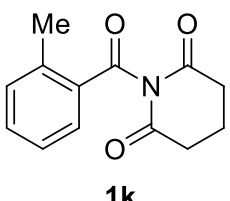

(400 $\mathrm{MHz} \mathrm{CDCl}_{3}$ )
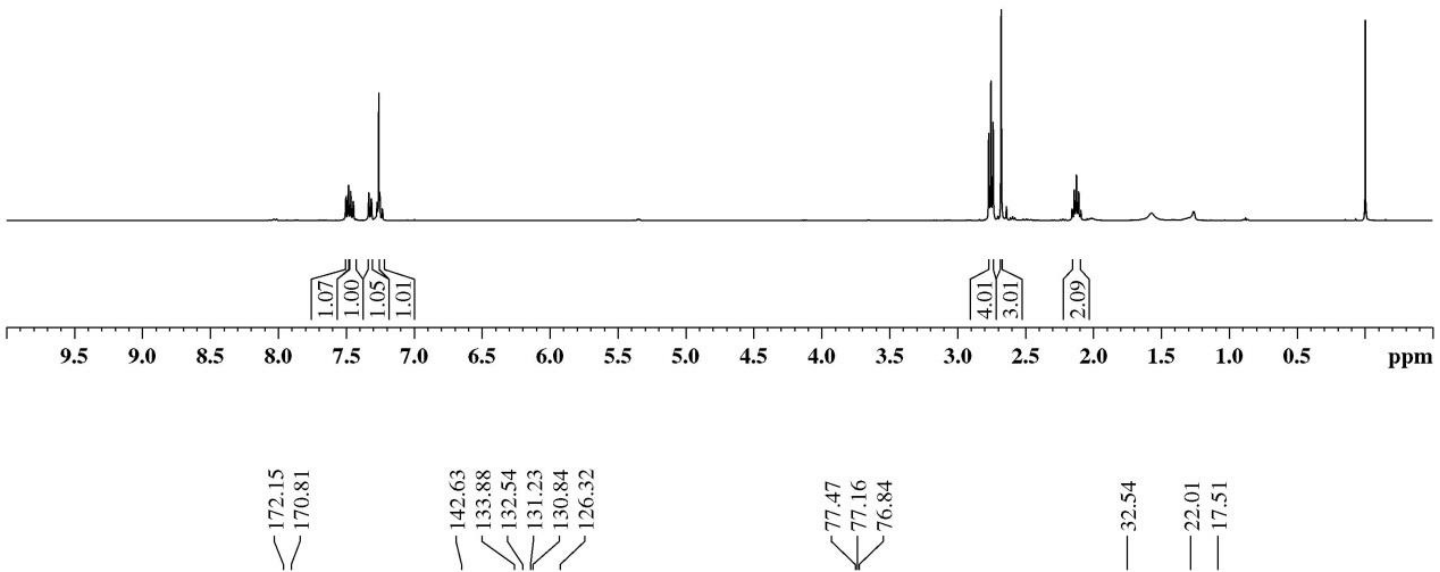

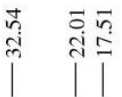

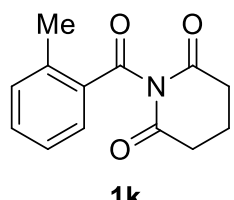

(100 MHz, $\mathrm{CDCl}_{3}$ )

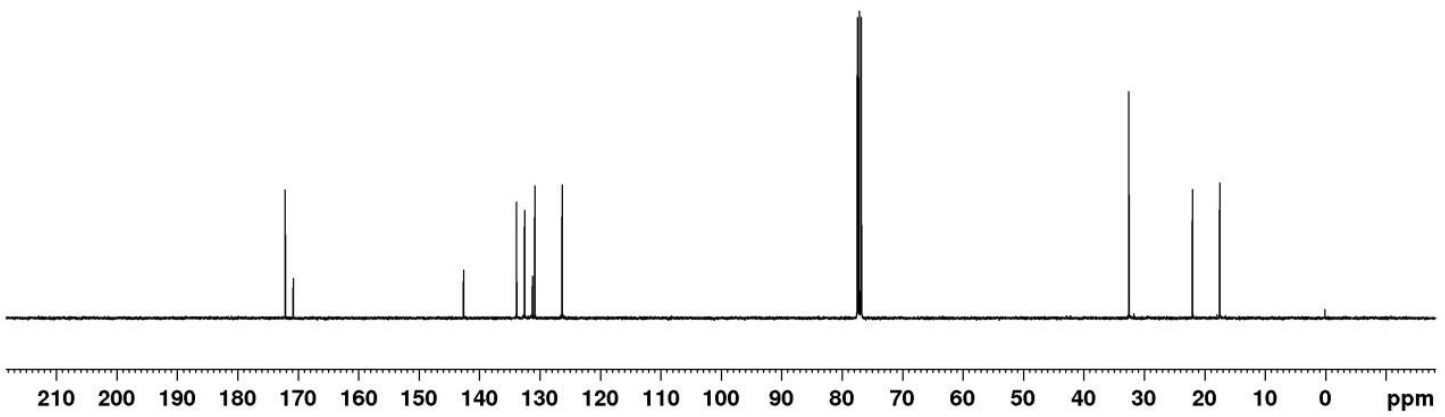


<smiles>O=C1CCCC(=O)N1C(=O)c1ccccc1F</smiles>

11

(400 $\mathrm{MHz}, \mathrm{CDCl}_{3}$ )
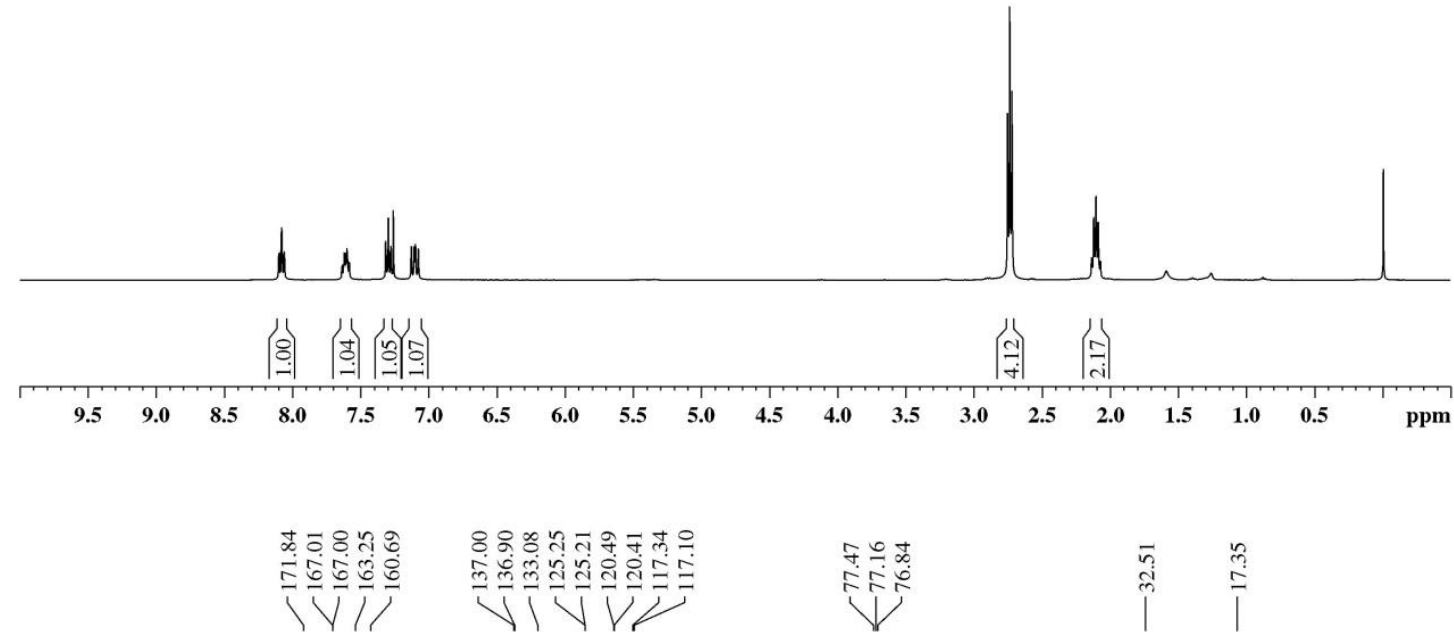

in<smiles>O=C1CCCC(=O)N1C(=O)c1ccccc1F</smiles>

11

$\left(100 \mathrm{MHz}, \mathrm{CDCl}_{3}\right)$

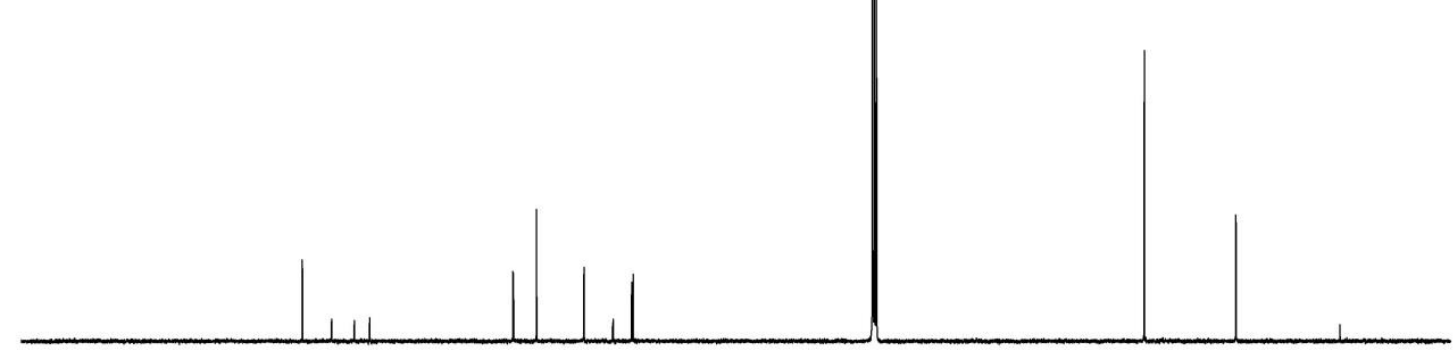

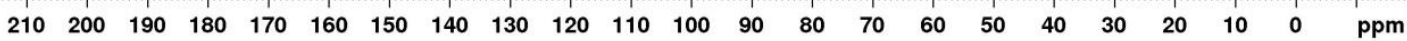




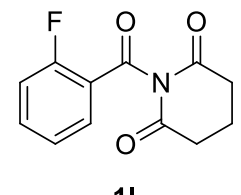

(376 MHz, $\mathrm{CDCl}_{3}$ )

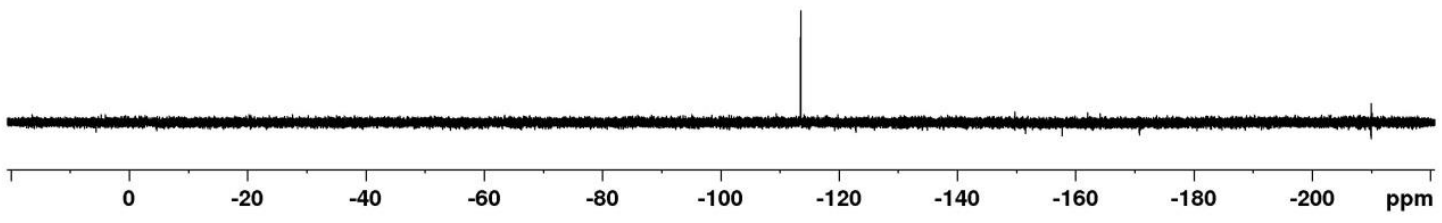



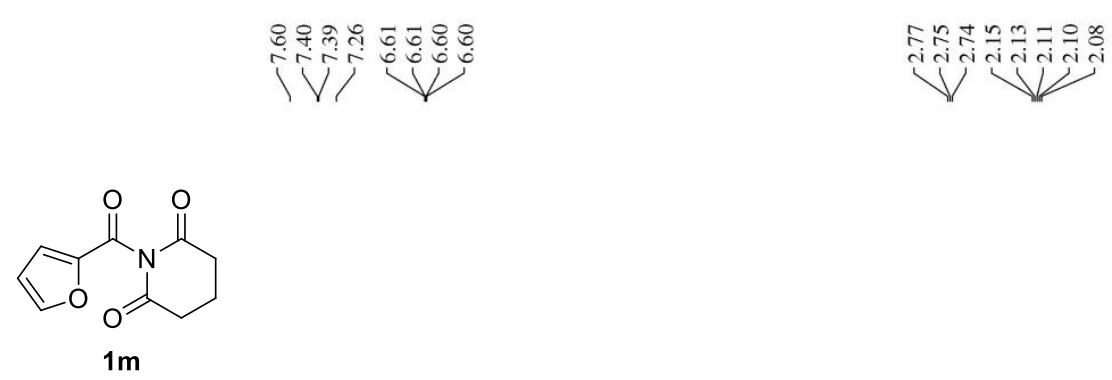

$\left(400 \mathrm{MHz}, \mathrm{CDCl}_{3}\right)$
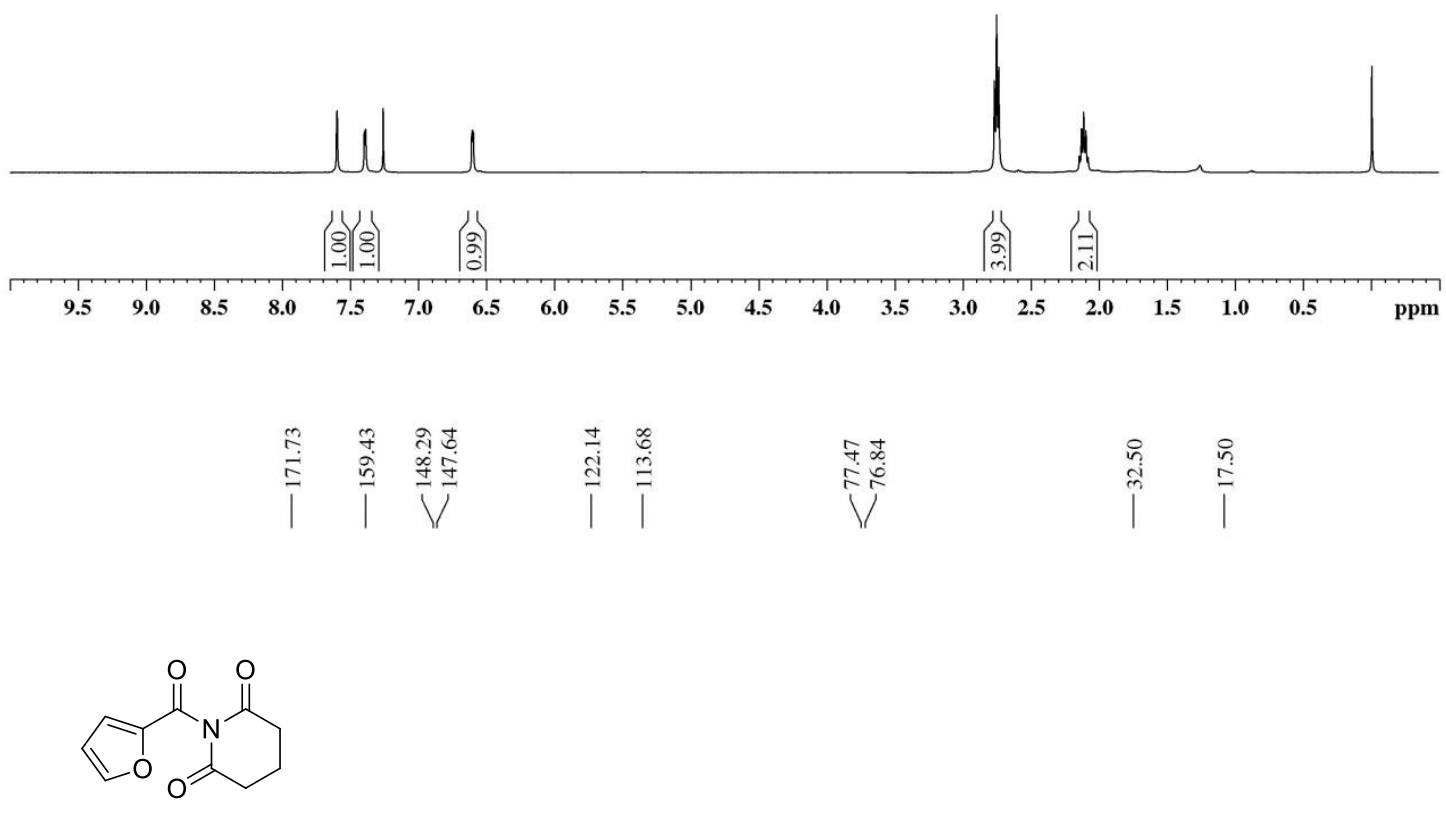

$1 \mathrm{~m}$

$\left(100 \mathrm{MHz}, \mathrm{CDCl}_{3}\right)$

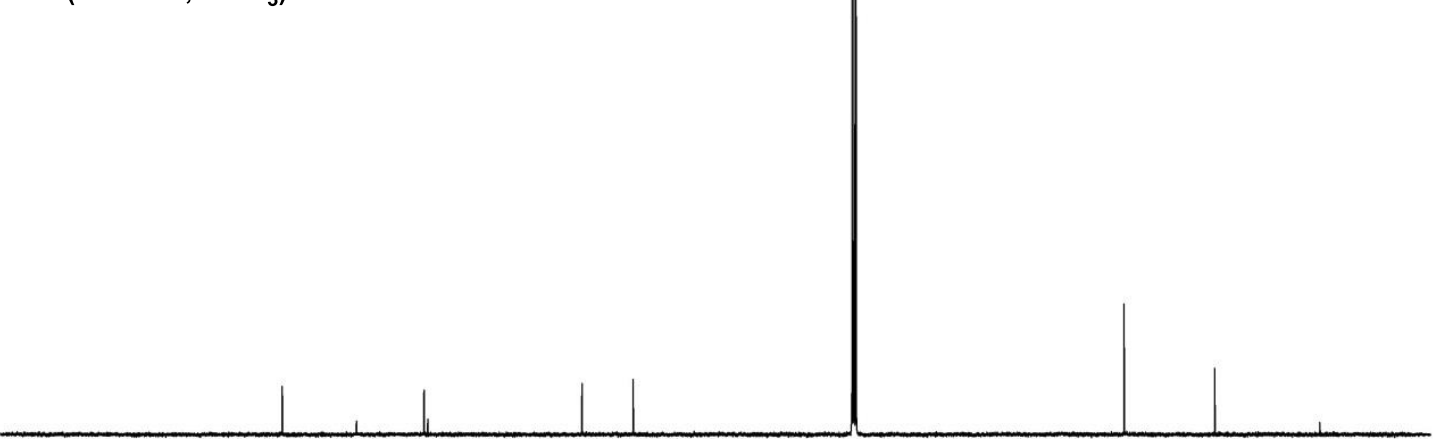

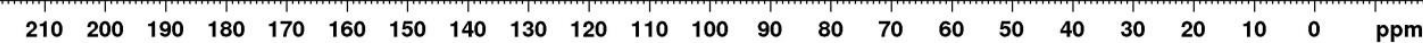




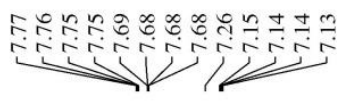<smiles>O=C1CCCC(=O)N1C(=O)c1cccs1</smiles>

1n

$\left(400 \mathrm{MHz}, \mathrm{CDCl}_{3}\right)$

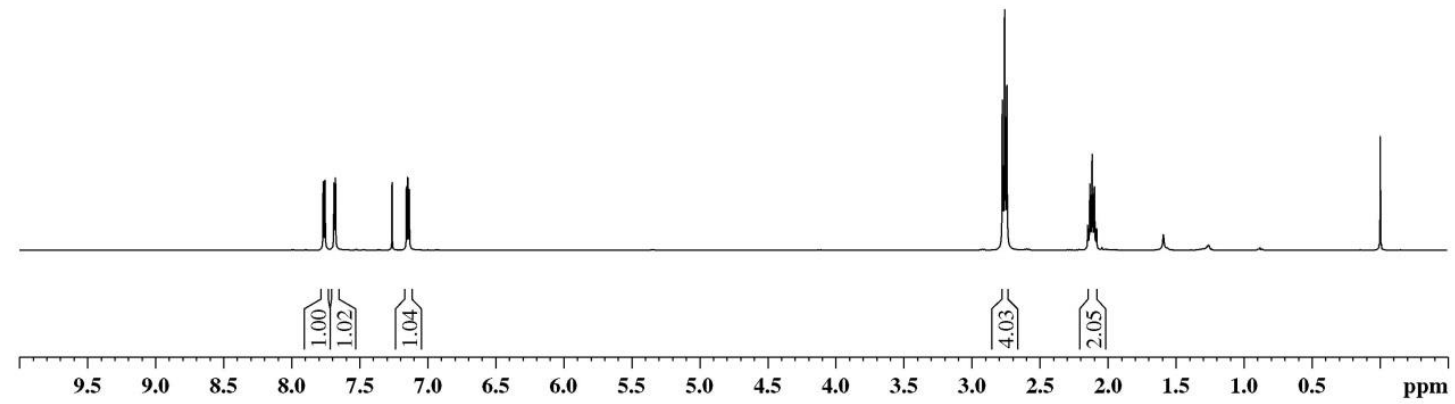

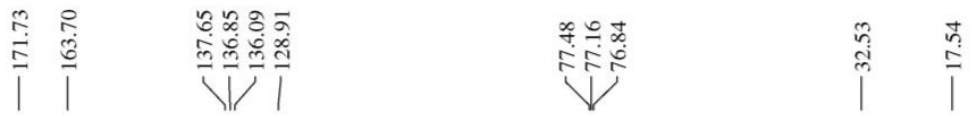

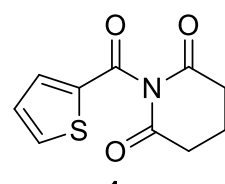

$$
\text { 1n }
$$

$\left(100 \mathrm{MHz}, \mathrm{CDCl}_{3}\right.$ )
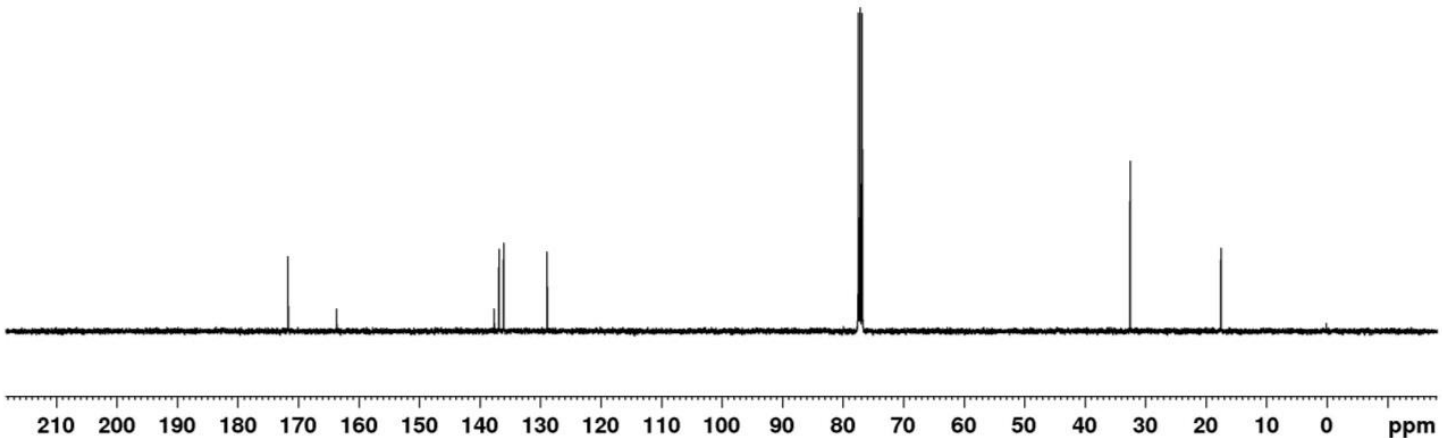

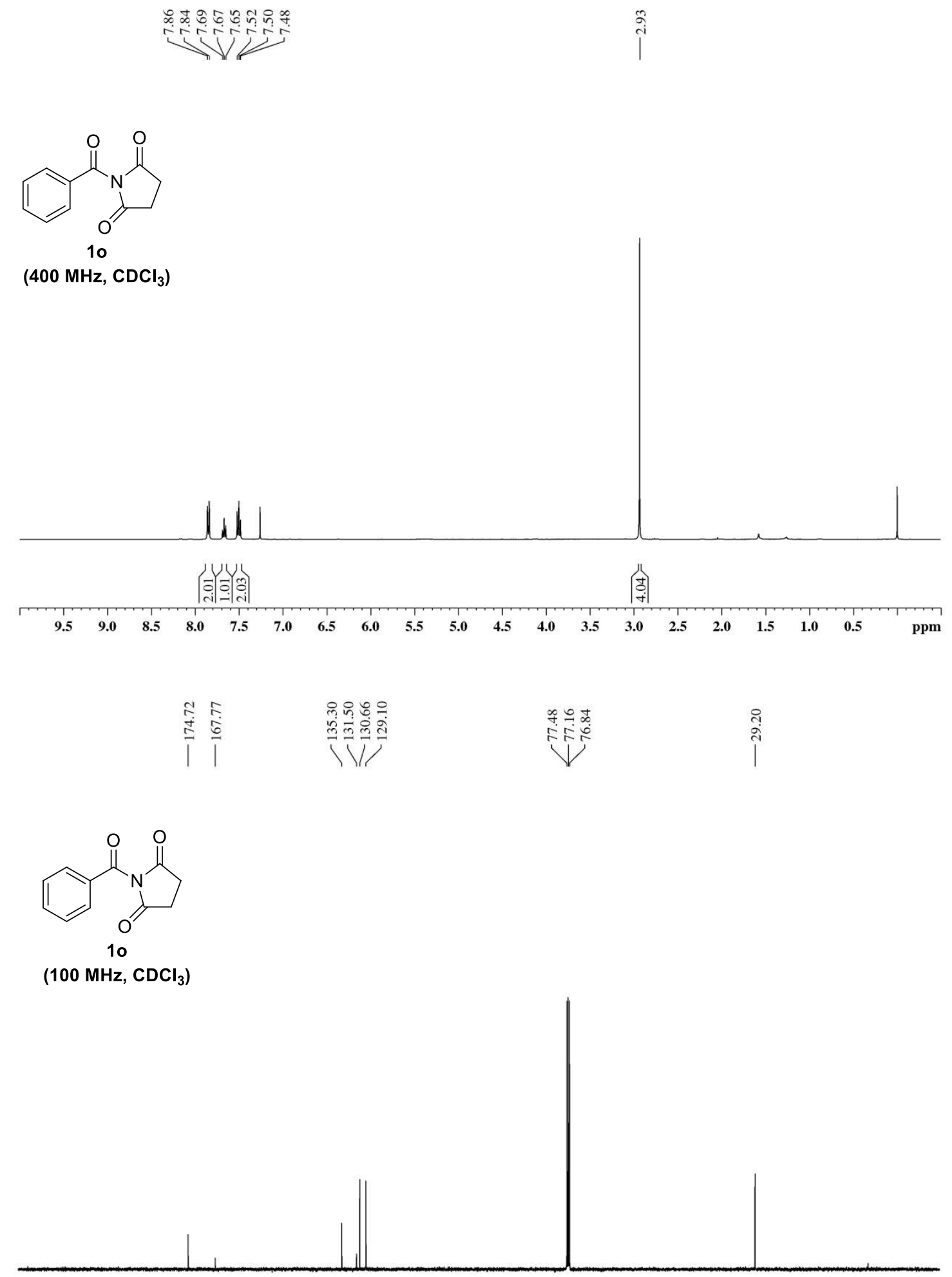

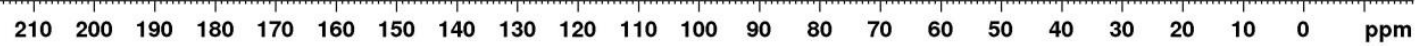



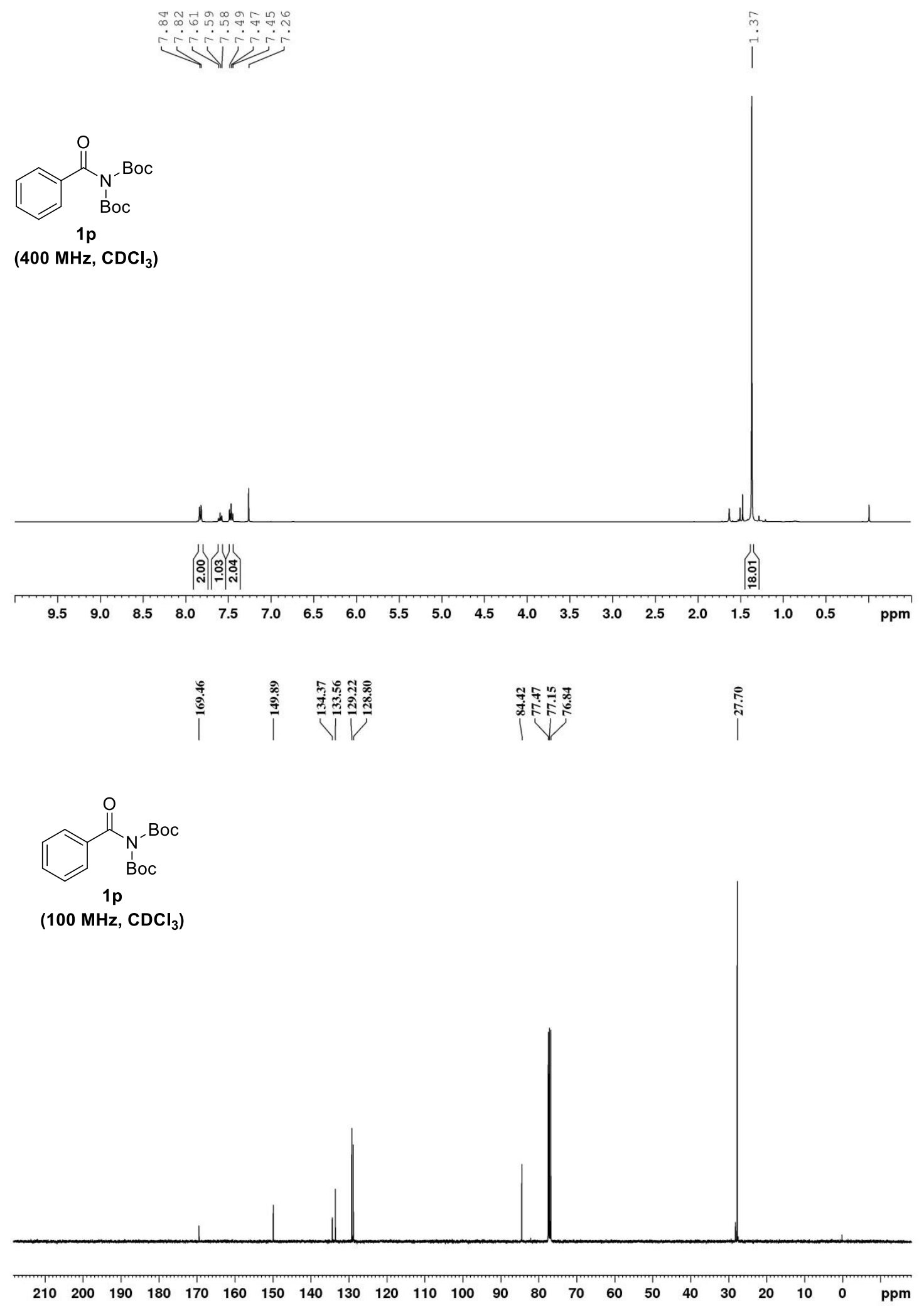

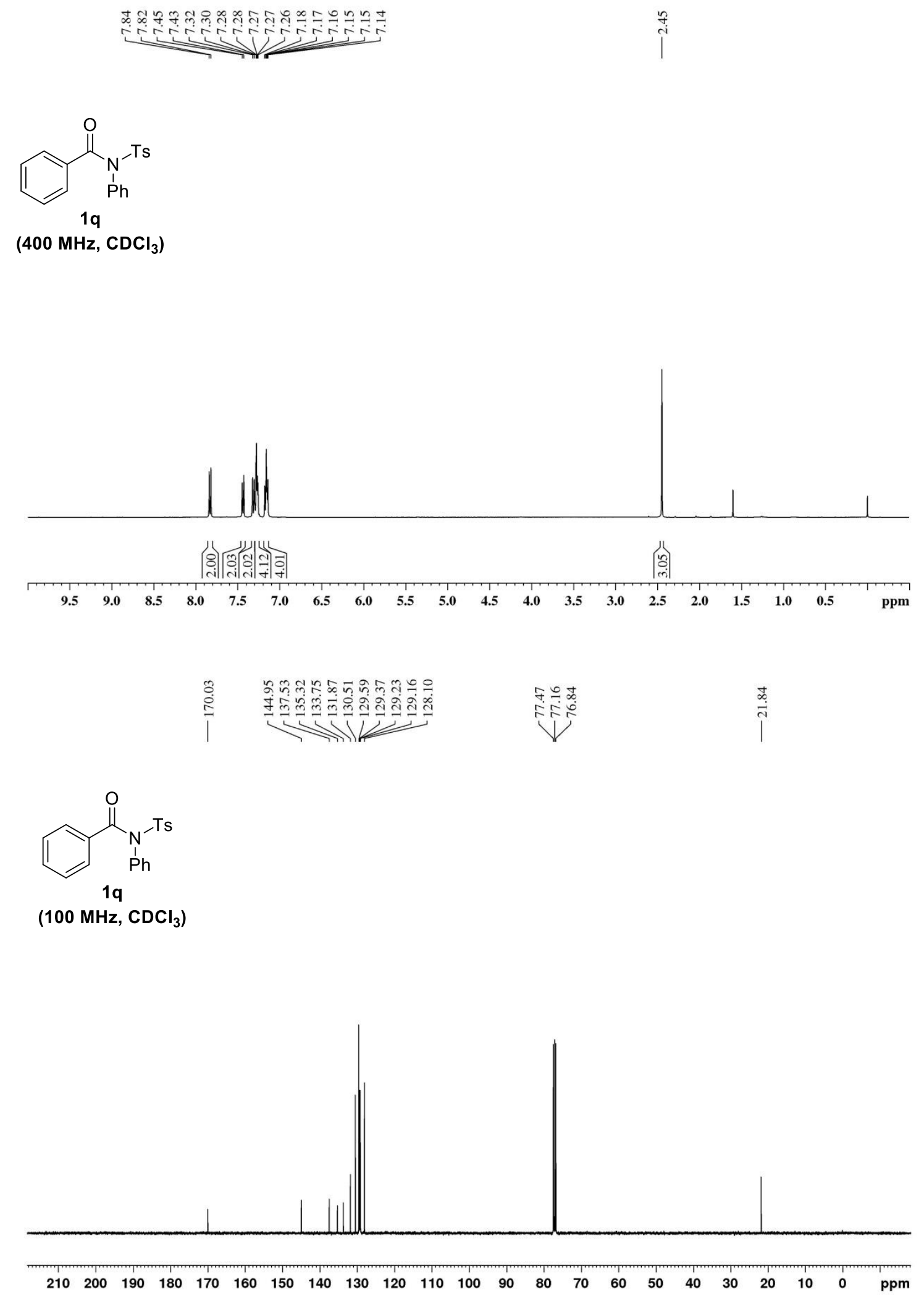


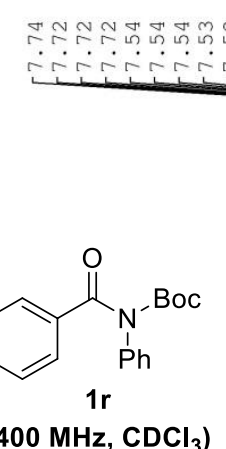

$$
\text { (400 MHz, } \mathrm{CDCl}_{3} \text { ) }
$$
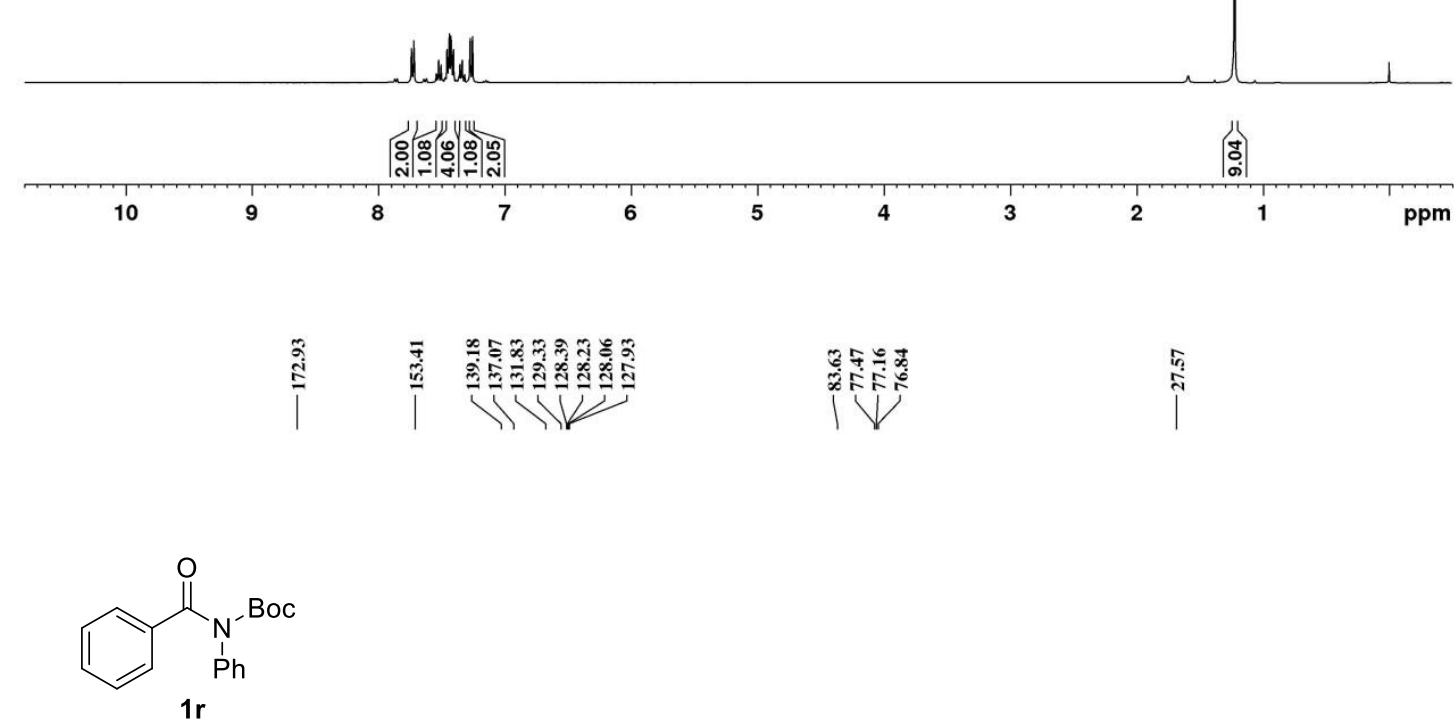

(100 MHz, $\mathrm{CDCl}_{3}$ )
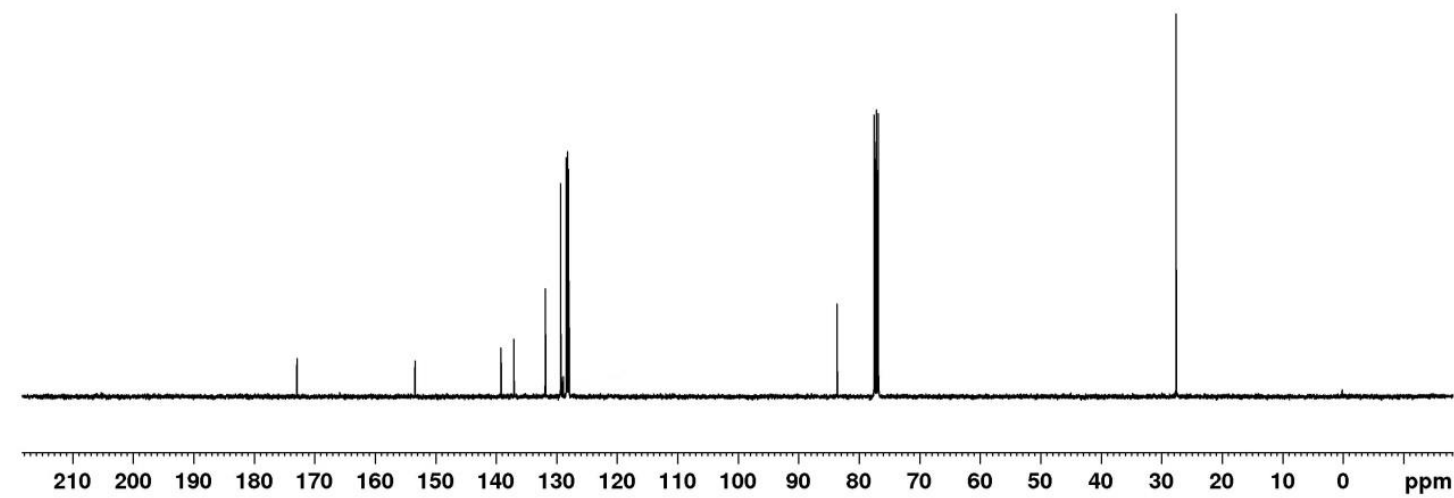

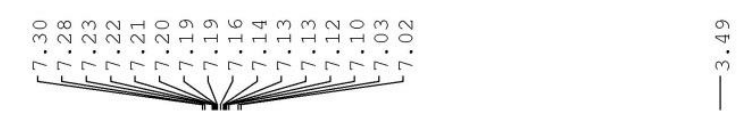<smiles>CN(C(=O)c1ccccc1)c1ccccc1</smiles>

1s (400 MHz, $\mathrm{CDCl}_{3}$ )
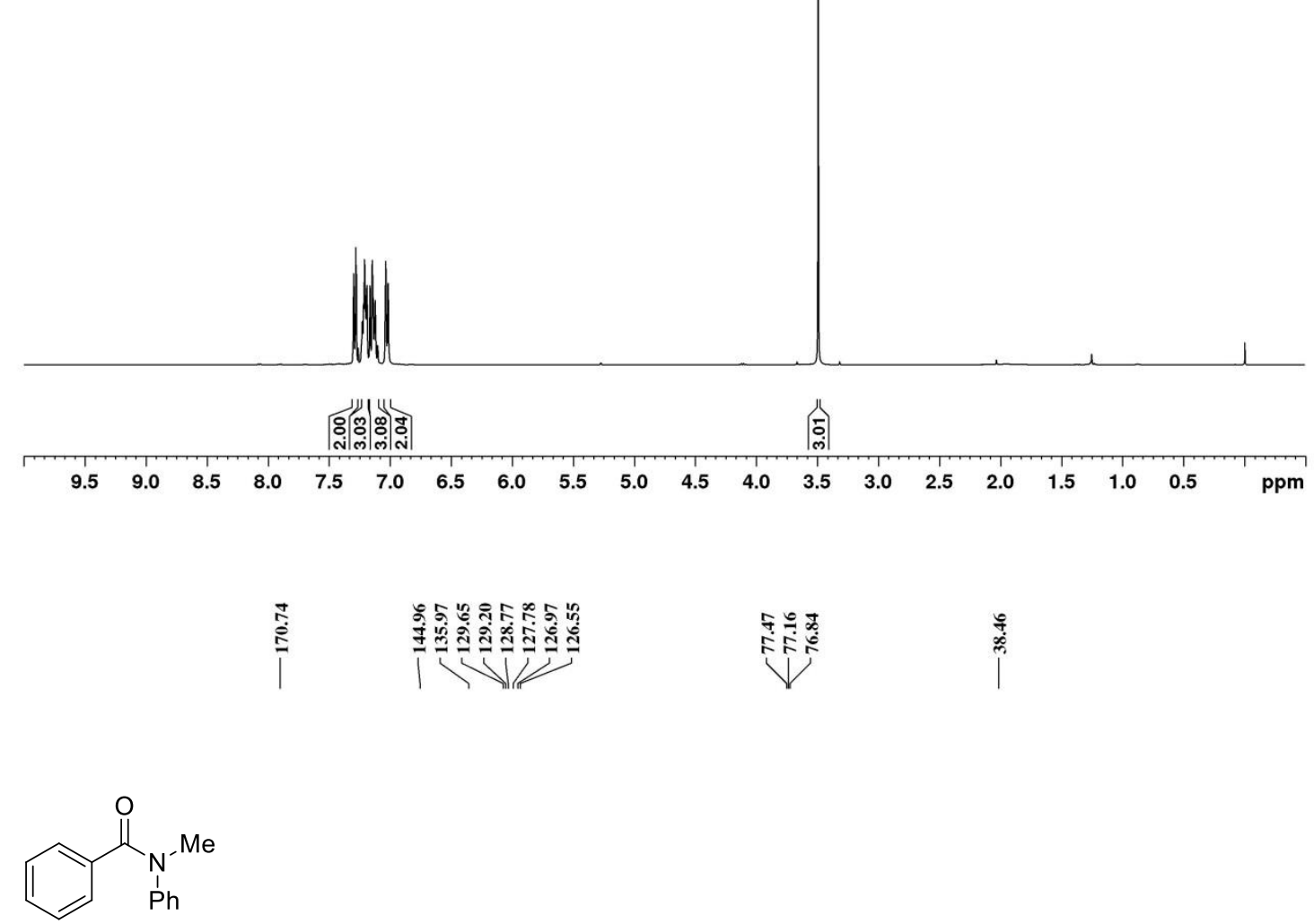

$1 \mathrm{~s}$

$\left(100 \mathrm{MHz}, \mathrm{CDCl}_{3}\right)$

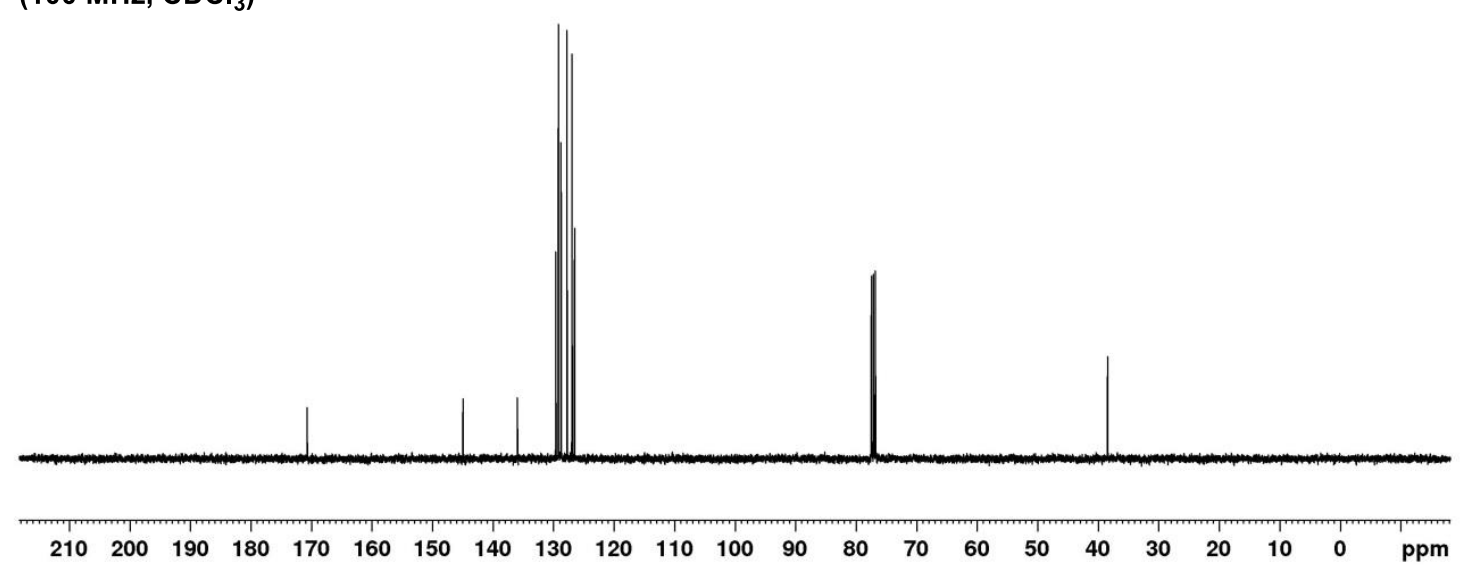




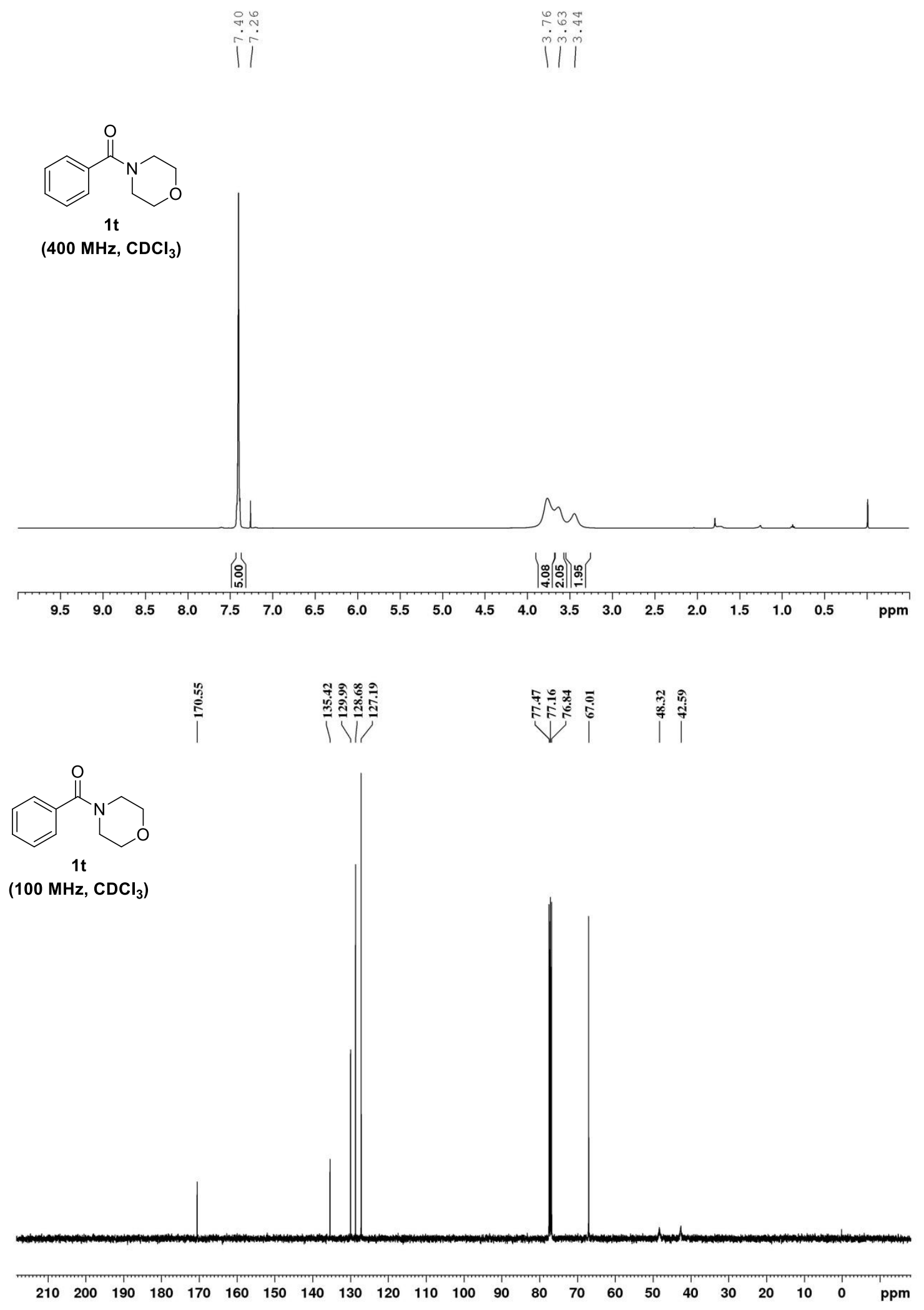



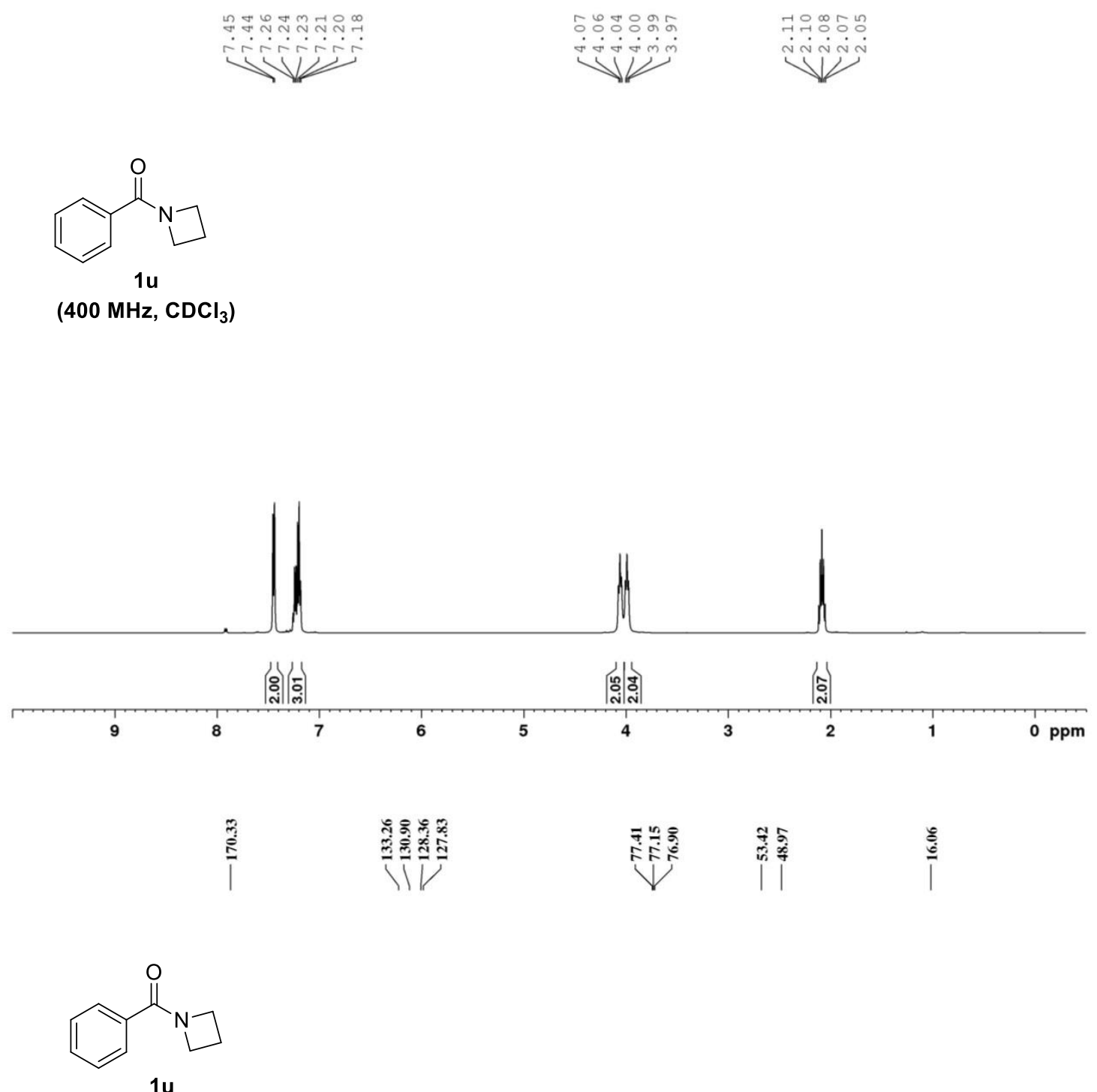

$\left(100 \mathrm{MHz}, \mathrm{CDCl}_{3}\right)$

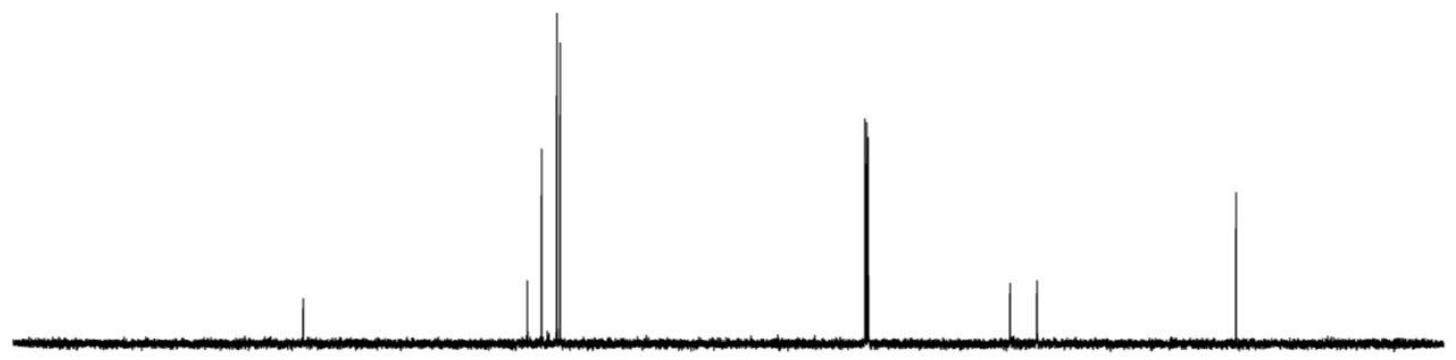

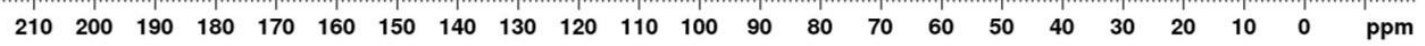




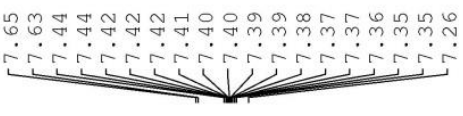<smiles>CON(C)C(=O)c1ccccc1</smiles>

1v

(400 $\left.\mathrm{MHz}, \mathrm{CDCl}_{3}\right)$

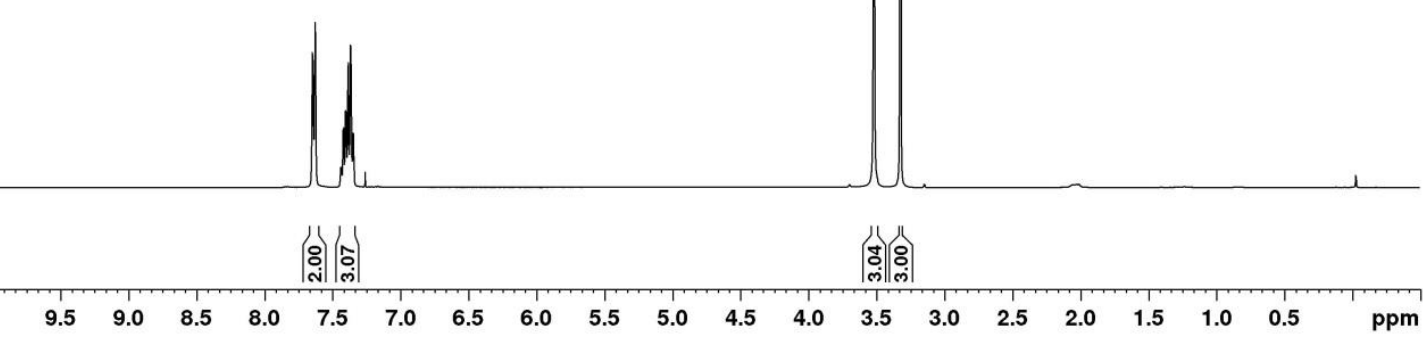

|

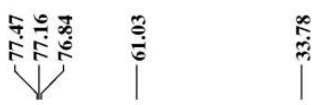<smiles>CN(C)C(=O)c1ccccc1</smiles>

1v

$\left(100 \mathrm{MHz}, \mathrm{CDCl}_{3}\right)$

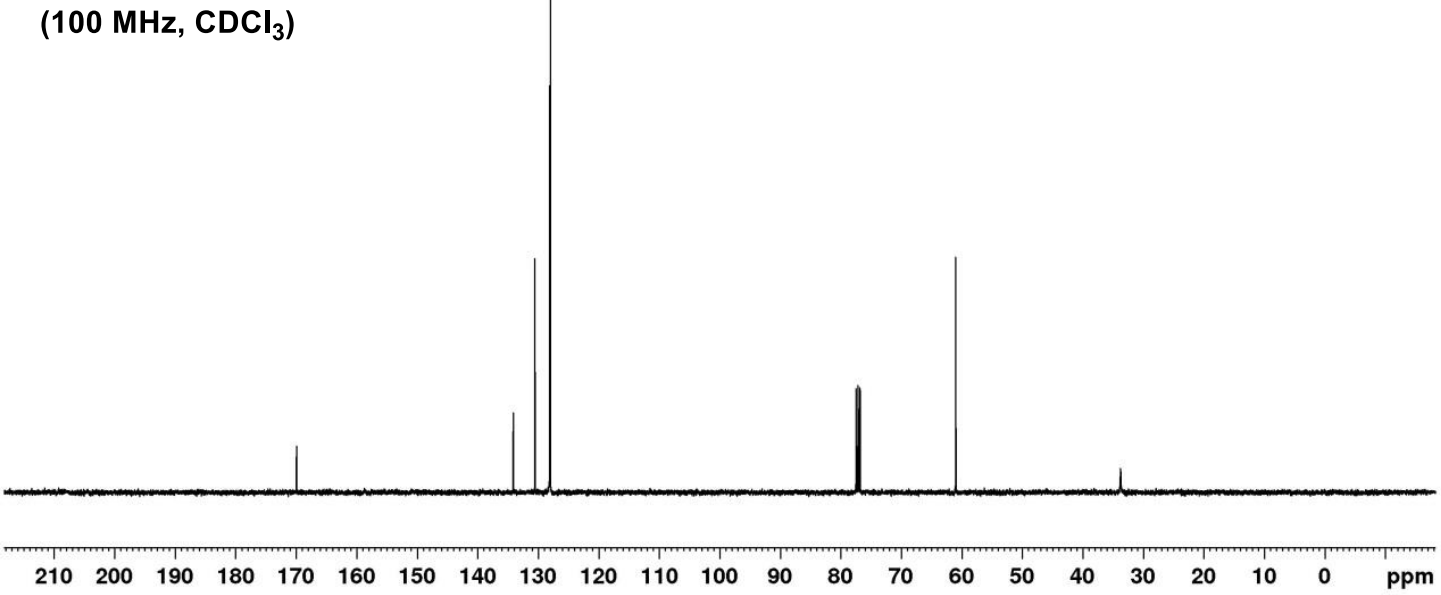




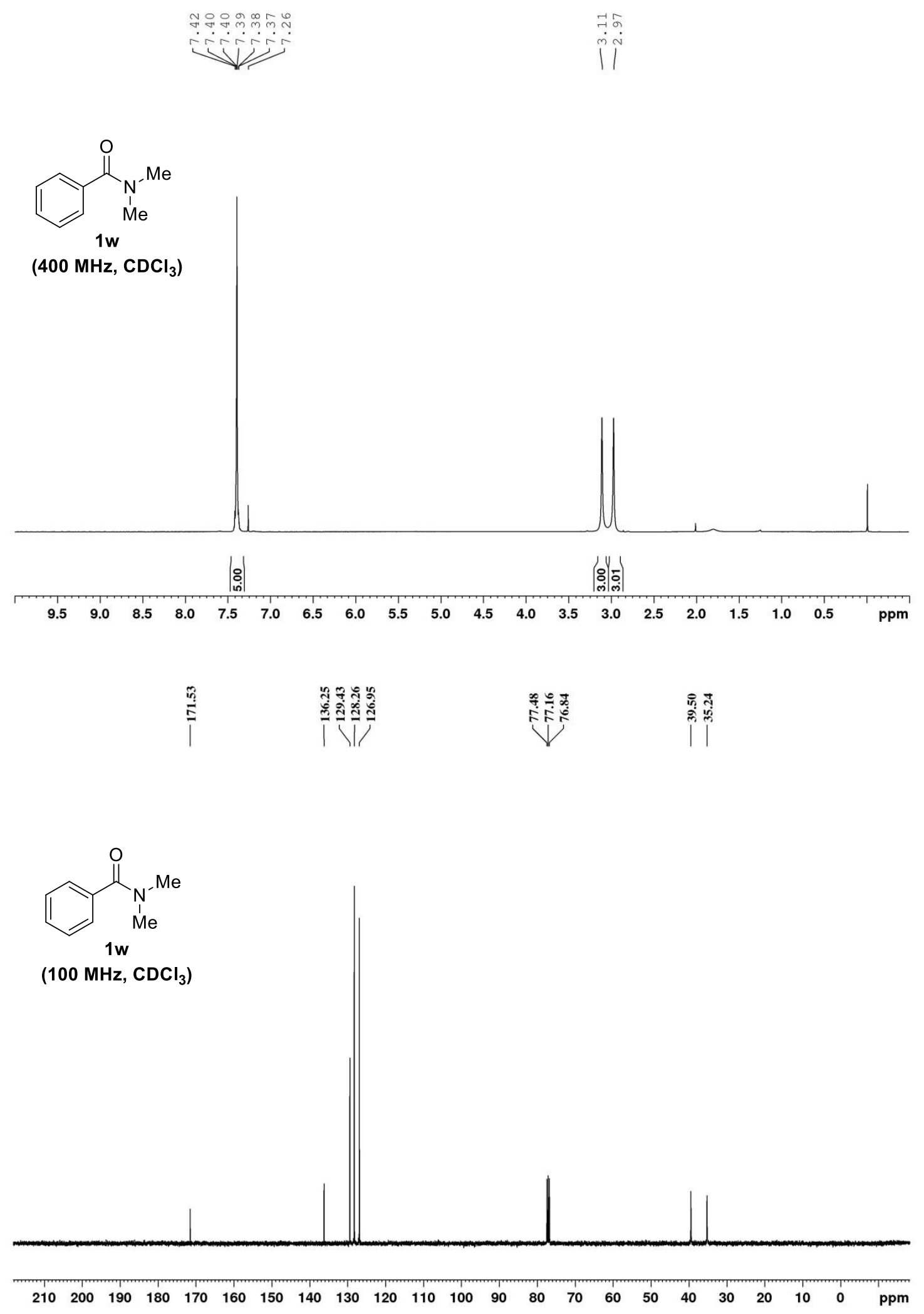



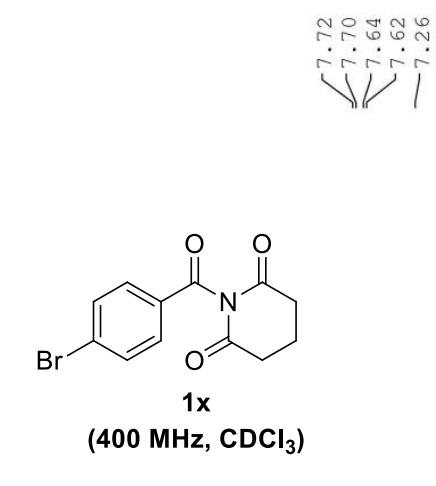

ำำㄱำ

inisingin

VW
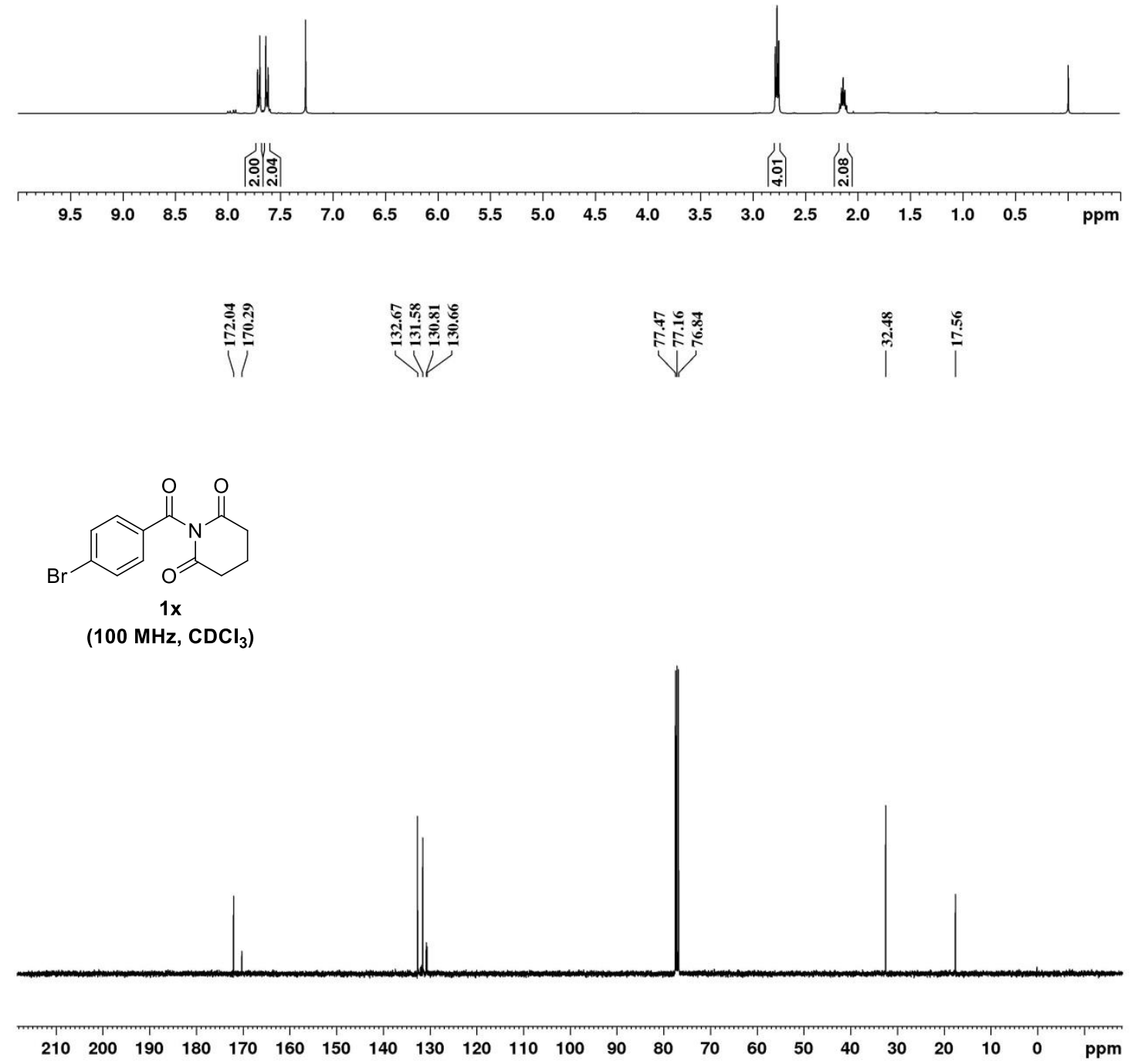


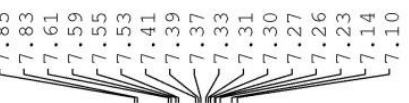

일

$\sqrt[2]{2}$
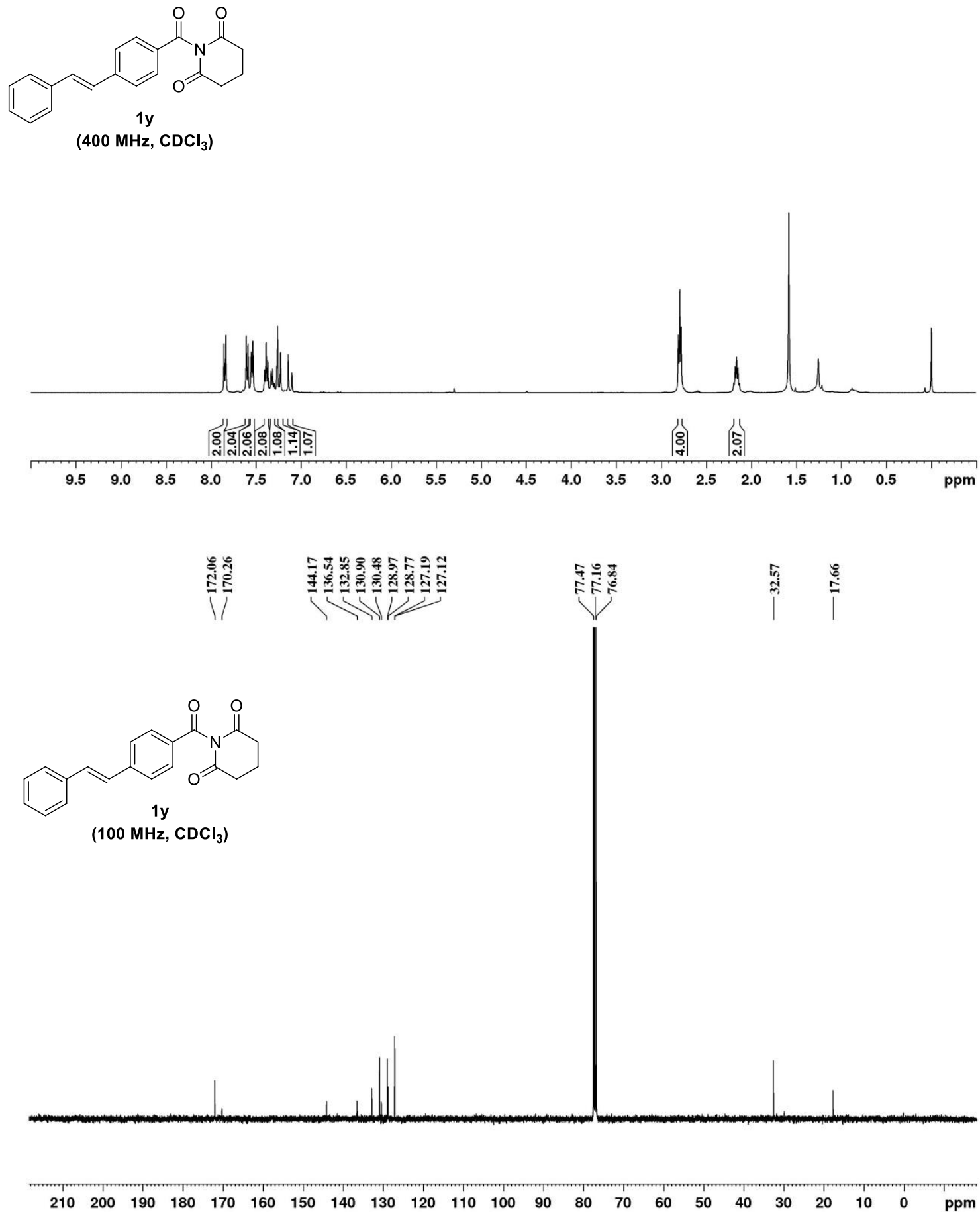

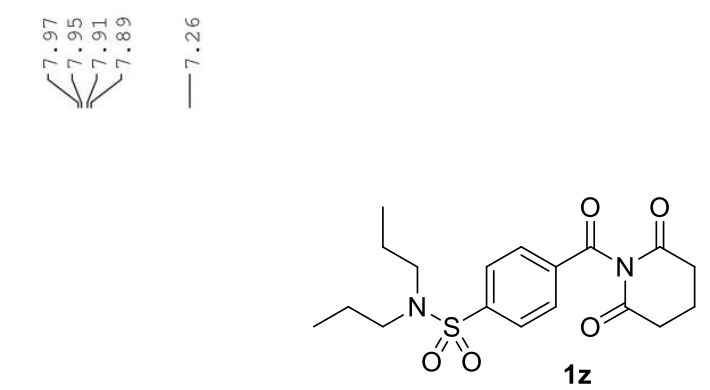

$\left(400 \mathrm{MHz} \mathrm{CDCl}_{3}\right)$

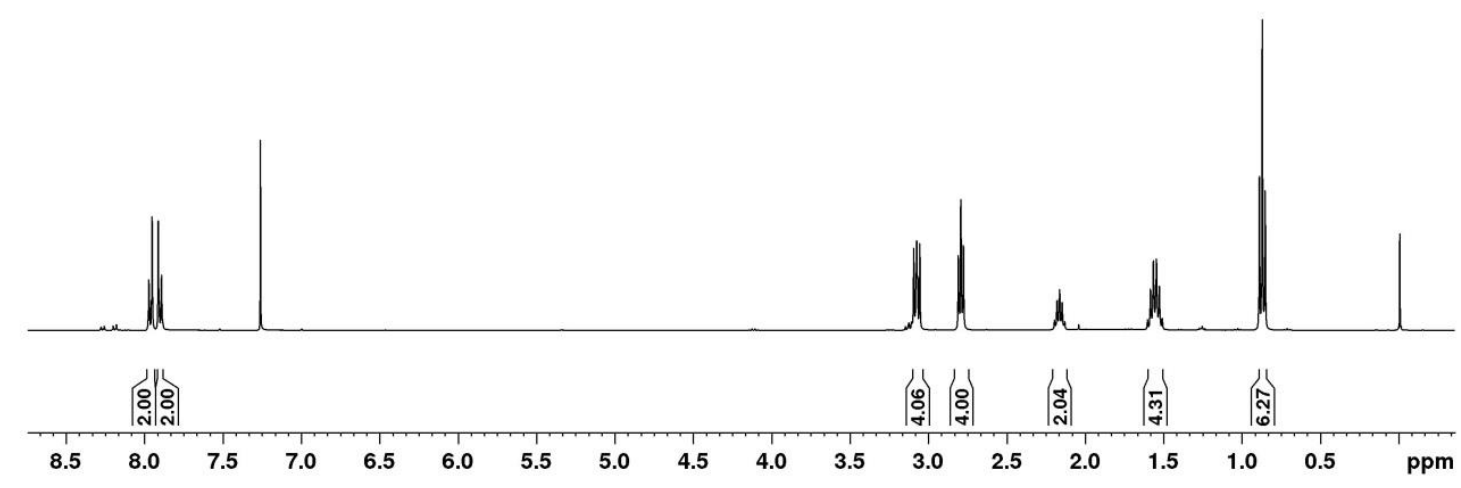

|l

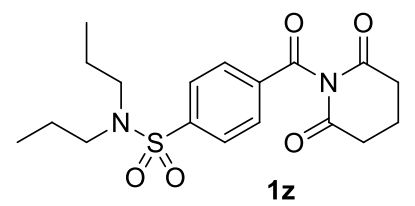

$\left(100 \mathrm{MHz} \mathrm{CDCl}_{3}\right)$

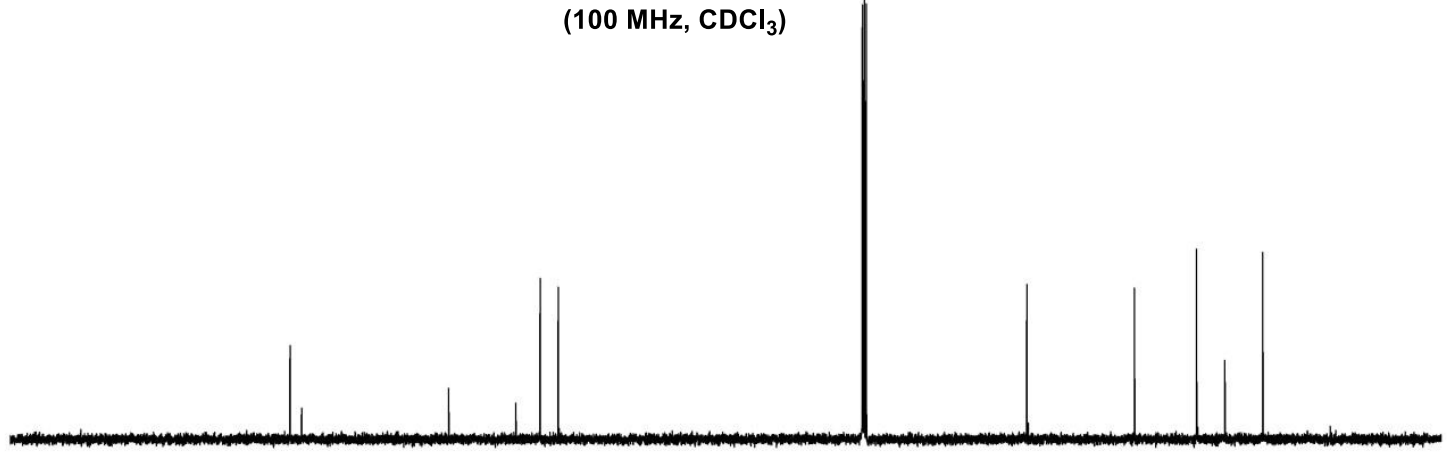

$\begin{array}{lllllllllllllllllllllll}210 & 200 & 190 & 180 & 170 & 160 & 150 & 140 & 130 & 120 & 110 & 100 & 90 & 80 & 70 & 60 & 50 & 40 & 30 & 20 & 10 & 0 & \mathrm{ppm}\end{array}$ 

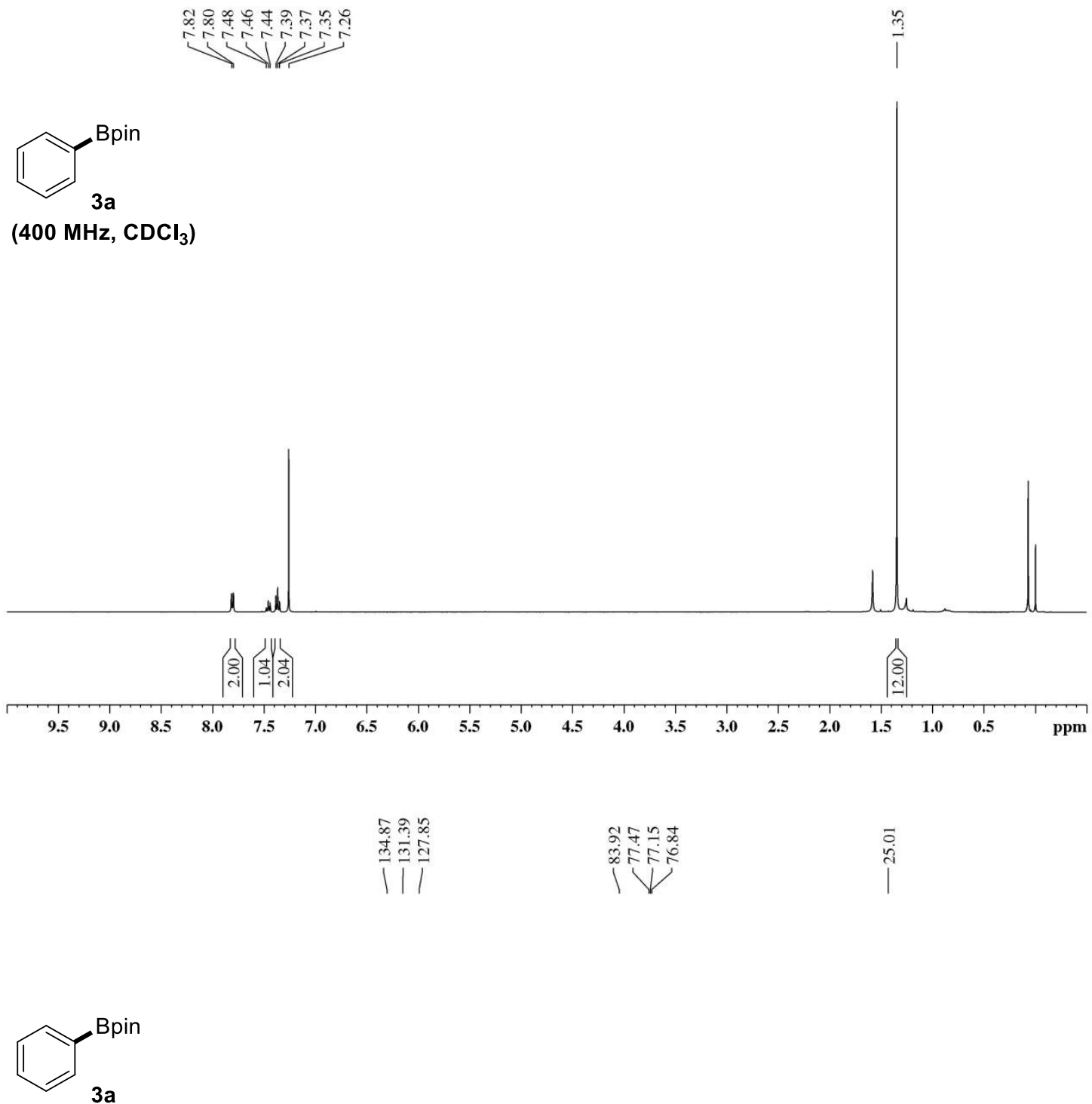

$\left(100 \mathrm{MHz}, \mathrm{CDCl}_{3}\right)$

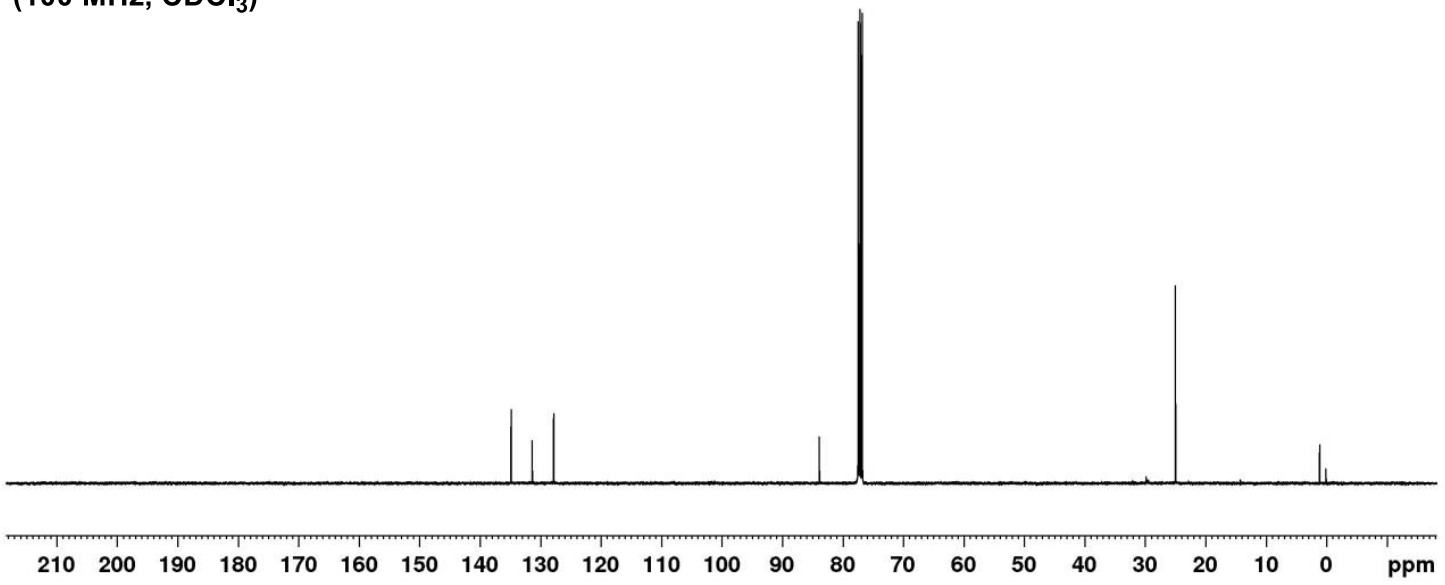



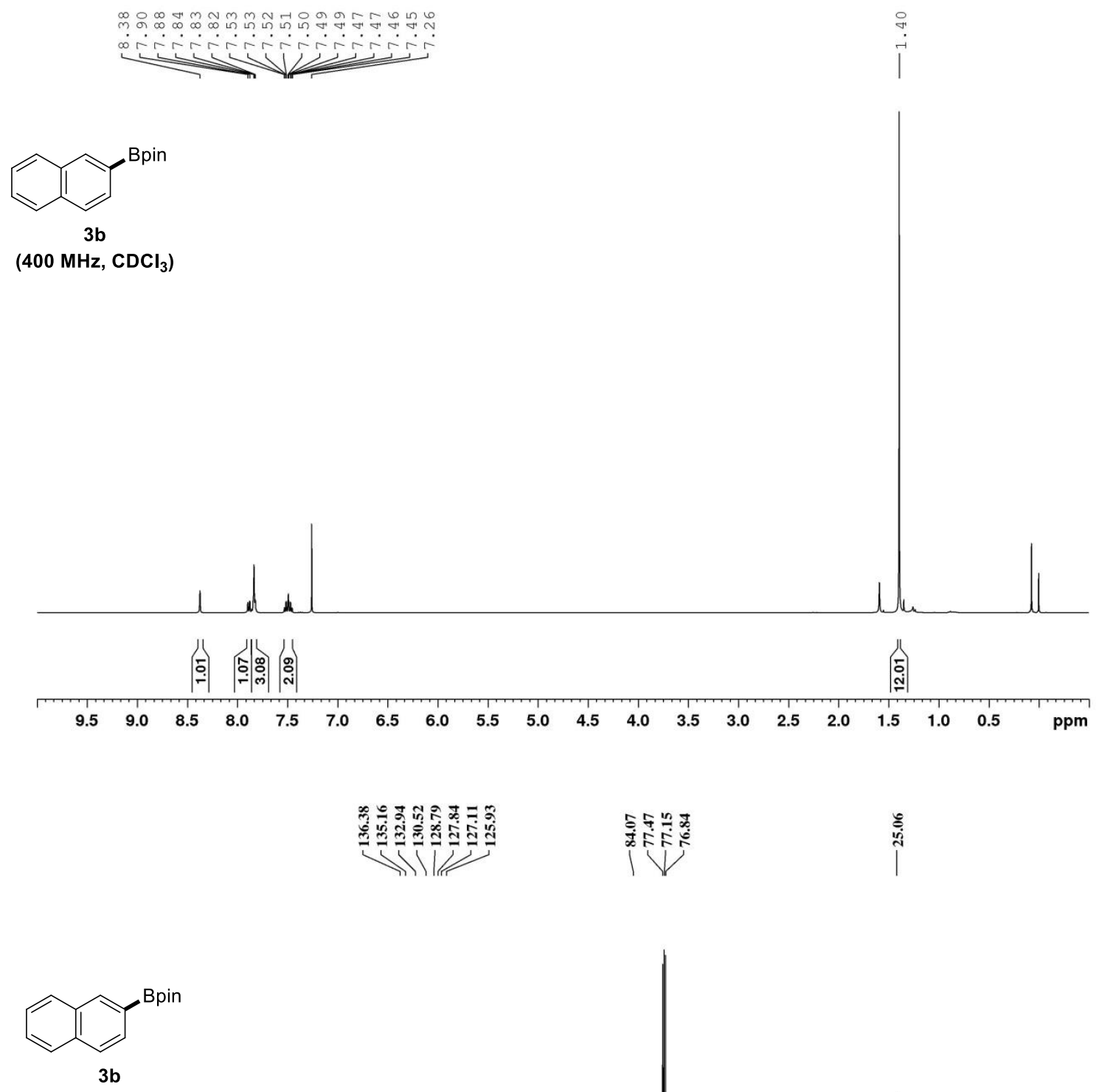

$\left(100 \mathrm{MHz}, \mathrm{CDCl}_{3}\right)$

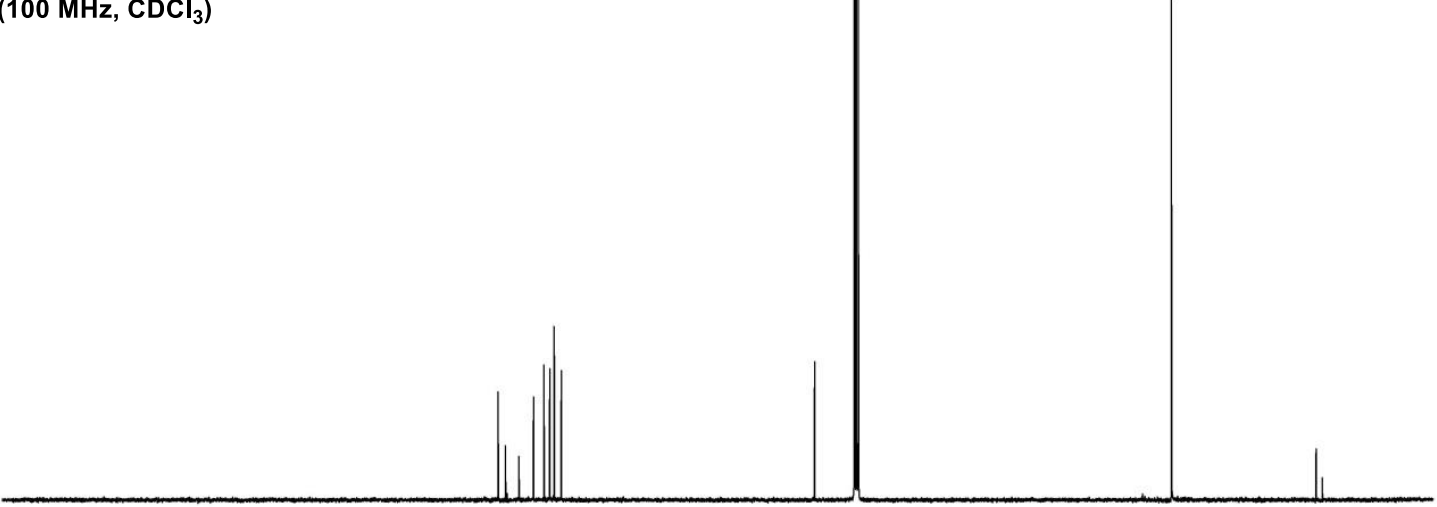

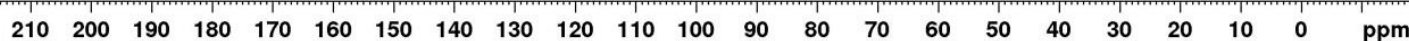




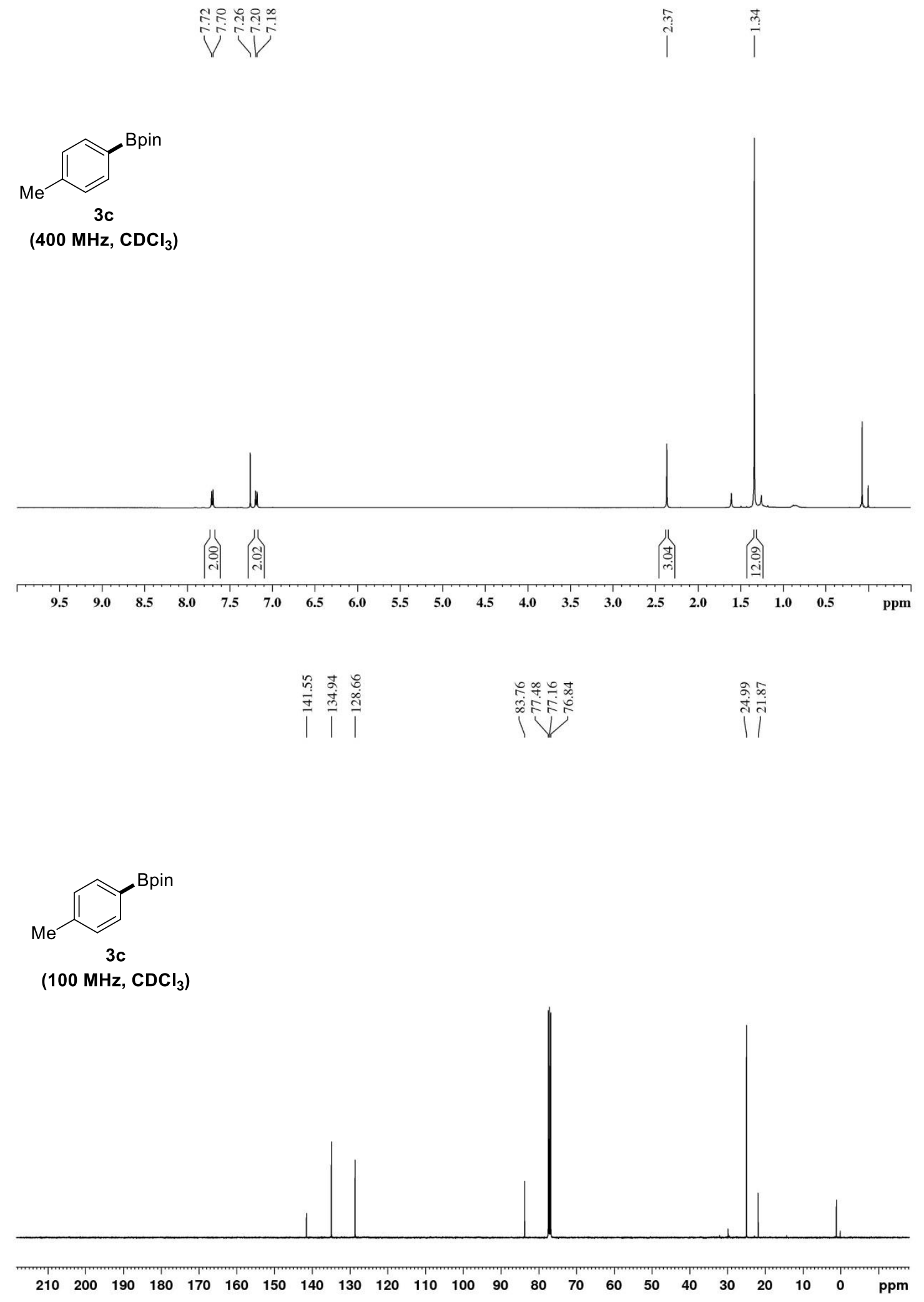

SI-33 

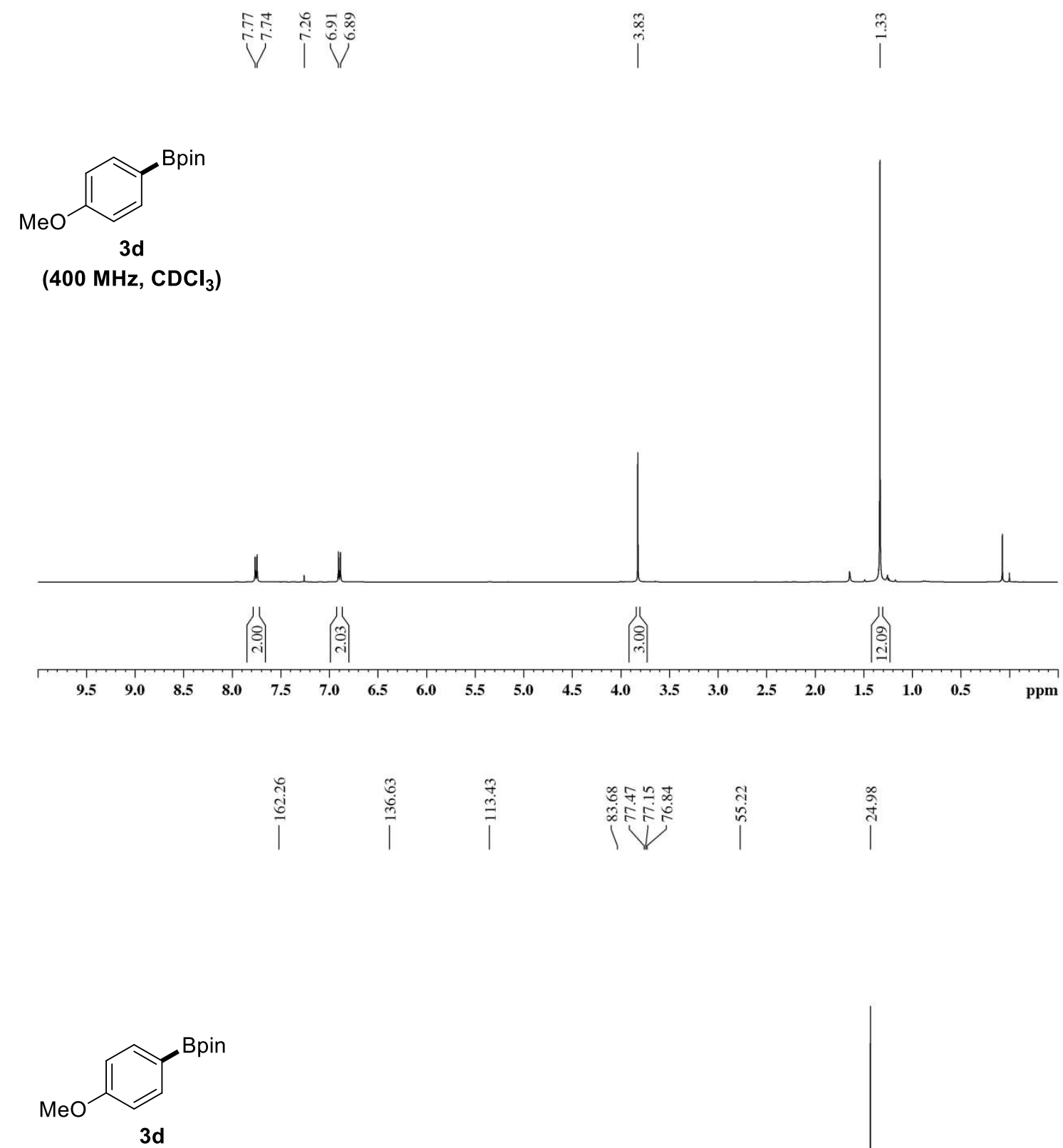

$\left(100 \mathrm{MHz}, \mathrm{CDCl}_{3}\right)$

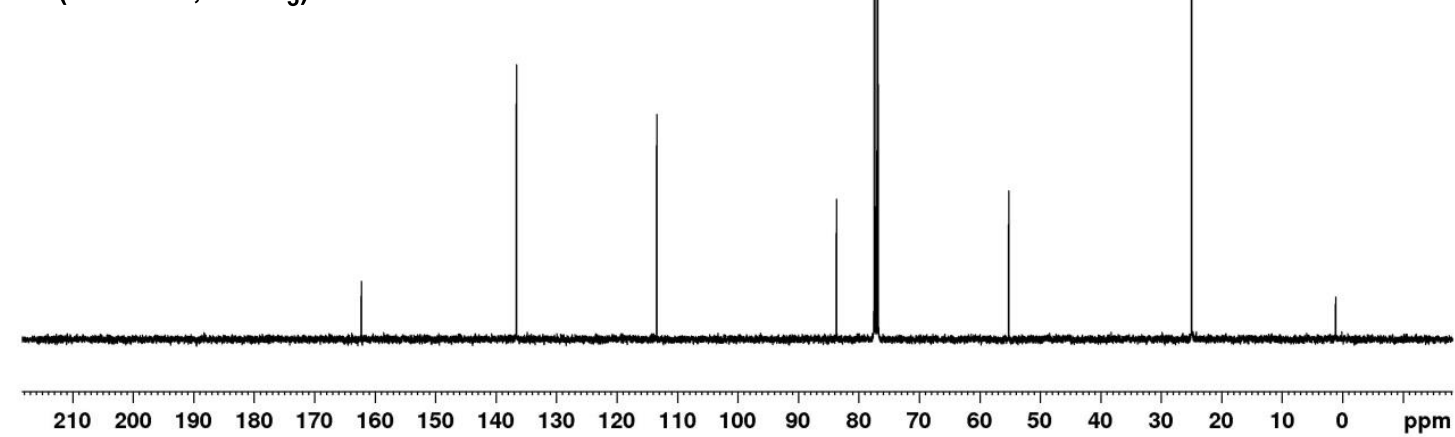



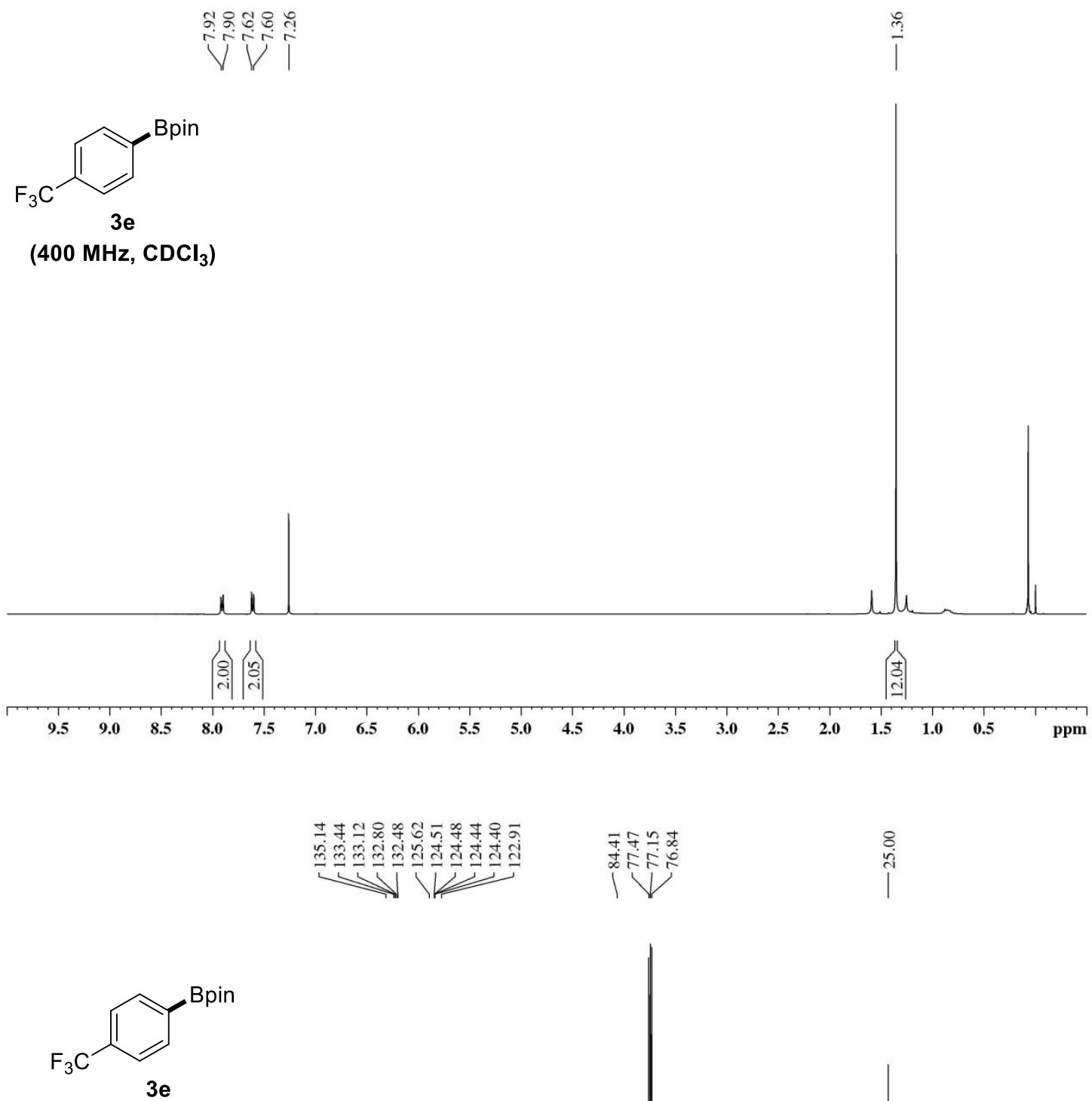

$\left(100 \mathrm{MHz}, \mathrm{CDCl}_{3}\right)$
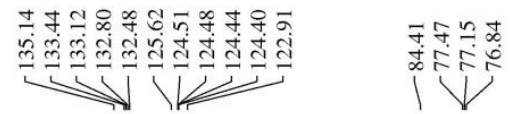

iิ

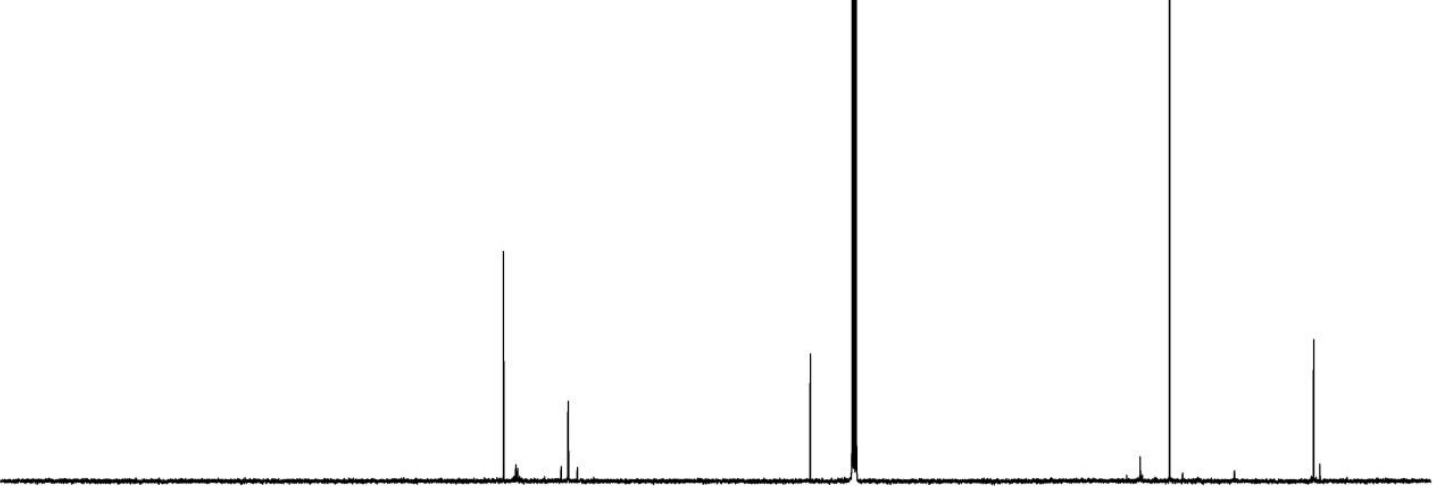

$\begin{array}{lllllllllllllllllllllll}210 & 200 & 190 & 180 & 170 & 160 & 150 & 140 & 130 & 120 & 110 & 100 & 90 & 80 & 70 & 60 & 50 & 40 & 30 & 20 & 10 & 0 & \mathrm{ppm}\end{array}$ 

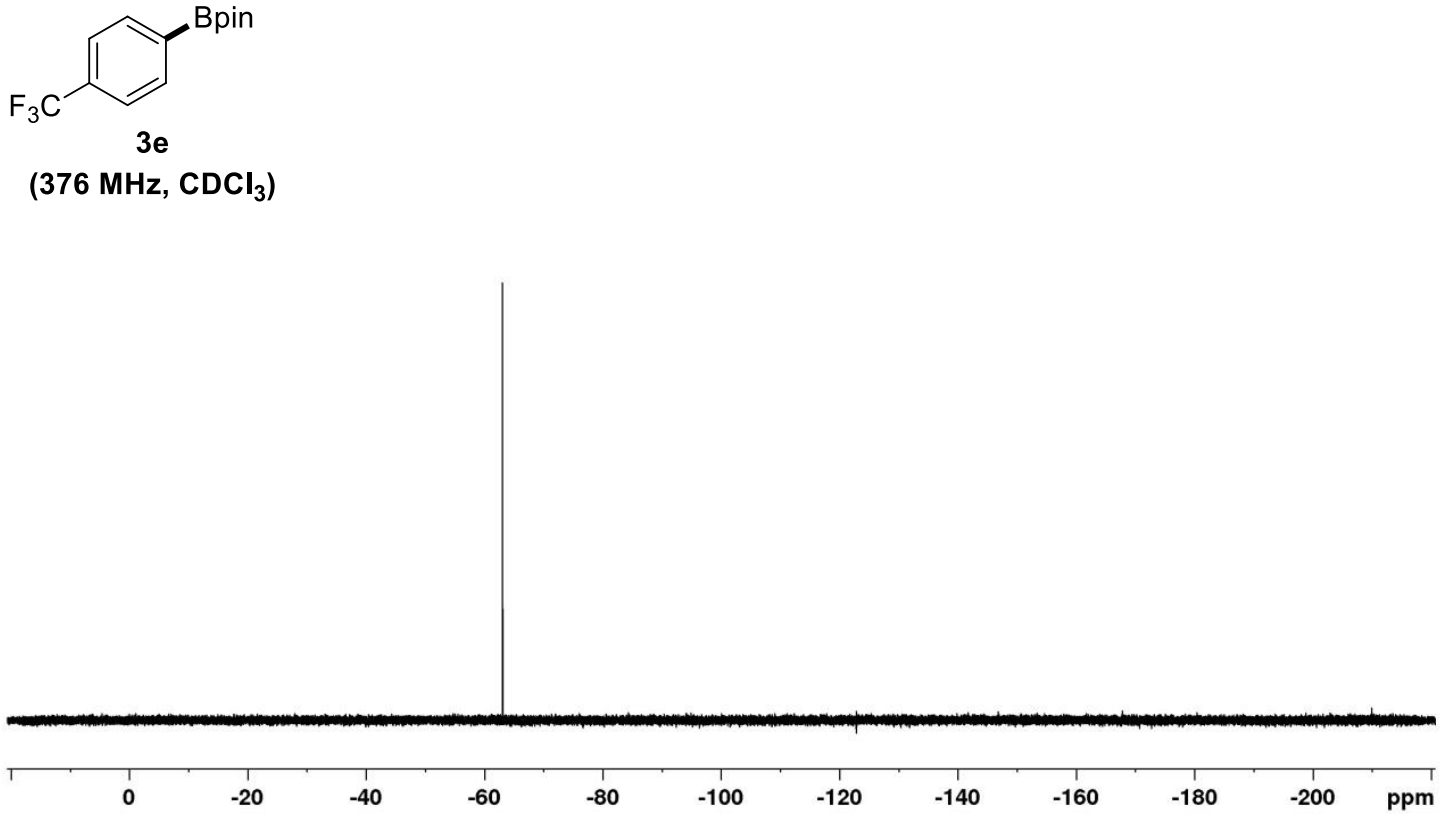

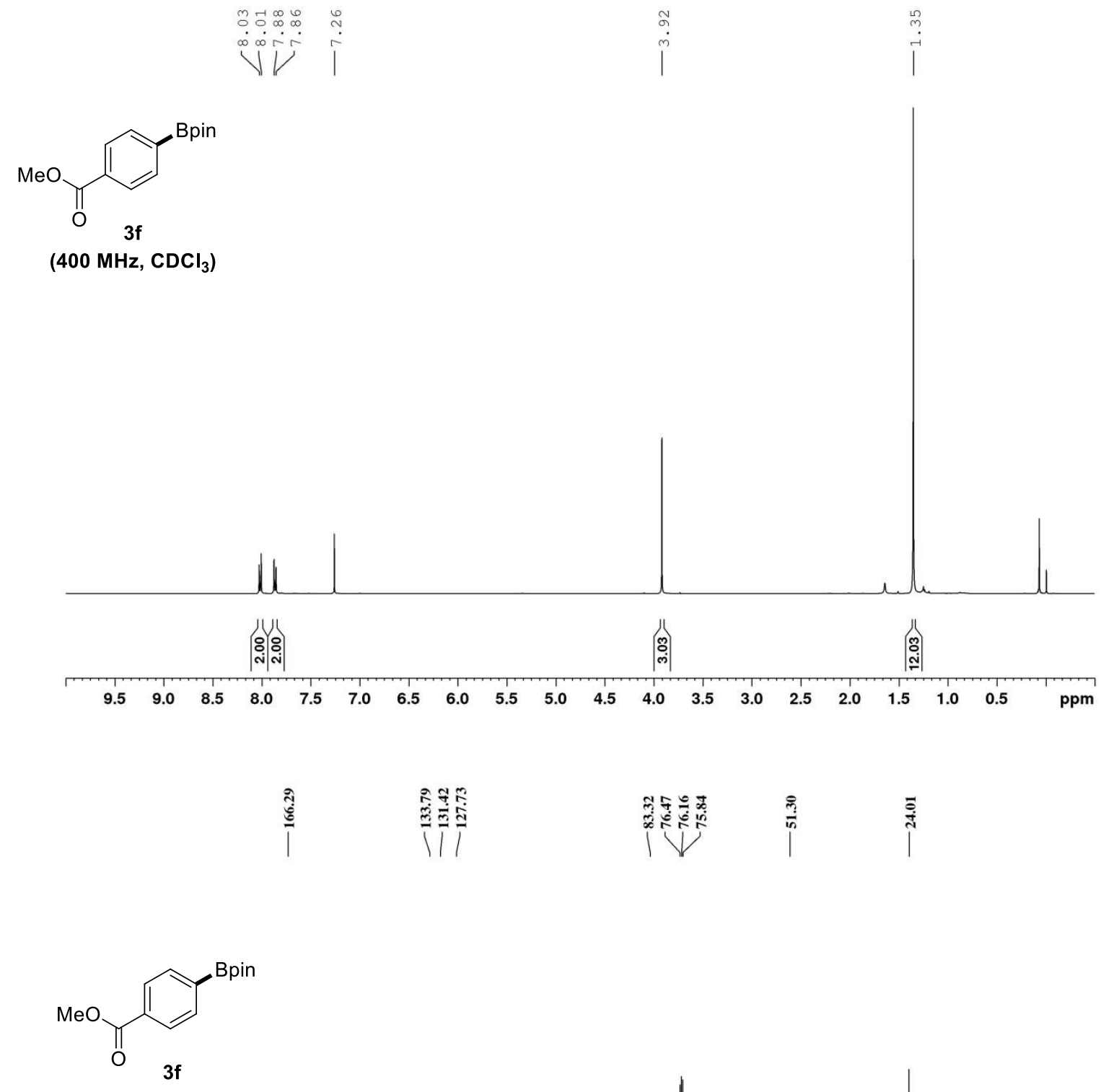

$\left(100 \mathrm{MHz}, \mathrm{CDCl}_{3}\right)$

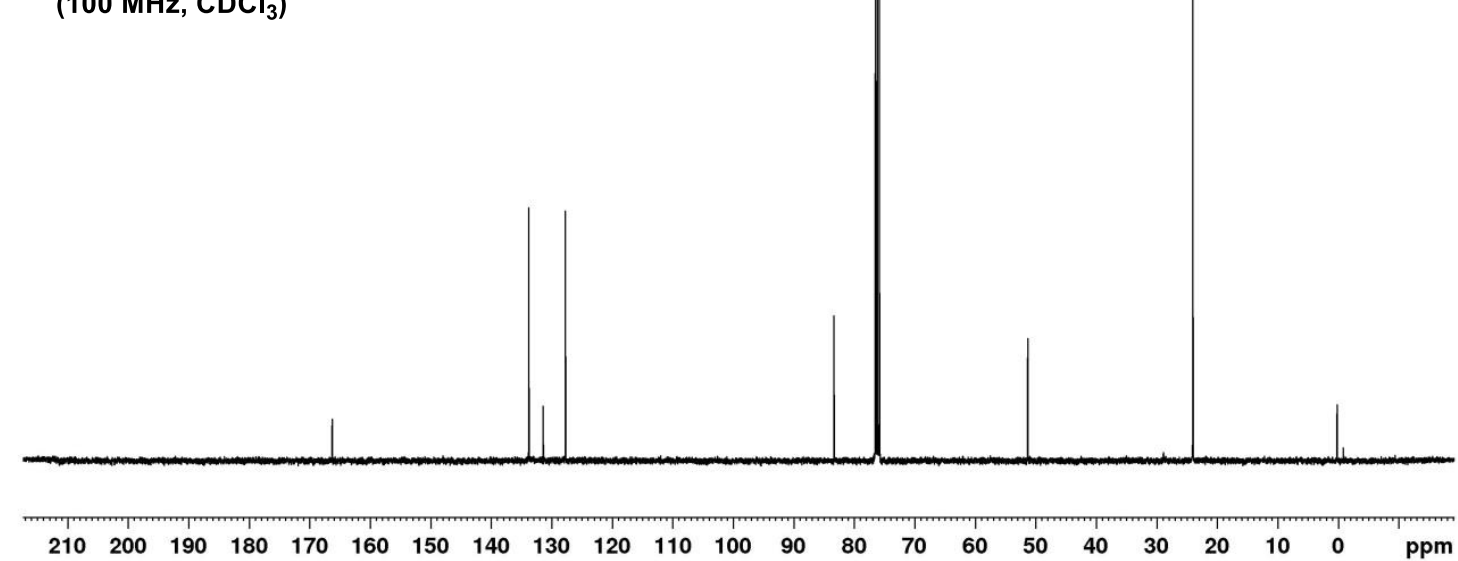




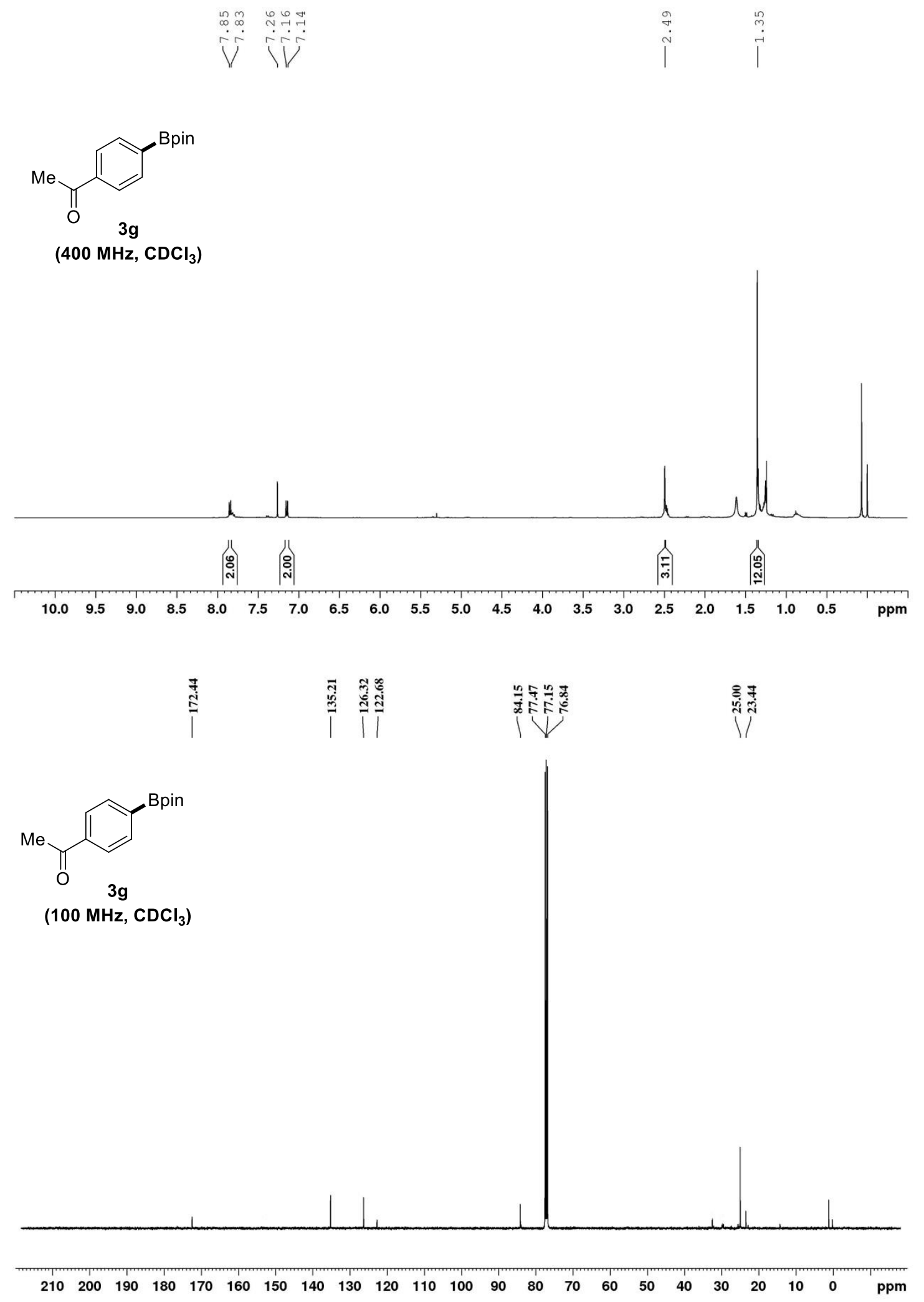



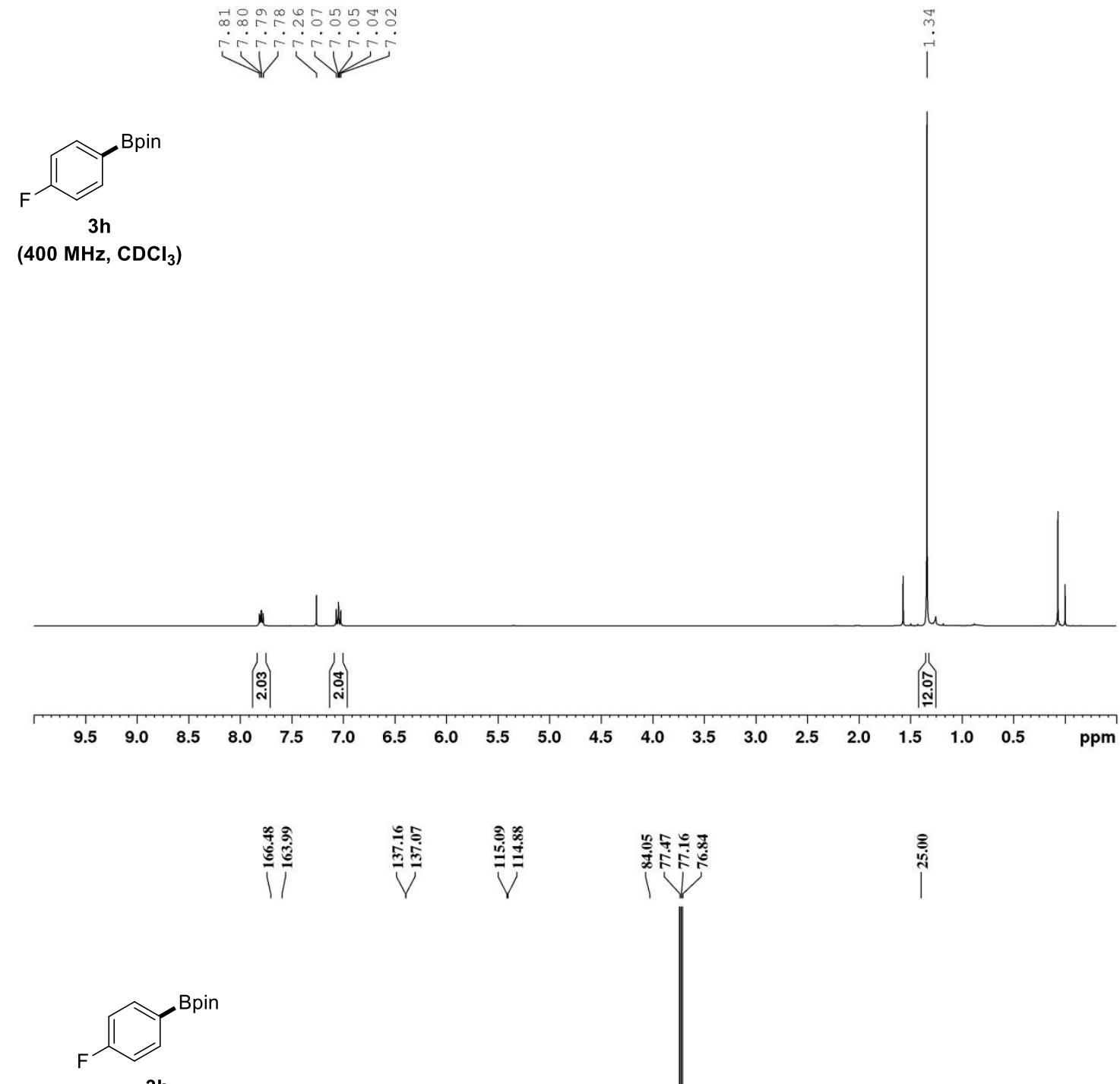

$3 \mathbf{h}$

$\left.\left(100 \mathrm{MHz}^{\mathrm{CDCl}}\right)_{3}\right)$
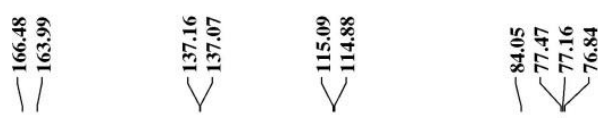

$\stackrel{8}{\text { ì }}$

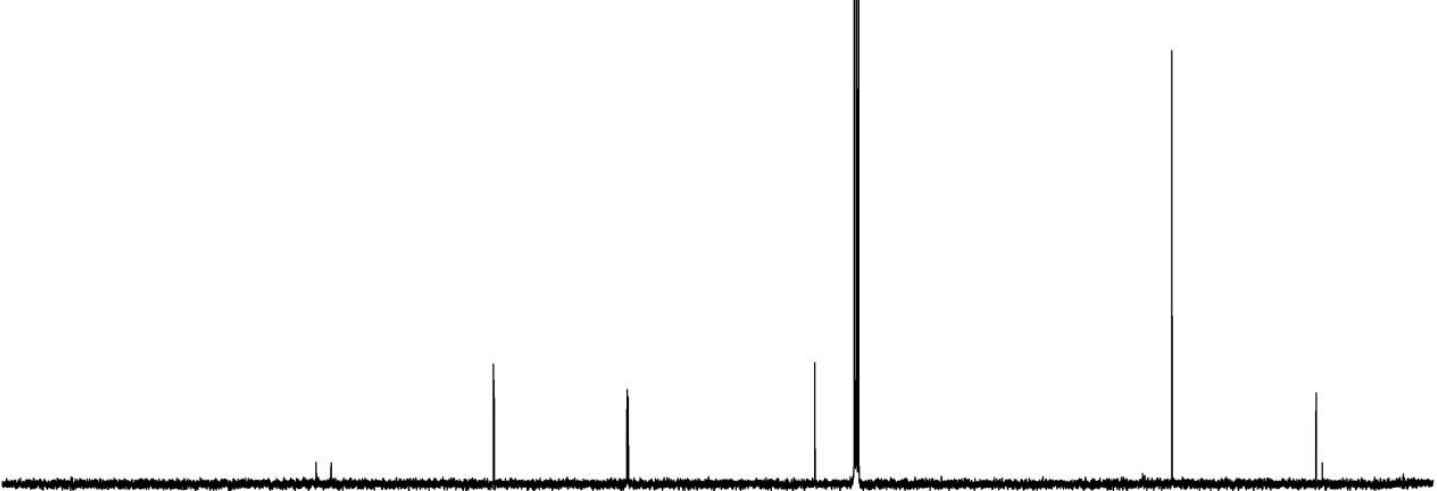

$\begin{array}{lllllllllllllllllllllll}210 & 200 & 190 & 180 & 170 & 160 & 150 & 140 & 130 & 120 & 110 & 100 & 90 & 80 & 70 & 60 & 50 & 40 & 30 & 20 & 10 & 0 & \mathrm{ppm}\end{array}$ 


$$
\stackrel{19}{\stackrel{10}{7}}
$$<smiles>Fc1ccc(Br)cc1</smiles>

(376 $\mathrm{MHz}, \mathrm{CDCl}_{3}$ )

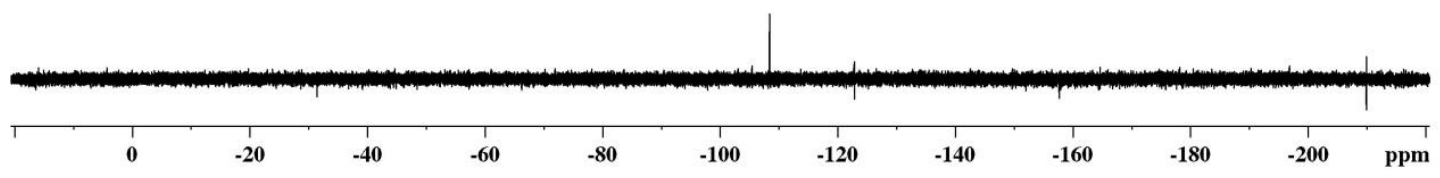




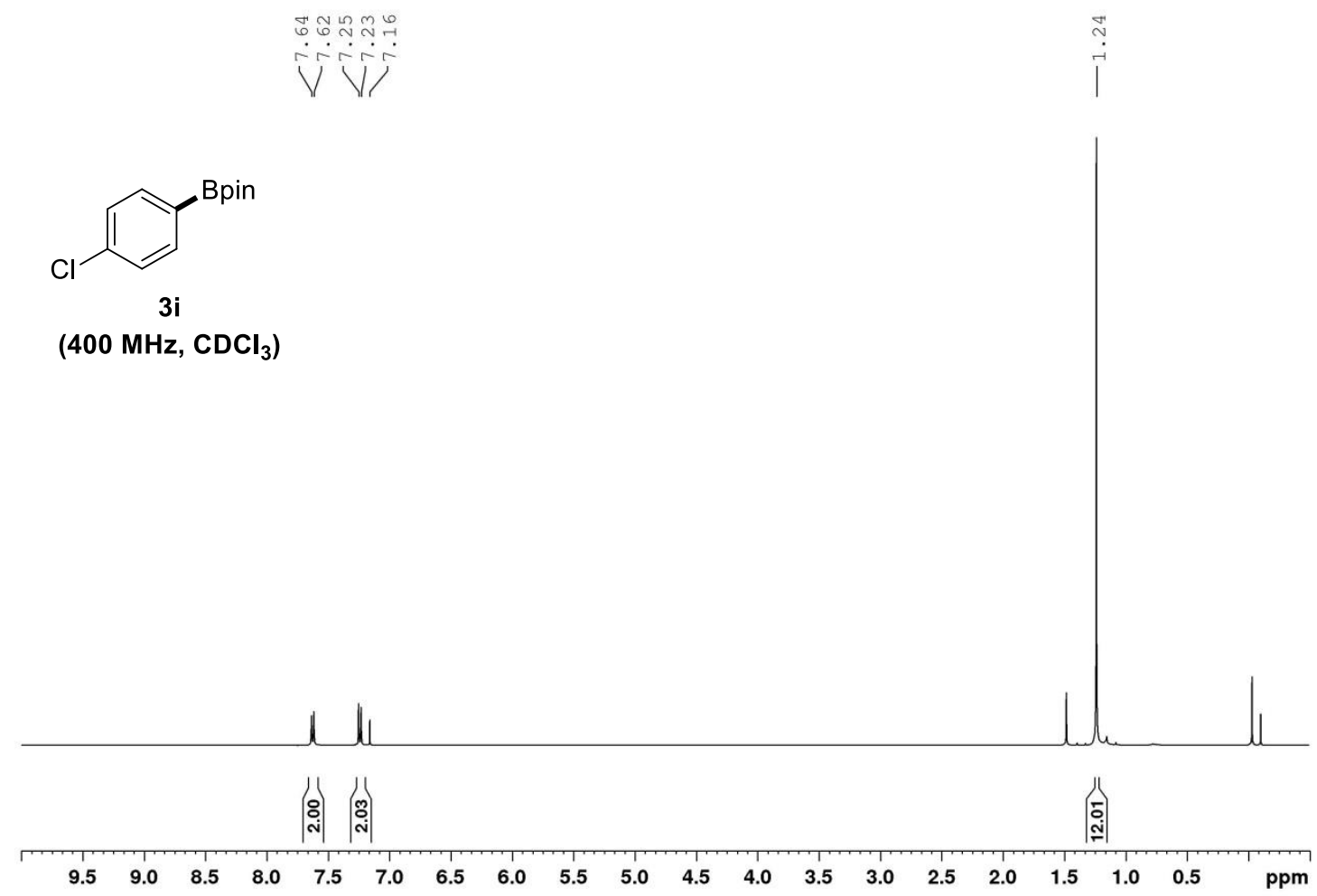

ل|

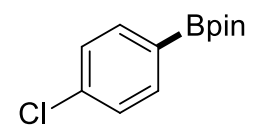

$3 \mathbf{i}$

$\left(100 \mathrm{MHz}, \mathrm{CDCl}_{3}\right)$
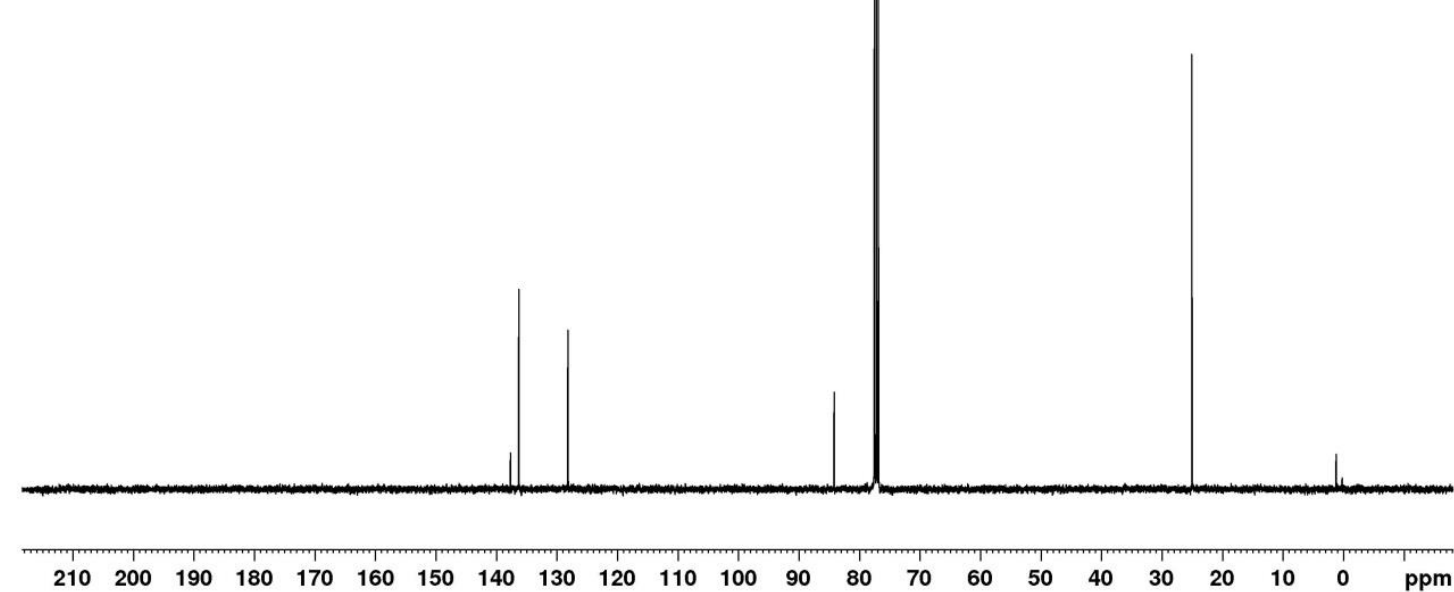

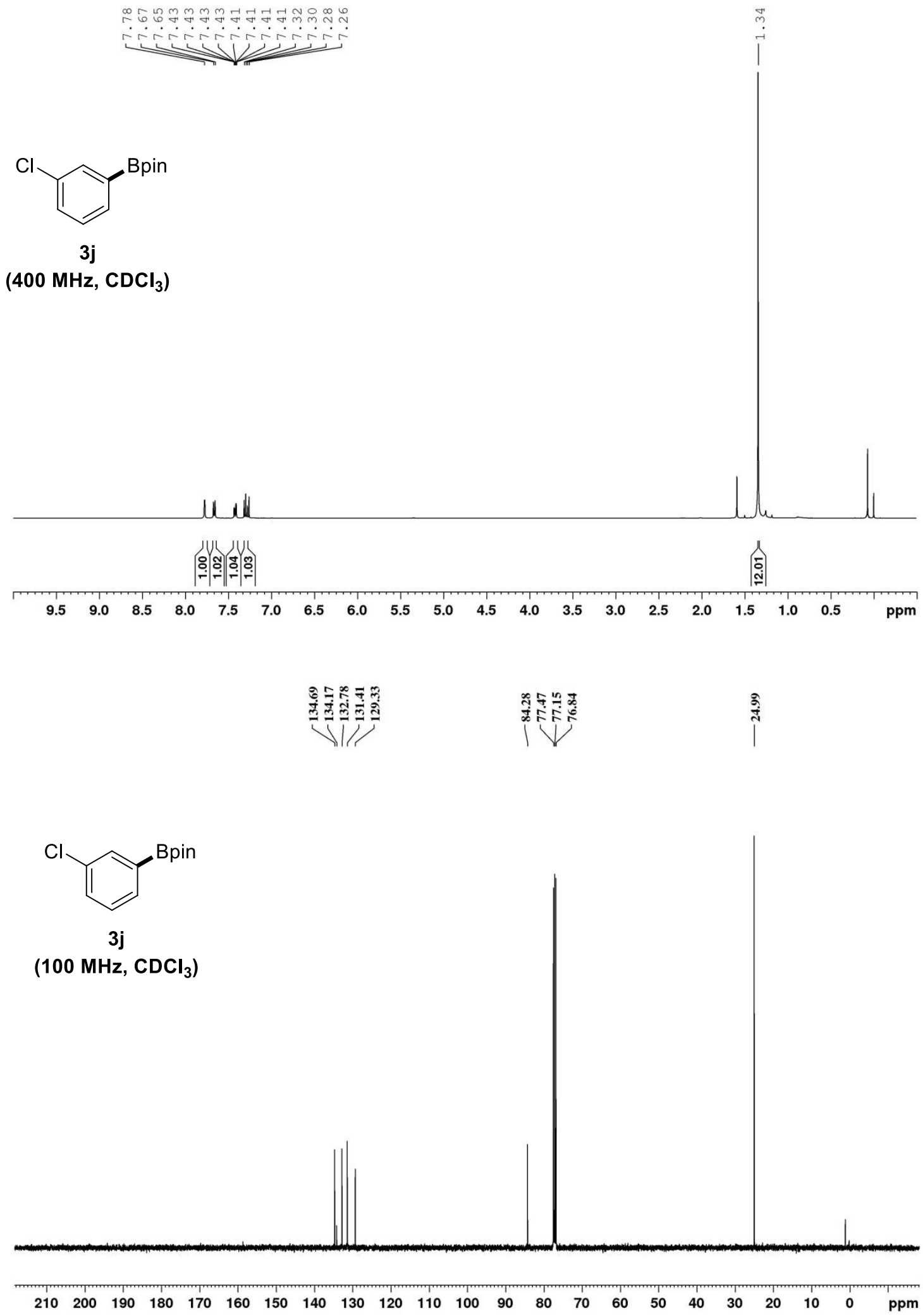


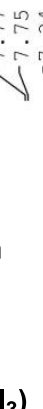

(400 $\mathrm{MHz}, \mathrm{CDCl}_{3}$ )
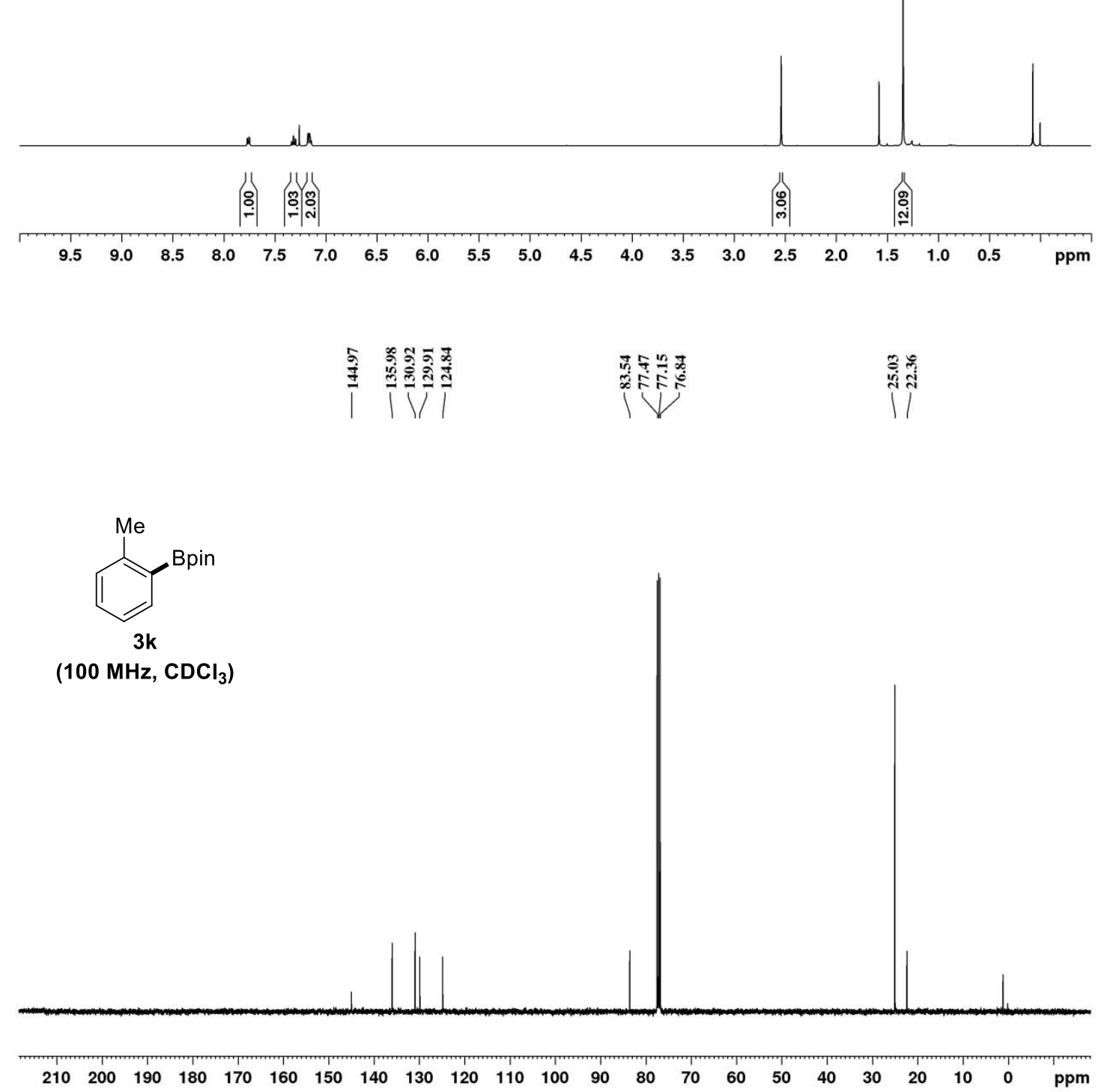


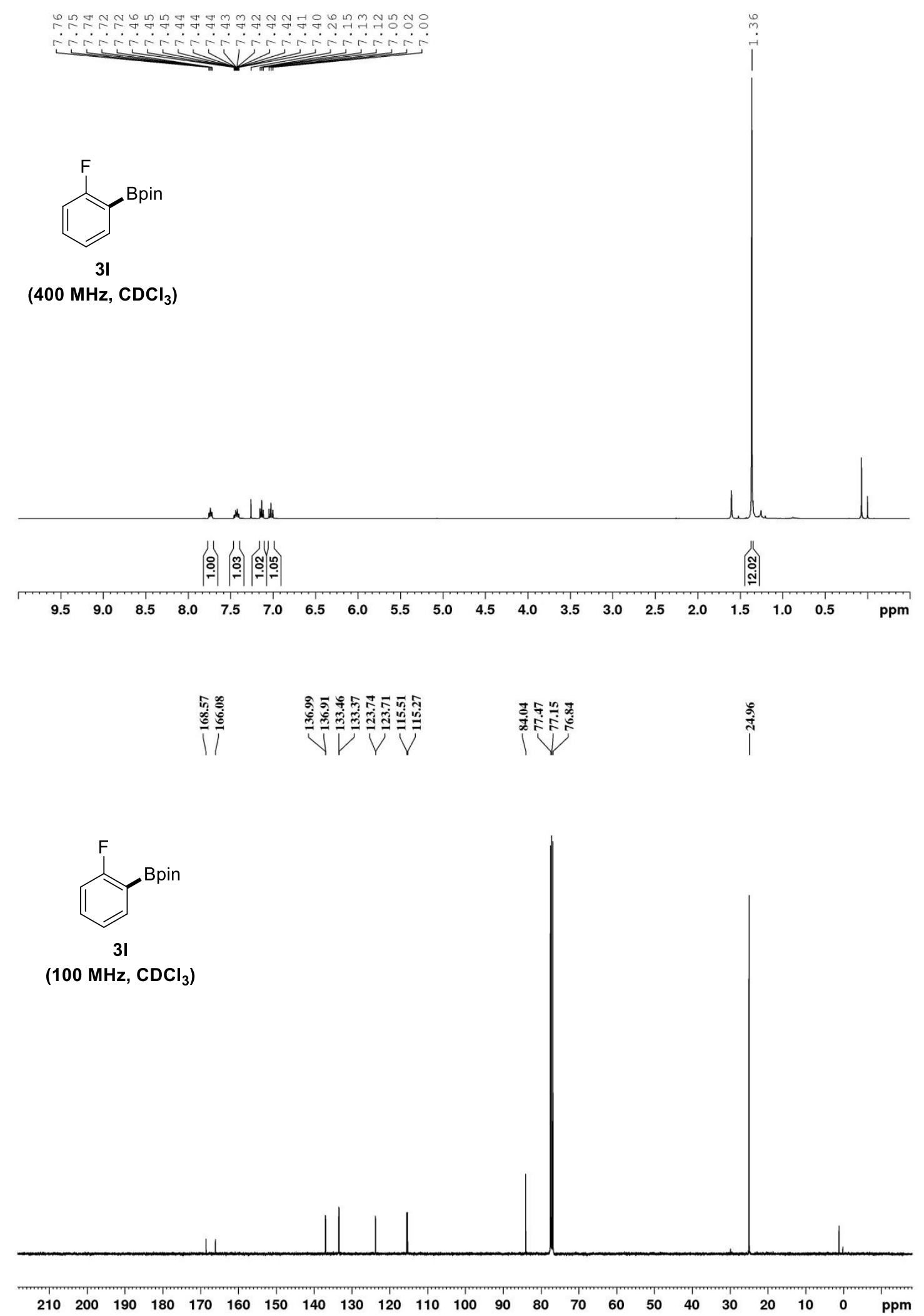




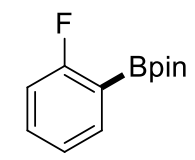

31

(376 $\mathrm{MHz}, \mathrm{CDCl}_{3}$ )

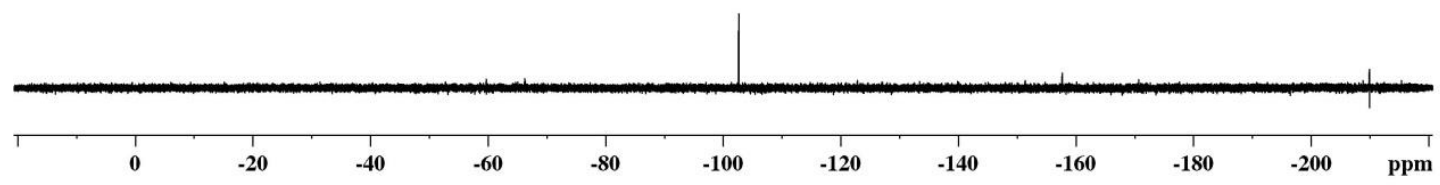



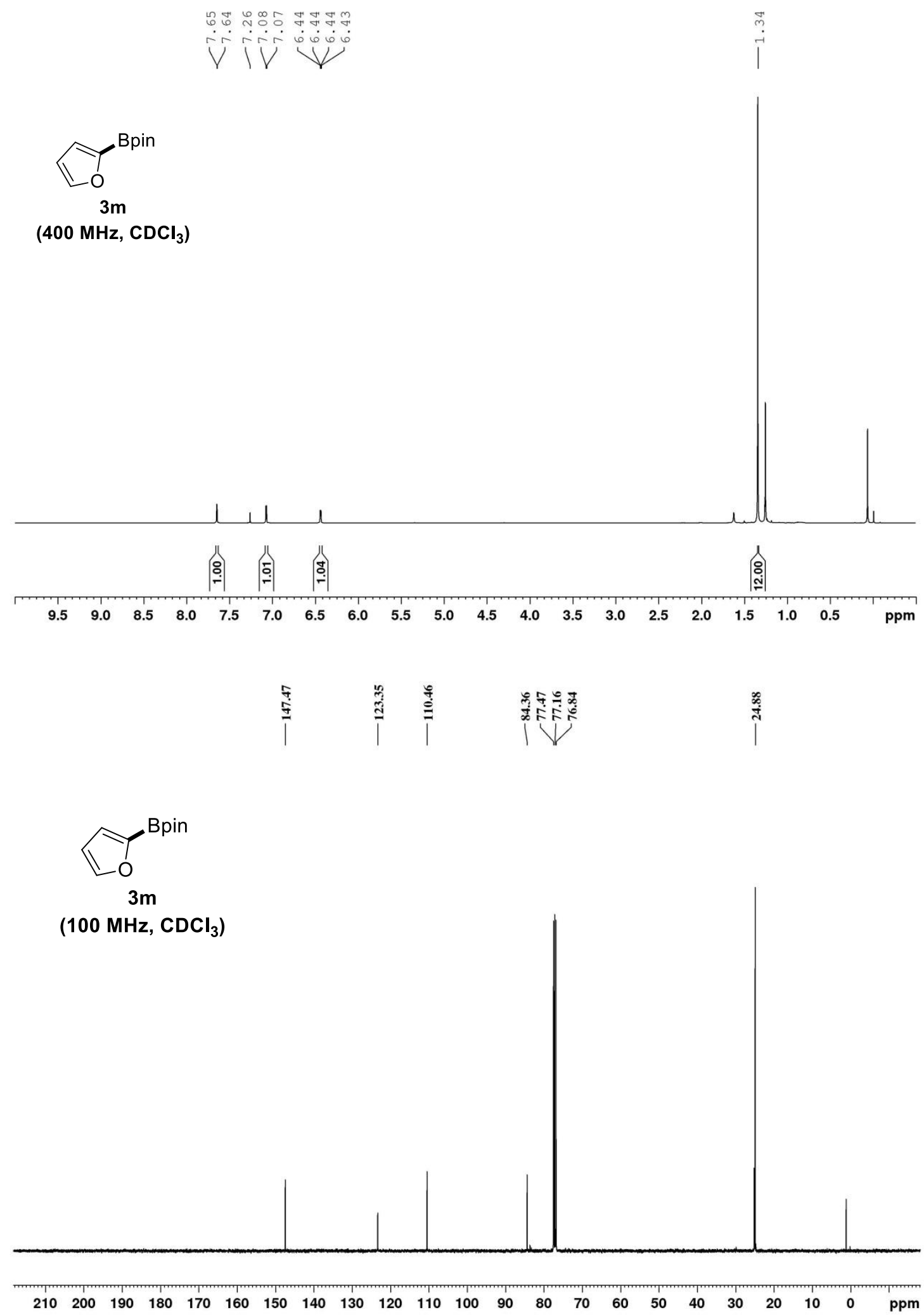


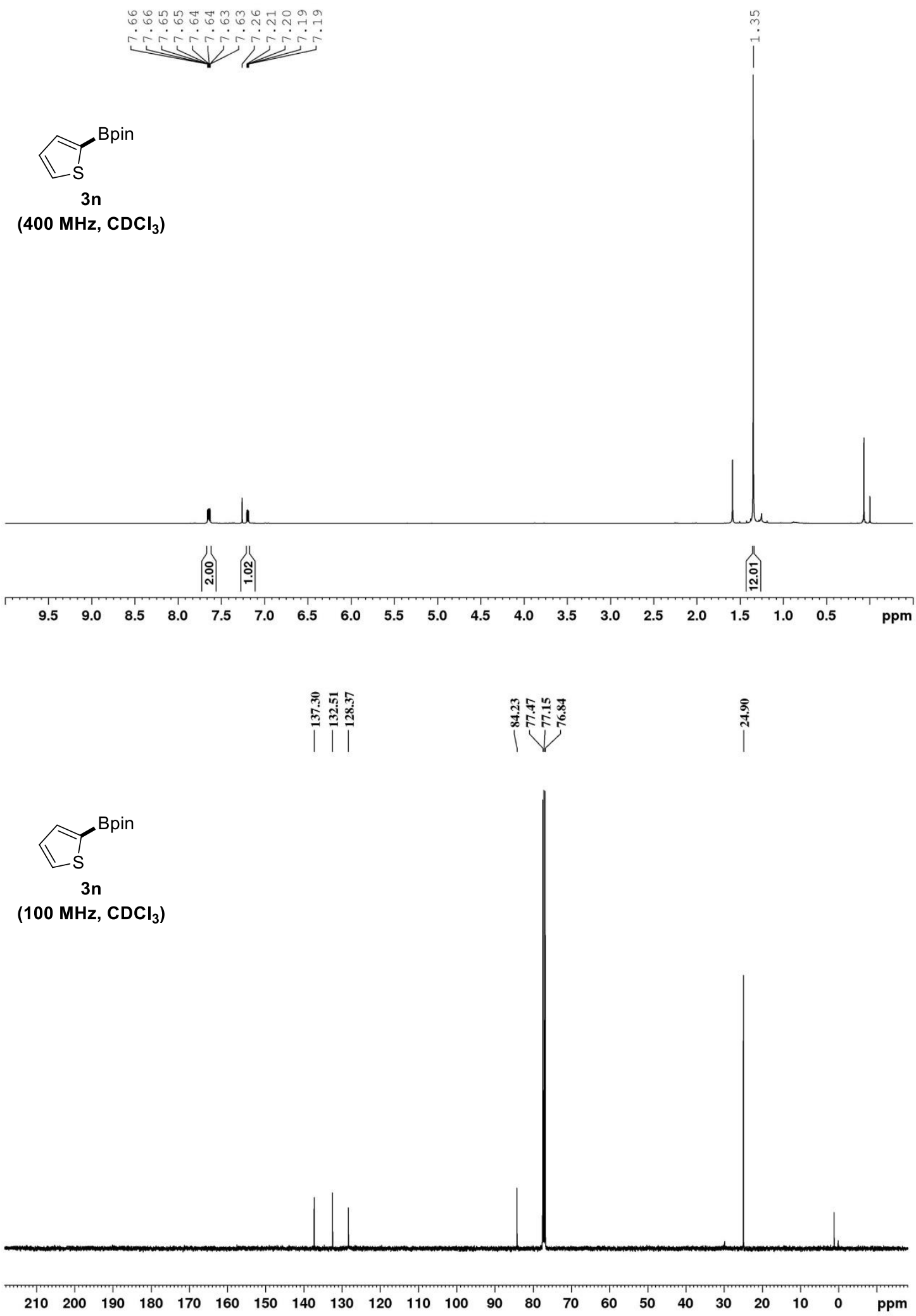




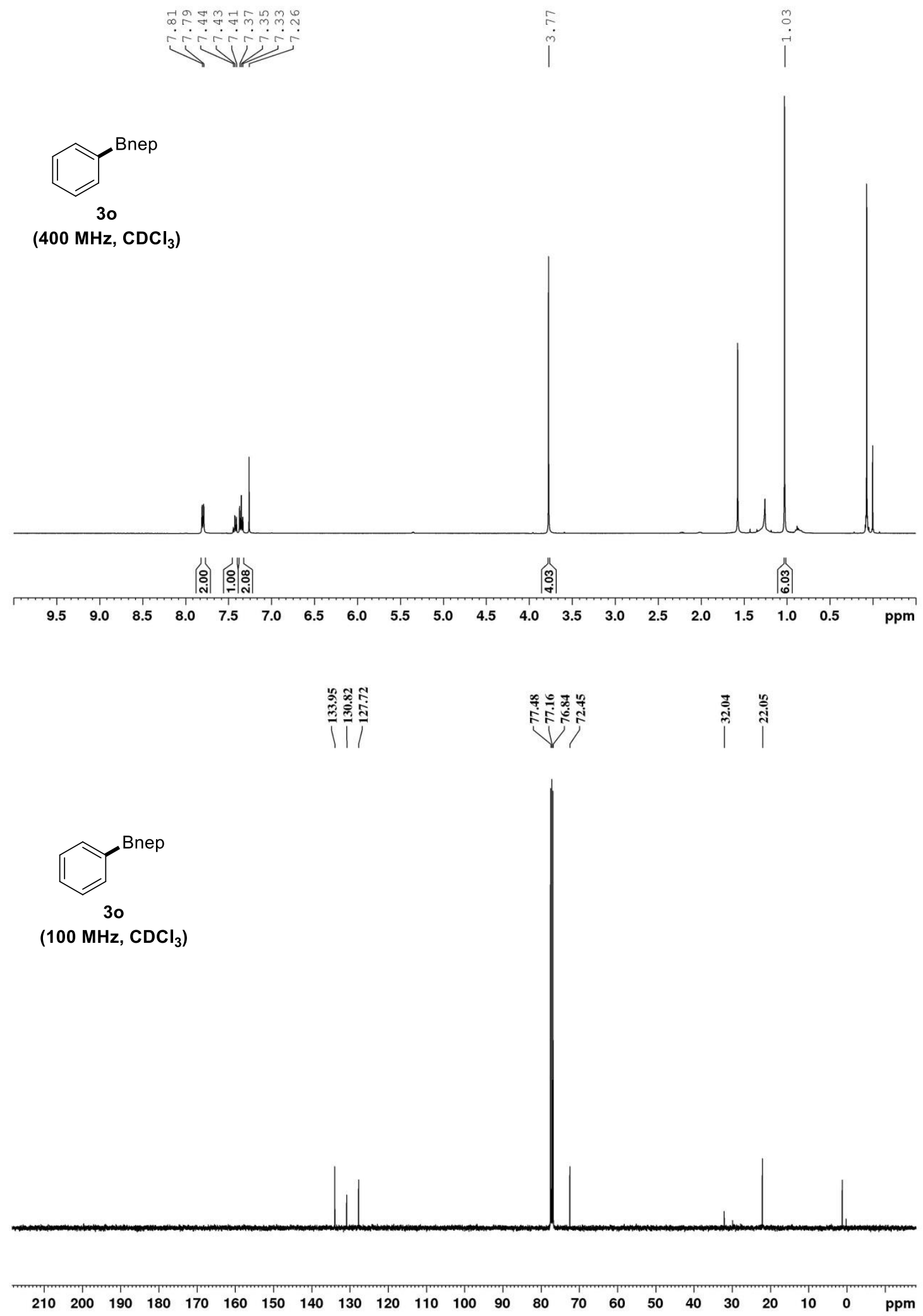




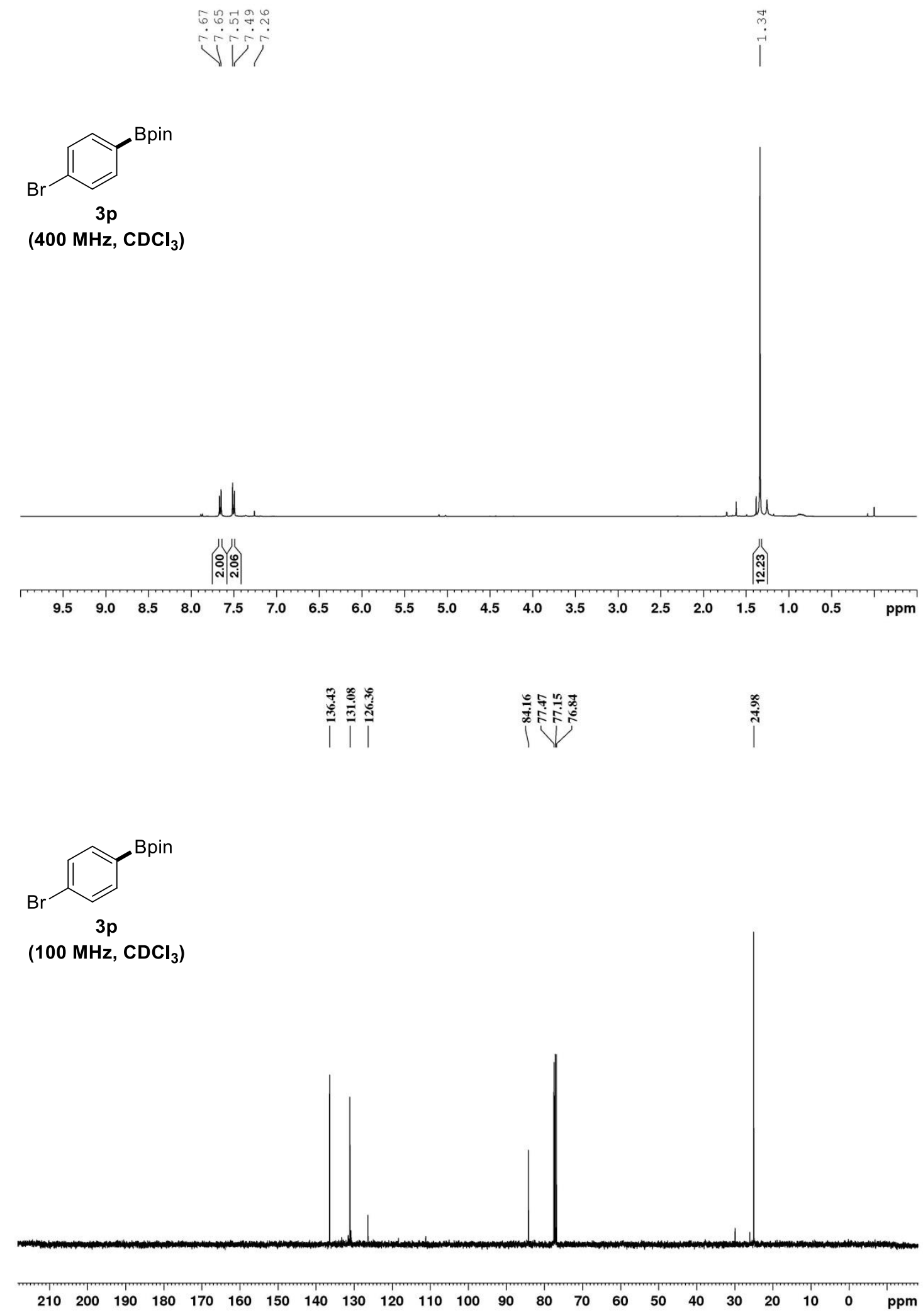



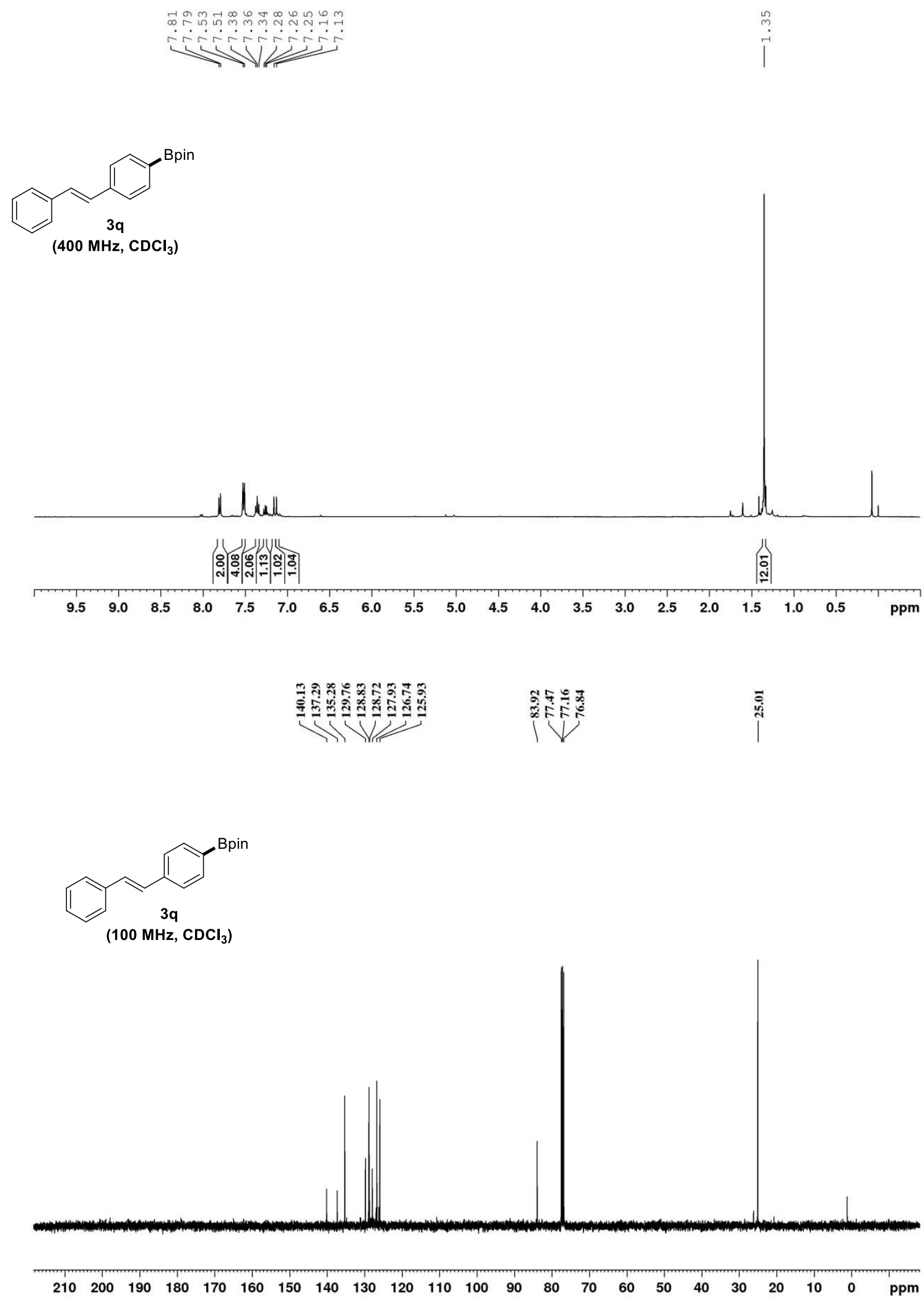

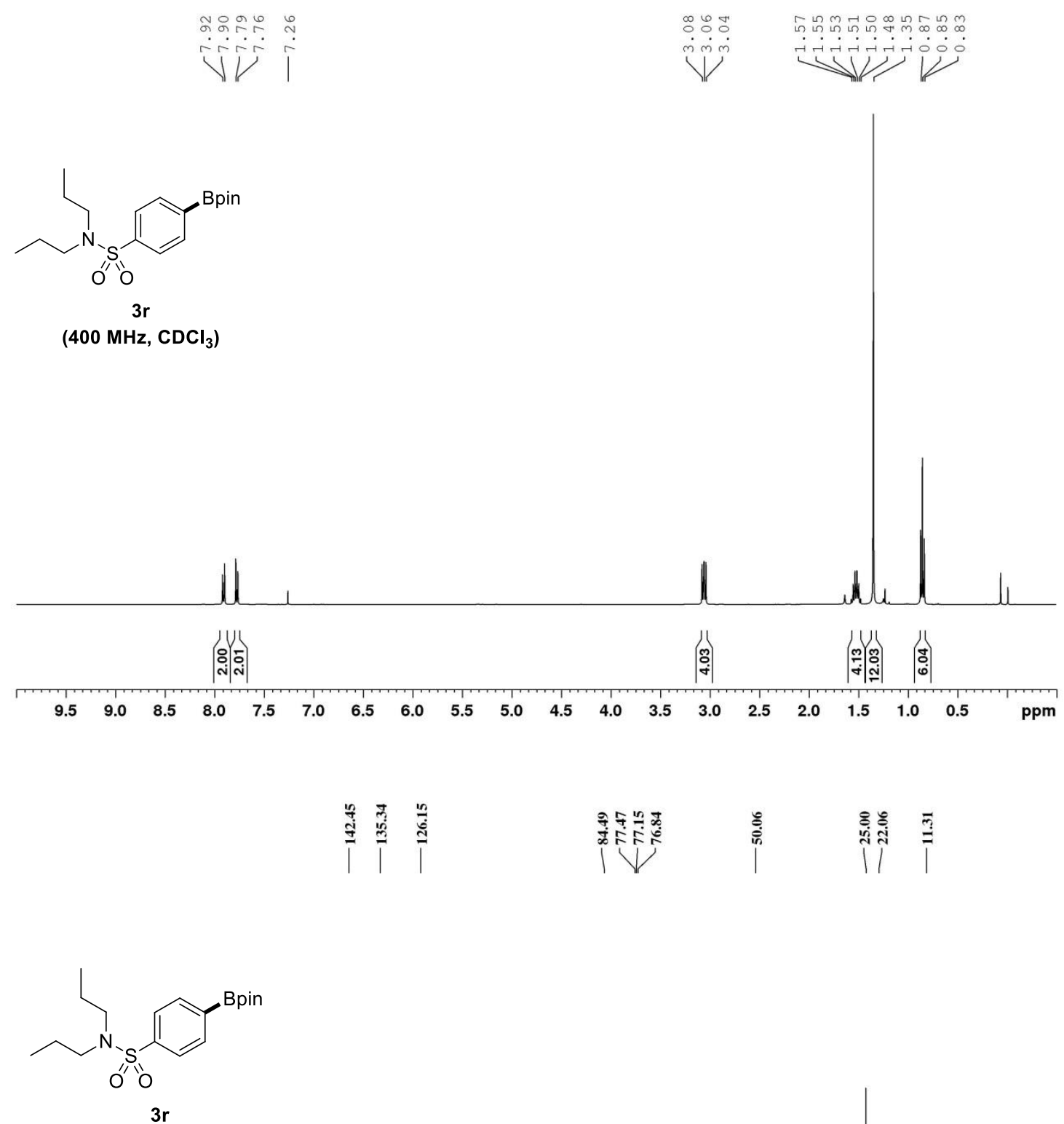

(100 MHz, $\mathrm{CDCl}_{3}$ )
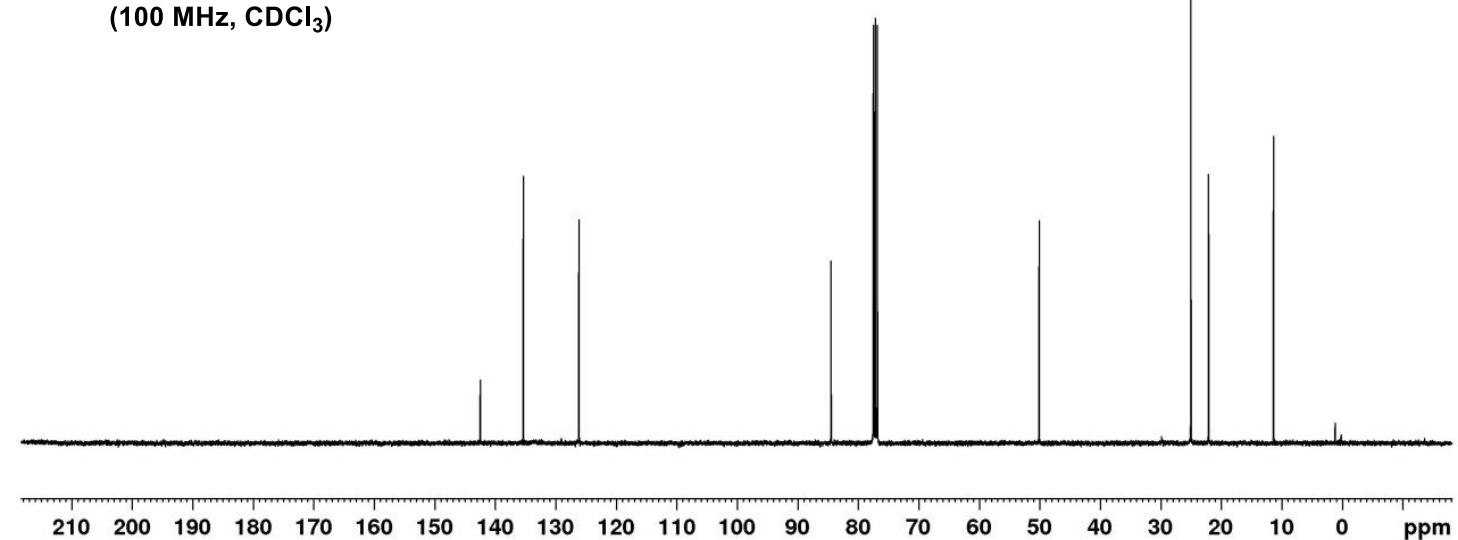